LBL- -29128

DE91 000188

First-Order Kinetics-Controlled Multiple Species Reactive Transport of Dissolved Organic Compounds in Groundwater:

Development and Application of a Numerical Model

Walt Whitney McNab, Jr.

(M.S. Thesis)

Department of Materials Science and Mineral Engineering

University of California

and

Earth Sciences Division

Lawrence Berkeley Laboratory

University of California

Berkeley, California 94720

May 1990

This work was supported in part by the U.S. Department of Energy under Contract No. DE-AC0376SF00098.

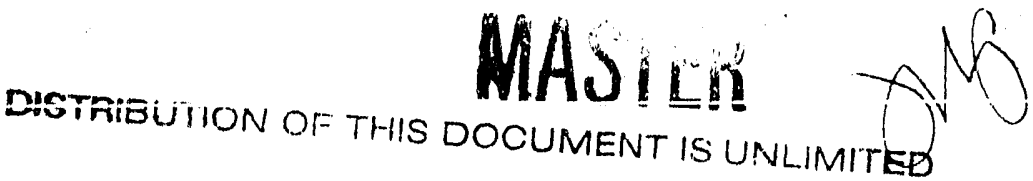




\title{
First-Order Kinetics-Controlled Multiple Species Reactive Transport of Dissolved Organic Compounds in Groundwater: Development and Application of a Numerical Model
}

by

Walt W. McNab, Jr.

\begin{abstract}
Reactive chemical transport models developed over the past decade have generally relied on the assumption that local thermodynamic equilibrium is achieved at all times between aqueous species in a given system. Consequently, homogeneous aqueous systems characterized by a number of kinetically slow reactions, particularly problems involving organic species, cannot be satisfactorily modeled . In this study, we present a prototype computer model, KINETRAN, which is designed to handle kinetically-controlled homogeneous reactions in the aqueous phase, along with the transport of the various species involved, through geologic media.

The most important feature of the model is the kinetically-controlled reaction facility. The kinetics algorithm allows a number of user-specified homogeneous reactions to simultaneously approach overall equilibrium under the control of first-order reaction kinetics. We achieve this by discretizing the first-order rate rquations, using a time-averaging factor, for all of the aqueous-phase reactions, both forward and backward. Th: resulting set of implicit, linear equations is solved through the use of matrix algebra.
\end{abstract}


The kinetics algorithm is dynamically coupled with a transport model that explicitly solver the advection-diffusion-dispersion equation, with adsorption being handled throurh the use of retardation coefficients. The transport equations are solved according to the Integral Finite Difference Method (Narasimkan aild Witherspoon, 1977). The coupling with the kinetics equations is accounted for through the use of source terms.

We apply this model to a hypothetical problem involving the simultaneous transport and chemical degradation of two halogenated hydrocarbons through a one-dimensional soil column. The results of the modeling study show that the transient species produced as intermediate products of the degradation of the halogenated hydrocarbons occur in significant amounts before they too are degraded. This phenomenon, which is known to occur in the field, has received little attention in previous modeling studies. More important, the simulation results show that the model is mathematically internally consistent and produces credible results with the input data.

In the second part of this study, we apply KINETRAN to the experimental data of Curtis et al. (1986), Freyberg (1986), MacKay et al. (1986), and Roberts et al. (1986), collected at a site near the Canadian Forces Base at Borden, Ontario. In that study, various dissolved halogenated hydrocarbons were injected into a well-characterized aquifer, along with conservative tracers. The data from this experiment, collected over a two-year period, indicate fairly complex behavior of the organic contaminants, including varying degrees of retardation and transformation.

Using the composition of the initial contaminant solution injected into the aquifer, we develop a possible decay scenario for the various species involved. This scenario includes organic decay products that were not originally present in the initial plume. Using the first- 
order decay constants derived from the Borden data, as well as hypothetical values for species not initially present, we first apply the chemical kinetics module of KINETRAN to the problem. KINETRAN is able to match the experimental results reasonably well. The modeling results also suggest possible explanations for some discrepancies in the experimental data.

KINETRAN is also used to examine the reactive transport phenomena of the Borden experiment. Again, as in the static batch simulation, KNNETRAN is able to simulate the results of the experiment fairly well, and the results suggest additional possibilities concerning the role of decay chains in reactive chemical transport of organic contaminants in groundwater.

As an final exercise, KINETRAN is applied to a two-dimensional problem, characterized by physical and chemical heterogeneities, involving the infiltration of halogenated hydrocarbon pollutants. The results of this study give. us confidence that the model is capable of handling more general, complex systems.

Our modeling suggests that KINETRAN is applicable to real contamination sites. Given reasonably well-constrained input data (hydrologic conditions and initial chemical composition), the model can simulate the fate not only of the initial contaminants, but also that of the host of the decay products that may be produced as well. A model of such capabilities will prove to be of value in predicting the fates of organic contaminants and will be useful in the design of remediation strategies. 


\section{Table of Contents}

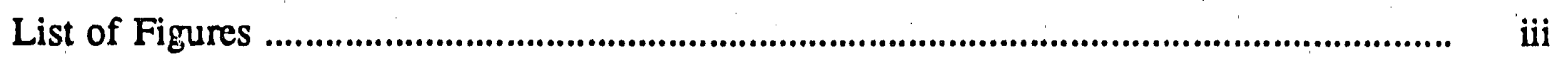

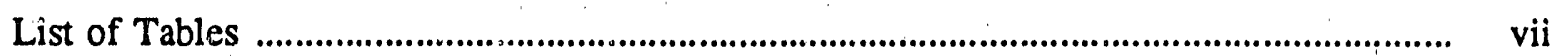

List of Symbols, Kinetics Equations ................................................................................. viii

List of Symbols, Transport Equations .............................................................................. $\mathrm{x}$

Acknowledgements ........................................................................................................

Chapter 1: Introduction ...................................................................................... 1

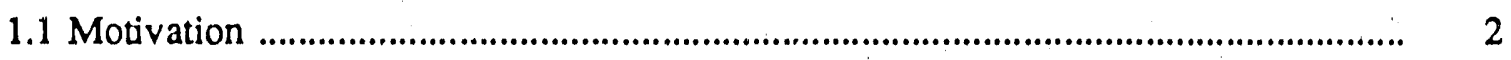

1.2 Purpose and Scope ............................................................................................. 5

Chapter 2: Theoretical Basis ............................................................................................... 10

2.1 First-Order Kinetic Processes _............................................................................... 10

2.2 Solution Techniques .............................................................................................

2.3 The Kinetics Equations ............................................................................. 16

2.3.1 Equilibrium Calculations ............................................................................ 16

2.3.2 Calculation of Parameters ............................................................................. 21

2.3.3 Assembling the Matrix of Equations ............................................................... 22

2.4 The Transport Equation ..................................................................................... 26

Chapter 3: Application to a Hypothetical Problem .......................................................... 31

3.1 Batch Simulation ...................................................................................... 31

3.2 Combined Transport and Transformation Effects ..................................................... 33

3.2.1 Problem Definition ........................................................................................ 33

3.2.2 Simulation Results …................................................................................... 34

3.2.3 Reactive Hydrocarbon Transport in the Presence of a Reducing Layer ............ 35

Chapter 4: Model Verification ........................................................................................... 51

4.1 Hypothetical Equilibration of Formic Acid with Carbon Dioxide ............................ 51

4.2 Verification of the Transport Model ....................................................................... 52

Chapter 5: Application to a Field Problem ........................................................................ 56

5.1 Problem Definition .................................................................................................... 56

5.1.1 Overview of the Borden Experiment ............................................................ 56

5.1.2 Chemical Characteristics ....................................................................... 57

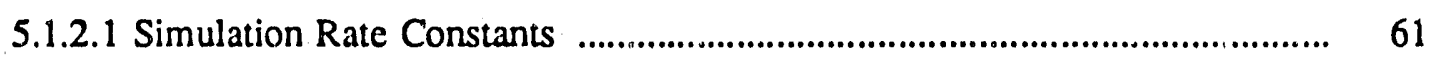

5.1.3 Transport Characteristics ........................................................................... 64 
5.2 Simulation Results ......................................................................................... 68

5.2.1 Batch Simulation ........................................................................................ 68

5.2.2 Transport Simulation ................................................................................... 73

5.2.2.1 Centers of Mass of Contaminant Plumes ..................................................... $\quad 73$

5.2.2.2 Breakthrough Curves ................................................................................ 74

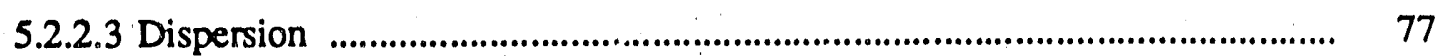

5.2.3 Reactive Transport Results .............................................................................. 78

Chapter 6: Application to a Two-Dimensional Hypothetical Problem .................................. 106

6.1 Problem Definition .................................................................................................... 106

6.2 Simulation Results ........................................................................................ 108

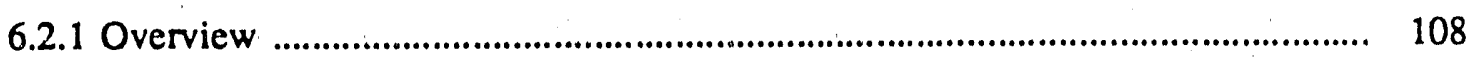

6.2.2 Temporal Evolution of Species Concentrations ................................................. 109

6.3 Implications .................................................................................................. 114

Chapter 7: Conclusions ........................................................................................... 124

7.1 Summary and Conclusions ............................................................................... 124

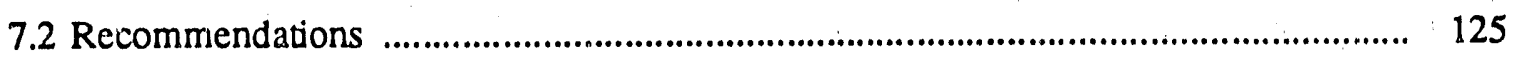

Appendix A: Chemical Reactions Considered in the One Dimensional Problem .............. 127

Appendix B: Numerical Dispersion .............................................................................. 129

Appendix C: Numerical Approximation for Decay Greater Than First-Order .................... 133

Appendix D: Logic Structure of the KINETRAN Algorithm .......................................... 137

Appendix E: Instructions for Preparing KINETRAN Input Deck .................................... 141

Appendix F: Additional Important KINETRAN Variables ............................................. 150

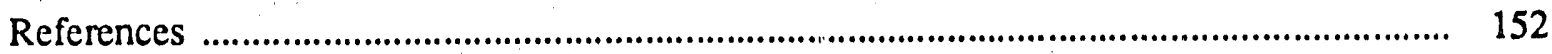




\section{LIST OF FIGURES}

Figure 1.1. Hypothetical $\log$ concentrations (moles/liter) of methyl chloride and methyl bromide as a function of Eh at a $\mathrm{pH}$ of 7.0 and at $25^{\circ} \mathrm{C}$.

Figure 1.2. Hypothetical $\log$ concentrations of organic species involved in the degradation of methyl chloride and methyl bromide as a function of Eh.

Figure 3.1. Possible pathways for the degradation of methyl chloride and methyl bromide under oxidizing conditions.

Figure 3.2. Batch simulation concentrations of methyl chloride and methyl bromide, along with the free halogen ions, as a function of time.

Figure 3.3. Batch simulation concentrations over time of the secondary species produced by the degradation of the two methyl halides.

Figure 3.4. Physical configuration for the hypothetical soil or rock column used for the example simulation.

Figure 3.5. Concentration profiles of methyl chloride in the soil column after 20 days, showing the reactive and non-reactive cases.

Figure 3.6. Concentration profiles of methyl chloride in the soil column after 100 days, showing reactive and non-reactive cases.

Figure 3.7. Concentration profiles for methyl bromide in the column after 20 days for reactive and non-reactive cases.

Figure 3.8. Concentration profiles for methyl bromide in the column after 100 days for reactive and non-reactive cases.

Figure 3.9. Reactive transport profiles for the secondary species in the soil column after 20 days.

Figure 3.10. Reactive transport profiles for the secondary species after 100 days have elapsed.

Figure 3.11. Reactive transport profiles of the degradation products of the methyl halides in the presence of a reducing layer; $t=20$ days.

Figure 3.12. Reactive transport profiles of the secondary species in the soil column containing a reducing layer, $t=100$ days. 
Figure 4.1. Hypothetical equilibration of formic acid with carbon dioxide over time.

Figure 4.2. Comparison of the transport module in KINETRAN with the results from the chemical/heat transport program TRUMP.

Figure 5.1. Possible degradation pathways for the transformation of hexachloroethane.

Figure 5.2. Simplified degradation scheme for the reductive dehalogenation of carbon tetrachloride.

Figure 5.3. Simplified degradation scheme for the degradation of bromoform, carbon tetrachloride, and 1,2-dichlorobenzene.

Figure 5.4. Hypothetical equilibrium concentrations of the chlorinated hydrocarbon species at $\mathrm{pH}=7.6$.

Figure 5.5. Hypothetical equilibrium concentrations of the secondary hydrocarbon species at $\mathrm{pH}=7.6$.

Figure 5.6. Physical configuration of the transport problem.

Figure 5.7. Evolution of the total mass of bromoform in the batch simulation over time.

Figure 5.8. Evolution of the total mass of 1,2-dichlorobenzene in the batch simulation over time.

Figure 5.9. Evolution of the total mass of carbon tetrachloride in the batch simulation over time.

Figure 5.10. Evolution of the total mass of hexachloroethane in the batch simulation over time.

Figure 5.11. Evolution of the total mass of tetrachloroethylene in the batch simulation over time.

Figure 5.12. Comparative temporal evolution of the chlorinated two-carbon hydrocarbons during the batch simulation.

Figure 5.13. Comparative temporal evolution of the secondary hydrocarbons during the batch simulation.

Figure 5.14. Center of mass location of the chloride plume during the transport simulation. 
Figure 5.15. Center of mass location of the carbon tetrachloride plume during the transport simulation.

Figure 5.16. Center of mass location of the bromoform plume during the transport simulation.

Figure 5.17. Center of mass location of the tetrachloroethylene plume during the transport simulation.

Figure 5.18. Center of mass location of the 1,2-dichlorobenzene plume during the transport simulation.

Figure 5.19. Center of mass location of the hexachloroethane plume during the transport simulation.

Figure 5.20. Breakthrough curves for chloride, carbon tetrachloride, and tetrachloroethylene at $10 \mathrm{~m}$ from the source.

Figure 5.21. Evolution of chloride plume over time through the soil column, showing clear evi-. dence of dispersion.

Figure 5.22. Evolution of bromoform plume profile in the soil column over time.

Figure 5.23. Evolution of hexachloroethane plume profile in the soil column over time.

Figure 5.24. Evolution of tetrachloroethylene plume profile in the soil column over time.

Figure 5.25. Evolution of trichloroethylene plume profile in the soil column over time.

Figure 5.26. Evolution of vinyl chloride plume profile in the soil column over time.

Figure 6.1. Physical configuration of the hypothetical two-dimensional problem.

Figure 6.2. Temporal evolution of total $\mathrm{CO}_{2}$ concentration at the various monitoring points.

Figure 6.3. Temporal evolution of formic acid concentration at the various monitoring points.

Figure 6.4. Temporal evolution of formaldehyde concentration at the various monitoring points.

Figure 6.5. Temporal evolution of methanol concentration at the various monitoring points.

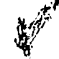

Figure 6.6. Temporal evolution of methane concentration at the various monitoring points. 
Figure 6.7. Temporal evolution of methyl chloride concentration at the various monitoring points.

Figure 6.8. Temporal evolution of methylene chloride concentration at the various monitoring points.

Figure 6.9. Temporal evolution of chloroform concentration at the various monitoring points.

Figure 6.10. Temporal evolution of carbon tetrachloride concentration at the various monitoring points.

Figure 6.11. Temporal evolution of free chloride concentration at the various monitoring points. 


\section{LIST OF TABLES}

Table 3.1. Degradation Reactions for Methyl Chloride and Methyl Bromide at $\mathrm{pH}=7.0$ and $\mathrm{Eh}=+0.1$ Voils

Table 3.2. Degradation Reactions for Methyl Chloride and Methyl Bromide at $\mathrm{pH}=7.0$ and $E h=-0.3$ Volts

Table 5.1. Organic Species, Borden Simulation

Table 5.2. Initial Contaminant Concentrations in Injection Plume

Table 5.3. Equilibration Reactions for Borden Organic Species

Table 5.4. Degradation Reactions at $\mathrm{pH}=7.6$ and $\mathrm{Eh}=+0.3$ Volts

Table 5.5. Retardation of Original Organic Species

Table 5.6. Initial Contaminant Concentrations for Transport Simulation

Table 6.1. Reactions for the two-dimensional problem in the oxidizing zone $(\mathrm{Eh}=+0.1$ Volts).

Table 6.2. Reactions for the two-dimensional problem in the reducing zone (Eh $=-0.3$ Volts). 


\section{LIST OF SYMBOLS, KINETICS EOUATIONS}

Symbol Definition

\begin{tabular}{|c|c|}
\hline$A_{i, m}$ & Element in the implicit kinetics matrix \\
\hline$\left[\mathrm{A}_{0}\right]$ & Initial concentration of $A$ at start of time step \\
\hline $\mathbf{B}_{\mathbf{i}}$ & Element in the explicit kinetics matrix \\
\hline$B_{n(i, m)}^{\prime}$ & Factor used in calculation of $B_{i}$ \\
\hline$c_{i}$ & Concentration of species $i$ \\
\hline$c_{i}^{0}$ & Initial concentration of species $i$ \\
\hline$c_{\mathrm{mj}}^{0}$ & Initial concentration of species $m$ in reaction $j$ \\
\hline$c_{m j^{r}}^{0}$ & Initial concentration of species $m$ in reaction $j^{\prime}$ \\
\hline$e^{-}$ & The hypothetical aqueous electron \\
\hline Eh & Electrical potential with reference to the standard hydrogen electrode \\
\hline $\mathbf{F}$ & Faraday constant \\
\hline$[i]$ & Concentration/activity of any species $i$ \\
\hline$[i]^{*}$ & Virtual concentration/activity of species $i$ \\
\hline $\mathbf{J}_{\mathbf{p}}$ & Number of reactions in which a given species is produced \\
\hline$J_{\mathbf{r}}$ & Number of reactions in which a given species is destroyed \\
\hline $\mathbf{K}_{\text {eq }}$ & Thermodynamic equilibrium constant \\
\hline$k_{1}$ & Kinetic coefficient for a given forward reaction \\
\hline $\mathbf{k}_{2}$ & Kinetic coefficien. for a given reverse reaction \\
\hline $\mathbf{k}_{\mathrm{j}, \mathrm{f}}$ & Kinetic coefficient for reaction $j$, forward direction \\
\hline $\mathbf{k}_{\mathrm{j}, \mathbf{r}}$ & Kinetic coefficient for reaction $j$, reverse direction \\
\hline$d$ & Kinetic coefficient for reaction $n$, direction $d, t$ \\
\hline
\end{tabular}


$\mathbf{N}$

pE

pH

$\mathbf{s}_{\mathbf{i}}$

$S_{\mathbf{m j}}$

$S_{\text {mj }}$

$\mathbf{x}$

$\Delta c_{i}$

$\Delta c_{\mathrm{mj}}$

$\Delta c_{m j^{\prime}}$

$\Delta t$

$\lambda$

$\lambda_{j, s}$

$\lambda_{j, y}$

$\lambda_{n(i, m) d}$

$\mu_{i j}$

$\mu_{i j^{\prime}}$

$\mu_{\mathrm{m} j}$

$\mu_{m j^{\prime}}$

$\mu_{i, n(i, m)}$

$\mu_{m \Omega(i, m)}$

v
Total number of reaction said to occur in system

Negative logarithm of the hypothetical aqueous electron concentration

Negative logarithm of the hydrogen ion concentration

Species $i$, as written in a reaction equation

Species $\boldsymbol{m}$ produced in reaction $j$

Species $m$ destroyed in reaction $j^{\prime}$

Total concentration of a given component prior to normalization

Change in concent tion of $i$ due to transformation

Change in concentration of $m$ in reaction $j$

Change in concentration of $m$ in reaction $j^{\prime}$

Simulation time increment

Time-averaging coefficient for aqueous species concentration

Time-averaging coefficient for reaction $j$, forward direction

Time-averaging coefficient for reaction $j$, reverse direction

Time-averaging coefficient for reaction $n$, direction $d$, involving $i$ and $m$

Stoichiometric coefficient of $i$, reaction $j$

Stoichiometric coefficient of $i$ reaction $j^{\prime}$

Stoichiometric coefficient of $m$, reaction $j$

Stoichiometric coefficient of $m$, reaction $j^{\prime}$

Stoichiometry of $i$ in reaction $n$ with $m$

Stoichiometry of $m$ in reaction $n$ with $i$

Mass conservation normalization factor for equilibration 


\section{LIST OF SYMBOLS, TRANSPORT EQUATIONS}

Symbol Definition

$A_{1, n} \quad$ Interfacial area between nodes $l$ and $m$

$c_{L m}^{i}$

Average concentration of $i$ at interface between $l$ and $m$

$D_{d}^{i}$

Effective diffusion coefficient for $i$

$\mathbf{D}_{\mathbf{H}}^{\mathbf{i}}$

Hydrodynamic dispersion coefficient for $i$

$F_{1 \mathrm{~m}}$

Advectance between nodes $l$ and $m$

$\mathbf{G}_{1}^{\mathbf{i}}$

Source/sink term for species $i$

$K_{d}^{i}$

Distribution coefficient for species $i$

n

Material porosity

$q_{1, m}$

Darcy velocity between $l$ and $m$, normal to interface

$\mathbf{R}_{\mathbf{i}}$

Retardation coefficient for species $i$

$\mathrm{U}_{1 \mathrm{~m}}$

Conductance between nodes $l$ and $m$

$\mathrm{V}_{B, 1}$

Bulk yolume of node $l$

$x_{1}$

Distance from nodal point $l$ to interface

$\mathbf{x}_{\mathrm{Lm}}$

Distance between noda' points $l$ and $m$

$\boldsymbol{x}_{\mathbf{m}}$

Distance from nodal point $m$ to interface

$\Delta c_{L, m}^{i}$

Spatial concentration gradient for $l$ between nodes $l$ and $m$

$\Delta c^{i}$

Temporal change in species $i$

$\Delta \mathbf{t}$

Discrete time step

$\rho_{b}$

Material bulk dry density 


\section{ACKNOWLEDGEMENTS}

First and foremost, I wish to thank my research advisor, Professor T.N. Narasimhan, for his encouragement, valied advice, and consistent support throughout my graduate studies at Berkeley. I wculd also like to thiank Dr. John Apps of Lawrence Berkeley Laboratory for very helpful discussions and criticisms. I thank Dr. Apps and Professor Douglas Fuerstenau of the Mineral Engineering Department, U.C. Berkeley, for serving on my thesis committee.

I would also like to express my appreciation to my family and friends who helped and encouraged me. My parents and my fiancee, Maria Crosson, have provided me with constant love, support, and encouragement during my graduate work. I wish to give special thanks to my fellow graduate students for their friendship and advice, especially Jeff Lehman, Matt Small, and Ming Zhu.

This work was supported in part by the U.S. Department of Energy under contract number DE-AC03-765F00098. The Cray Research Institute also provided valuable computing time on the Cray XMP/14 machine at U.C. Berkeley, which was utilized to develop and debug the FORTRAN 77 version of the KINETRAN program. These two supports are sincerely appreciated. 


\section{CHAPTER 1: INTRODUCTION}

The problem of groundwater contamination by halogenated hydrocarbons has grown into an issue of great concem in recent years. This is reflected in the copious amounts of literature now available describing instances of pollution by industrial solvents, landfill leachates, pesticides, polychlorinated biphenyls (PCB's), and so forth. Many of these substances are highly toxic and pose a very real threat to domestic water supplies, soils, and the local ecology. Thus, an understanding of their eventual fate is of considerable concem to environmental engineers.

Once dissolved in the aqueous state in groundwater, the behavior of halogenated hydrocarbons is determined through a variety of processes. The materials are generally transported very slowly through tixe subsurface as a result of fluid advection, molecular diffusion, and hydrodynamic dispersion. Some of these organics are very hydrophobic and tend to adsorb onto organic substrates on soil particle surfaces, thus their movement may be significantly retarded. In addition to transport phenomena, the chemical transformation of these substances also plays a crucial role in their behavior. Halogenated hydrocarbons can be shown to be thermodynamically unstable with respect to species such as $\mathrm{CO}_{2}$ or $\mathrm{CH}_{4}$. However, their degradation under natural conditions is often a very slow process, thus many pollutants will persist in groundwater for very long time periods, perhaps thousands of years in some cases.

A large variety of mechanisms are known to be involved in the transformation of organic species in groundwater. These include abiotic processes, such as hydrolysis, and biologicallymediated reactions which require the presence of various microbes. Under certain conditions, these microorganisms will metabolize (or often co-metabolize) organic pollutants in order to extract energy and, in some cases, generate cell material (mineralization). Regardless of the mechanism, ear $h$ of these degradation processes can be viewed as the transformation of one 
material into another, and may often be assigned a first-order rate constant as a good approximation. Thus, with a sufficient knowledge of the chemistry of a given system, the entire degradation scheme of a group of halogenated hydrocarbons, and the subsequent generations of daughter products, may be characterized by a set of reversible chemical reaction equations that follow first order kinetics. Bearing this in mind, we seek to develop a numerical model which is capable of predicting the fate of such contaminants in groundwater.

\subsection{Motivation}

Reactive chemical transport models have appeared in the literature in recent years for simulating chemical transport in groundwater systems. Essentially, these solve the classical advection-diffusion-dispersion equation, coupled with appropriate equations for reactions involving thermodynamic equilibrium among the various species involved. Liu (1988) and Liu and Narasimhan (1989a) provide a summary of some the more recent work in this field.

Many of the reactive transport models that are currently available are designed to solve problems of a geological interest, although some are geared to applied, engineering-oriented problems. Because the time scales involved in geological problems are generally very large compared to chemical reaction times, the assumption of local thermodynamic equilibrium, at least among the aqueous species, is often an acceptable approximation. This is the basis for the use of equilibrium geochemical models such as PHREEQE (Parkhurst et al., 1980) and EQ3/EQ6 (Wolery, 1979, 1983) to handle heterogeneous interactions in reactive transport models (Ague, 1987 and Liu and Narasimhan, 1989a). Problems that are highly dependent on mineral dissolution reactions cannot always be studied with pure equilibrium chemistry models, thus attempts at including mineral dissolution kinetics in reactive transport models have been 
made (Ague, 1987 and Liu, 1988). These attempts at incorporating non-equilibrium effects have focused on heterogeneous interactions. With rare exceptions, the kinetics of homogeneous reactions in the aqueous phase have so far received little attention in the literature in relation to transport modeling.

Aqueous systems in which the reaction times between the various reactive species present become significant compared to the overall simulation time require that non equilibrium effects be duly considered. Systems with dissolved organic specius frequently involve reactions with high activation energies which often have low reaction rates under normal environmental conditions. Of particular environmental concem are the degradation reactions that determine the eventual fate of organic industrial solvents and petroleum products that find their way into groundwater. Equilibrium-based reactive transport models are not capable of simulating these systems with adequate detail and accuracy to assist in designing efficient remedial strategies.

To illustrate this point, consider the following hypothetical problem. A small amount of dissolved methyl chloride and methyl bromide are added to a fully water-saturated soil or rock mass with background concentrations of dissolved carbon dioxide, free chloride, and free bromide. Both compounds are normally found as gases at standard temperature and pressure, but they are slightly soluble in water. These halogenated hydrocarbons were chosen for this illustration because of their relatively simple chemistry; only a small number of possible degradation reactions exist. Both compounds may undergo hydrolysis reactions that produce methyl alcohol and free halogen ions (Mabey and Mill, 1978). However, under very reducing conditions methane may be produced, while under more oxidizing conditions, microbes may assist in converting the materials into formaldehyde (Vogel et al., 1987). Alcohol and formaldehyde may in turn be oxidized into formic acid (Hart, 1987). In addition, all of these "daughter" 
organic compounds, methane, alcohol, formaldehyde, and formic acid, will themselves be eventually oxidized to carton dioxide under oxidizing conditions.

Bearing these possibilities in mind, we define the following initial conditions in the groundwater. All concentrations $†$ are given in moles per liter:

$$
\begin{aligned}
{\left[\mathrm{CH}_{3} \mathrm{Cl}(\mathrm{aq})\right] } & =10^{-4} \\
{\left[\mathrm{CH}_{3} \mathrm{Br}(\mathrm{aq})\right] } & =10^{-4} \\
\text { total }\left[\mathrm{CO}_{2}(\mathrm{aq})\right] & =10^{-3} \\
{\left[\mathrm{Cl}^{-}\right] } & =10^{-3} \\
{\left[\mathrm{Br}^{-}\right] } & =10^{-10}
\end{aligned}
$$

The initial concentrations of the other species (methane, methyl alcohol, formaldehyde, formic acid) are set equal to zero. The $\mathrm{pH}$ of the system is assumed to be buffered at 7.0 by the mineral species present in the soil matrix and by inorganic species in the aqueous phase. Aqueous complexing with inorganic species is not considered. All activity coefficients are assumed to be unity. A temperature of $25^{\circ} \mathrm{C}$ is assumed. Given these initial conditions, and the thermodynamic data describing this system (see Appendix A), the final equilibrium state of all of the species of interest can be calculated by a simple iterative technique, which will be described later.

Figures 1.1 and 1.2 show the equilibrium concentrations of the various hydrocarbon species as a function of Eh. Clearly, methane is the dominant species present under reducing conditions, whereas carbon dioxide is the significant species under oxidizing conditions. All of the other species occur in trivial (essentially zero) amounts. This is particularly true of the

it Throughour this paper, we use square brackets "I ]" to denote concenerations as well as activities, tince the two are approximately equal in tilute solutions because the activity coefficients will essentially be equal to unity. 
primary pollutants, methyl chloride and methyl bromide. These results are, of course, quite reasonable since carbon dioxide is ubiquitous in most groundwater environments, while methane is found in very reducing environments, isolated from atmospheric oxygen. Methyl alcohol, formaldehyde, and formic acid are generally not found in significant amounts natural sediments.

The limitation of the above instantaneous equilibrium approach is that it shows the state of the system that would exist only after a considerable amount of time has passed. For very slow reactions, this may mean hundreds or even thousands of years. If this model is used to solve reactive transport problems involving organic pollutants, the pollutant concentrations would fall to essentially zero immediately after the transport process begins and only $\mathrm{CO}_{2}$ or $\mathrm{CH}_{4}$ will remain and be transported through the system. However, the persistence of halogenated hydrocartons in carefully monitored polluted groundwater systems indicates that the establishment of equilibrium between the introduced constituents involves time. Therefore, the equilibrium approach must be abandoned in favor of a technique that treats the final equilibrium state of the system only as a "goal" which the concentrations of the participating species tend towards as the system evolves.

\subsection{Purpose and Scope}

The purpose of this study is to develop a numerical model for the transformation and transport of aqueous species that is not restricted by the assumption of instantaneous equilibrium. Such a model would solve for the spatial and temporal changes in concentration of a number of interacting species due to the effects of transport and kinetically-controlled chemical transformations within a given groundwater environment. If successful, such a model would be 
of value not only to contaminant transport hydrology but also to other branches of earth science as well, such as in the study of the evolution of petroleum reservoirs.

We introduce a model, KINETRAN (KINEtically-controlled reactive chemical TRANsport), in an attempt to meet this goal. In this thesis, the development of this model is discussed, with special emphasis on the theoretical basis of the kinetics algorithrn. We must emphasize that the model treats all kinetically-controlled transformation processes as black-box processes. No attempt is made to distinguish between abiotic degradation, such as hydrolysis reactions, and biodegradation. The model is first applied to a hypothetical one-dimensional problem in order to verify its mathematical consistency and to illustrate its applicability. Later, we apply the model to an actual field case in order to see how well KINETRAN matches experimental results. As an additional exercise, the model is applied to a hypothetical twodimensional problem characterized by physical and chemical heterogeneities in order to assess its applicability to more complex scenarios.

It is important to recognize that numerical models of chemical transport are not absolute predictive tools. Rather, they are devices that enhance our understanding of how complex natural systems may behave in response to different contamination scenarios. This is especially true of the type of problems of interest here because some of the parameters needed for the simulation, particularly the first-order kinetic rate constants, may not be known a priori. Indeed, these quantities are known to be dependent on such factors as the presence of catalysts and the type and amount of microbes present in the system. The parameters are thus systemdependent. The fact that the relevant kinetic parameters are not known a priori may be viewed by some as a very significant impediment to the applicability of the algorithm to realistic field problems of interest. We, however, feel that this lack of data on parameters may in fact 
enhance the utility of such an algorithtn as KINETRAN in that, given carefully collected field data, the model can be used as part of a history-matching scheme to "back-out" acceptable kinetic coefficients for certain systems. The parameters obtained by this calibration technique may indeed prove to be of greater practical value than those estimated from laboratory experiments carried out under highly idealized conditions. Such calibrated data may also prove to be of use at other sites where field conditions are of a similar nature.

The present version of KINETRAN is strictly a prototype, intended to test the feasibility of a concept. $A s$ of now, it is restricted to dilute solutions. Immiscible flow phenomena and volatilization are ignored. The concentrations of all species present are assumed to be low enough so as not to affect the physical properties of the solvent, namely water. No attempt is made to calculate activity coefficients; all are assumed to be unity. The activity of water is also taken to be unity.

The $\mathrm{pH}$ and Eh of the system are allowed to vary spatially, but are treated as constant in time. In other words, the $\mathrm{pH}$ and Eh at any given location in the system are assumed to be buffered by the existing mineral assemblage in the soil and by inorganic aqueous species, such as, for example, the $\mathrm{Fe}^{2+}-\mathrm{Fe}^{3+}$ redox couple. This assumption will be valid when the concentrations of the dissolved organic pollutants present are relatively small.

Additionally, other than adsorption, no heterogeneous reactions are considered. That is, any mineral phases preserit affect the aqueous phase onty by buffering the $\mathrm{pH}$ and Eh at constant values.

The program is capable of handling adsorption through the use of distribution coefficients. Adsorption is assumed to affect the system only by retarding the flux of the various species involved. Thus, the chemical kinetics algorithm treats sorbed species in exactly the 
same manner as their aqueous counterparts with regard to the rate and extent of any chemical reactions that occur. The altemative approach would be to model the adsorption process with the use of a sink term in the transport equation. In this case, sorbed species would simply remain part of the solid phase, removed from the aqueous phase and unable to undergo any aqueous chemical transformations. Presently, experimental data are insufficient to suggest precisely how sorbed organic species might behave chemically under realistic environmental conditions. It could well be that the process of adsorption itself may catalyze some of the degradation reactions with which we are concemed. For example, the interlayer sites of some clay minerals may serve to promote hydrolysis reactions of some organic species (Apps, 1989). This is clearly an area where further research is warranted.

Finally, the present model simulates only completely isothermal systems. For advective transport, the model is restricted to a steady fluid flow field. 


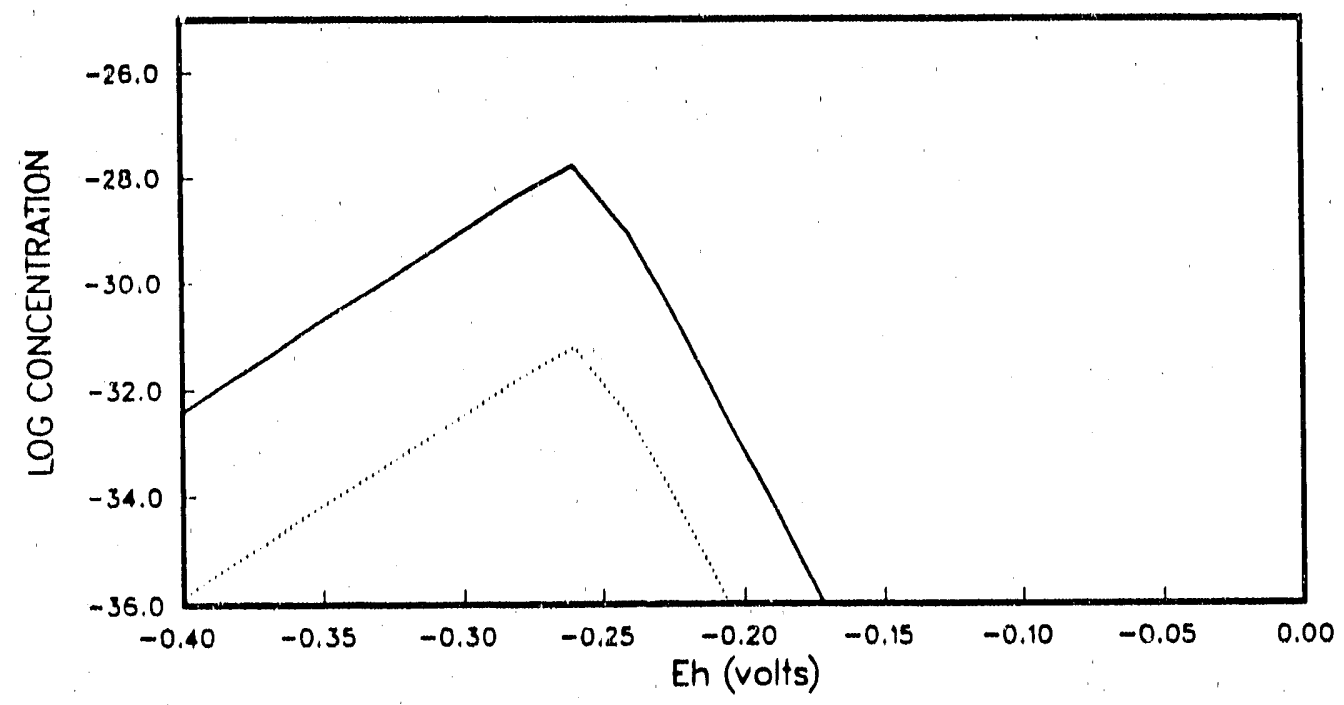

Legend

Methyl chloride

Mothy! bromide

Figure 1.1. Hypothetical log concentrations (moles/liter) of methyl chloride and methyl bromide as a function of $\mathrm{Eh}$ at a $\mathrm{pH}$ of 7.0 and at $25^{\circ} \mathrm{C}$.

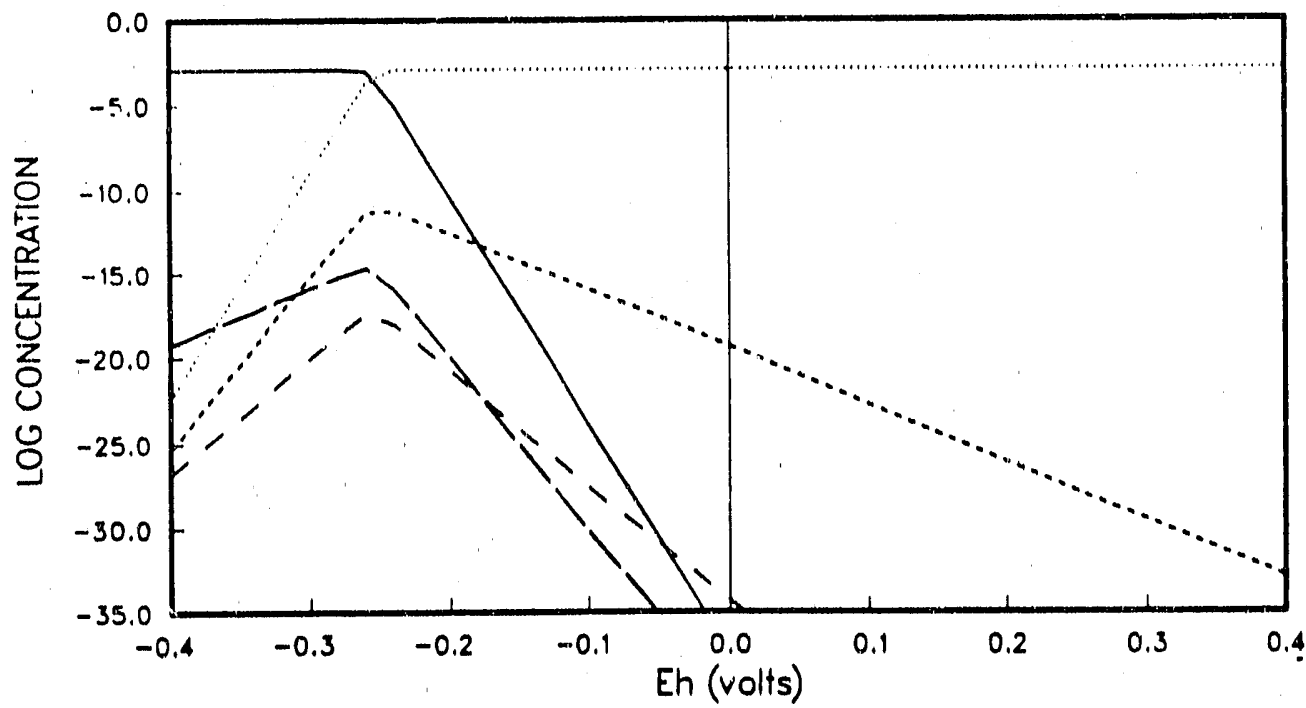

Legend

Methand

Methanol

Formaldehyde

Formle octd

Corbon dloxide

Figure 1.2. Hypothetical log concentrations of organic species involved in the degradation of methyl chloride and methyl bromide as a function of Eh. 


\section{CHAPTER 2: THEORETICAL BASIS}

In this chapter, we discuss the mathematical basis behind the numerical algorithm of the model. We consider reversible first-order kinetics processes, and develop a mathematical scheme for solving a system of interrelated first-order reactions simultaner,usly. We also present a brief description of the integral finite difference technique for solving the solute transport equations.

\subsection{First-Order Kinetic Processes}

Consider a system which contains only two hypothetical species, $\mathrm{A}$ and $\mathrm{B}$, and a solvent in which they are dissolved, water. The only possible reaction that can take place in this system is the reversible reaction

$$
A \leftarrow B
$$

Neglecting activity coefficients, at equilibrium, the concentrations of the species will satisfy the relation,

$$
\frac{[B]}{[A]}=K_{e q}
$$

where $K_{e q}$ is the equilibrium constant. Obviously, if any given initial concentrations for $A$ and B do not satisfy (1), this reaction will be driven in the direction that favors equilibrium. The net rate at which such a reaction will proceed is equal to the forward rate minus the reverse rate. These reaction rates, considered separately, often approximately follow first-order kinetics. Thus, 


$$
\begin{aligned}
& \frac{d[A]}{d t}=-k_{1}[A] \\
& \frac{d[B]}{d t}=-k_{2}[B]
\end{aligned}
$$

Chemical equilibrium is, of course, not a static equilibrium but a dynamic one. When the system is far from equilibrium, reaction in one direction will dominate, but as equilibrium is approached, the opposite reaction becomes significant. Finally, once equilibrium is established, the forward and reverse reaction rates must be equal. Hence,

$$
\frac{\mathrm{d}[\mathrm{A}]}{\mathrm{dt}}=\frac{\mathrm{d}[\mathrm{B}]}{\mathrm{dt}}
$$

Therefore, from (2) and (3),

$$
k_{1}[A]=k_{2}[B]
$$

So, at equilibrium,

$$
k_{2}=k_{1} \cdot \frac{[A]}{[B]}
$$

However, $[A] /[B]$ is already shown by (1) to be the reciprocal of the equilibrium constant, thus we find that the rate constant for the reverse reaction is related to that for the forward reaction by,

$$
k_{2}=\frac{k_{1}}{K_{e q}}
$$

Therefore, $k_{1}, k_{2}$, and $k_{e q}$ are mutually related. This very simple relationship, in fact, forms an important element in the logic of the kinetics-solving algorithm in KINETRAN. If one has an estimate for the value of $\mathrm{K}_{\mathrm{eq}}$, and an estimate for $\mathrm{k}_{1}$, the kinetic coefficient for the dominant initial reaction direction, then $\mathrm{k}_{2}$ can be calculated from an expression such as (5). 
As long as first-order kinetics are assumed, the above technique can be used for determining $k_{2}$ for more complicated reactions. For example, suppose that the reaction between $A$ and $B$ is actually an oxidation reaction such that

$$
A \rightarrow 3 B+H^{+}+\mathrm{e}^{-}+C
$$

where $\mathrm{H}^{+}$denotes a free hydrogen ion, $\mathrm{e}^{-}$denotes a hypothetical $\dagger$ free aqueous electron, and C refers to some other species. Now,

$$
\frac{[B]^{3}\left[\mathrm{H}^{+}\right]\left[\mathrm{e}^{-}\right][\mathrm{C}]}{[\mathrm{A}]}=\mathrm{K}_{\mathrm{eq}}
$$

Also, we assume a rate dependence on [B] only,

$$
\frac{d[B]}{d t}=-k_{2}[B]^{3}
$$

This will hold if $\left[\mathrm{H}^{+}\right],\left[\mathrm{e}^{-}\right]$, and $[\mathrm{C}]$ remain constant. The KINETRAN model assumes that the $\mathrm{pH}$ and $\mathrm{Eh}$ are indeed constant, as mentioned earlier. The quantity [C], which typically represents $\left[\mathrm{Cl}^{-}\right]$for problerns involving chlorinated hydrocarbons, may remain approximately constant if background concentrations are high compared to the dissolved organic pollutant concentrations.

As we will show later, rate law expressions other than first-order will lead to a system of non-linear equations. In order to avoid this difficulty and maintain a system of linear equations, we linearize this equation by using the approximation,

t The quantity [e-], which we refer to throughout this paper, does not refer to the satual concentration of froe aqueous electrons, which is essentially zera. Rather, it is a purely hypothetical concentration which is a reflection of the redox sute of the system. Withoul going through the derivation (Thoritenton, 1984), we state here that $[e-]=10(-p E)$, where $\mathrm{pE}=\mathrm{Eh}(\mathrm{F} / 2.303 \mathrm{RT})$. Eh = electrical potential with reference to the andard hydrogen elearode, $F=$ Faroday consunis $\bar{K}=$ Universai Gas Consianis and $\bar{T}=$ icmperaiure in Krivin. 


$$
\mathbf{k}_{2}^{\prime}=\mathbf{k}_{2}[B]^{2}
$$

Thus,

$$
\frac{\mathrm{d}[\mathrm{B}]}{\mathrm{dt}} \approx-\mathrm{k}_{2}^{\prime}[\mathrm{B}]
$$

We see that by analogy to (4)

$$
\mathbf{k}_{2}^{\prime}=\mathbf{k}_{1} \frac{[\mathrm{A}]}{[\mathrm{B}]}
$$

From the equilibrium condition,

$$
\frac{[A]}{[B]^{3}}=\frac{\left[H^{+}\right]\left[\mathrm{e}^{-}\right][\mathrm{C}]}{K_{\text {oq }}}
$$

Substituting this expression into (4), which relates the forward and reverse rate constants to each other, we find

$$
\mathbf{k}_{2}^{\prime}=\mathbf{k}_{1} \frac{\left[\mathrm{H}^{+}\right]\left[\mathrm{e}^{-}\right][\mathrm{C}][\mathrm{B}]^{2}}{\mathrm{k}_{\text {eq }}}
$$

Even in this case, $\mathrm{k}_{2}^{\prime}$ may still be determined if we assume that the $\mathrm{pH}$ and Eh are held constant and that we can calculate $[B]$ and $[\mathrm{C}]$ at equilibrium from thennoriynamic considerations. 


\subsection{Solution Techniques}

Consider again the reaction

$$
A \longleftrightarrow B
$$

If we look at only the forward reaction, we note that

$$
\frac{d[A]}{d t}=-k_{1}[A]
$$

may be intergrated in order to solve for the concentration of $A$ after an interval of time $\Delta t$ has elapsed:

$$
[A]=\left[A_{0}\right] e^{-k_{1} \Delta t}
$$

where $\left[A_{0}\right]$ is the concentration of $A$ at the beginning of $\Delta t$. Equation (6) will accurately represent the temporal evolution of $[A]$ if the reaction is far from equilibrium. However, as the reaction approaches equilibrium, species $\mathrm{A}$ will begin to be produced in significant amounts by the reverse reaction $B \rightarrow A$. This newly produced $A$ will itself begin to react to form $B$ again, and so on. Thus, the quantity $\left[A_{0}\right]$ in $(6)$ becomes ambiguous as equilibrium is approached. If the system is more complex, with additional species present and many reactions occurring, with each species being involved in a number of possible reactions, the problem is greatly compounded. If one choses to model this system by sequentially solving a number of explicit equations such as (6) for all of the possible forward and reverse reactions, very small time steps must be taken in order to achieve accuracy as the reactions approach equilibrium. If the simulation time is large, this could prove to be computationally inefficient. 
Clearly, if $i$ species are present in a system, there exists a strong motivation to find a method for simultaneously solving for all $\Delta c_{i}$ over a given $\Delta t$, where $c_{i}$ is the aqueous concentration of species $i$. This can be achieved by using a time-averaging discretization scheme analogous to those used in the time-integration of transient diffusion processes such as heat conduction or groundwater flow using numerical methods. Such a solution technique is as follows. First, instead of directly integrating the rate equation, discretize it. Thus,

$$
\frac{\Delta[A]}{\Delta t}=-k_{1}[\bar{A}]
$$

where $[\bar{A}]=\left[A_{0}\right]+\lambda \Delta[A]$, an effective average value for $[A]$ over the given time interval $\Delta t$. The task here is to choose a value for $\lambda$ that will allow the discretized equation to very closely approximate the differential rate equation. Note that in the modeling of transient diffusion processes, $\lambda=0.0,0.5$, and 1.0 are respectively known as Forward-Differencing, CentralDifferencing, and Backward-Differencing schemes.

By definition, the change in concentration $\Delta[A]$ over a time interval $\Delta t$ is,

$$
\Delta[A]=[A]-\left[A_{0}\right]=\left[A_{0}\right] e^{-k_{1} \Delta s}-\left[A_{0}\right]
$$

According to (7), the discretized rate equation, we wish to approximate this relation,

$$
\Delta[A]=-k_{1}\left[\left[A_{0}\right]+\lambda \Delta[A]\right] \Delta t
$$

Rearranging this equation in terms of $\Delta[A]$, we find,

$$
\Delta[A]=\frac{-k_{1} A_{0} \Delta t}{k_{1} \lambda \Delta t+1}
$$


Equating (8) and (9b), we obtain

$$
\lambda=\frac{1}{1-e^{-k_{1} \Delta}}-\frac{1}{k_{1} \Delta t}
$$

Thus, the approximation for $\lambda$ depends only on the value of $\mathbf{k}$ (forward or reverse reaction), and the time step. Therefore, a precise value for $\lambda$ can be calculated for every reaction in the system (forward or backward) in order to achieve maximum overall accuracy.

Using this method, one can write an expression $\Delta c_{i}$ for every reaction for every species $i$ in the system. Collecting the terms eventually yields a linear system of $i$ unknowns and $i$ equations, which can be solved for $\Delta \mathrm{q}_{\mathrm{i}}$ for all species in the system over $\Delta \mathrm{t}$. We discuss the process of setting up these equations in the following sections.

\subsection{The Kinetics Equations}

\subsubsection{Equilibrium Calculations}

Earlier, we showed that for general first-order kinețic reactions, we need to know the final equilibrium state of the system in order to calculate the kinetic coefficients in the reverse, or initially non-dominant directions. For relatively simple systems, this step in the model may seem trivial. For example, for a system containing chlorinated hydrocarbons, only concentrations such as $\left[\mathrm{Cl}^{-}\right]$at equilibrium would need to be predicted, which would essentially be equal to the total chlorine concentration. $\left[\mathrm{H}^{+}\right]$and $[\mathrm{e}]$ would already be externally fixed, and thus these need not be determined either. However, for more complicated systems involving com-

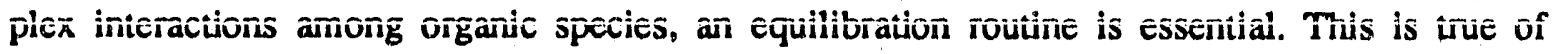


inorganic species as well. If sulfur is present as a component, for example, the equilibration routine would be needed to determine the relative concentrations of $\mathrm{SO}_{4}^{2-}, \mathrm{H}_{2} \mathrm{~S}$, or $\mathrm{HS}^{-}$as a function of $\mathrm{pH}$ and $\mathrm{Eh}$. Therefore, before we proceed with assembling the equations which describe the kinetically-controlled reactions, we present a method for determining the final equilibrium concentrations of the equilibrating species. Given the necessary equilibrium constants (see Appendix A), it is relatively simple to calculate this if the $\mathrm{pH}$ and Eh of the system are held constant, which we assume.

Many well-known geochemical simulators, PHREEQE (Parkhurst et al., 1980) and EQ3NR (Wolery, 1983), determine aqueous speciation through the use of mass action and mass baiance equations which constrain the possible final equilibrium state of a given system of aqueous species. Because of the extremely high concentration of water relative to any other species present in most problems, implementation of the mass balance constraint for the elements $\mathrm{H}$ and $\mathrm{O}$ is generally not feasible. Because of this, the mass balance equations for these two elements are replaced by charge balance and electron balance equations, respectively. Eventually, a set of highly non-linear equations is developed which may contain terms that differ from one another by many orders of magnitude, requiring fairly sophisticated mathematical techniques for solution. For this purpose, the Newton-Raphson iteration is a preferred method, with the starting estimates obtained by various optimization schemes (Parkhurst et al., 1980). However, because we choose to hold the $\mathrm{pH}$ and Eh constant, thus holding $\left[\mathrm{H}^{+}\right]$and [e] constant, in the present work we eliminate the need to solve a charge balance and an electron balance equation. This permits us to use a far simpler iteration scheme that is quite fast and is generally very reliable.

To illustrate this technique, consider again the hypothetical equilibration problem 
described section 1.1. There are three components present (aside from hydrogen and oxygen) that make up the system: carbon, chlorine, and bromine. These three give rise to the nine species that participate + in the degradation reactions:

\author{
methyl chloride, $\mathrm{CH}_{3} \mathrm{Cl}(\mathrm{aq})$ \\ methyl bromide, $\mathrm{CH}_{3} \mathrm{Br}$ (aq) \\ methane, $\mathrm{CH}_{4}(\mathrm{aq})$ \\ methyl alcohol, $\mathrm{CH}_{3} \mathrm{OH}$ \\ formaldehyde, $\mathrm{HCHO}$ \\ formic acid, $\mathrm{HCOOH}$ \\ total carton dioxide, $\mathrm{CO}_{2}(\mathrm{aq})$ \\ free chloride, $\mathrm{Cl}^{-}$ \\ free bromide, $\mathrm{Br}^{-}$
}

Under extemally fixed $\mathrm{pH}$ and Eh values, the final equilibrium state of the system is entirely defined by mass action equations between the various species and by mass balance constraints on the total amount of each element present. As a first step, we define a set of master species such that each element is represented by an appropriate species which is used in the mass action equations. The master species chosen for each element should be species whose equilibrium concentration is relatively large over a wide range of $\mathrm{pH}$ and Eh values and which never falls below the underflow tolerance of the computer system being used. Referring again to Figures 1.1 and 1.2 and using these criteria, we chose $\mathrm{CO}_{2}$ as our master species for carbon,

† Other apecies are present in the simulntion but are not included in this lia. H+ and o- are involved in many of the reactions but are externally fixed a consuant values. $\mathrm{HCO}$ - and $\mathrm{CO}$ - are alwo present bur are considered separately

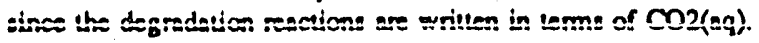


$\mathrm{Cl}^{-}$for chlorine, and $\mathrm{Br}^{-}$for bromine. Of course, $\mathrm{H}^{+}$and $\mathrm{e}^{-}$are actually master species, representing $\mathrm{H}$ and $\mathrm{O}$, respectively.

Nexh, we assign each of the master species a concentration value corresponding to the total amount of that element present. Thus, we define the virtual concentration of a master species to be equal to the sum of the concentrations of each compound in which the given element occurs times its stoichiometric coefficient. For our example,

$\left[\mathrm{CO}_{2}\right]^{*}=\left[\mathrm{CH}_{3} \mathrm{Cl}\right]+\left[\mathrm{CH}_{3} \mathrm{Br}\right]+\left[\mathrm{CH}_{4}\right]+\left[\mathrm{CH}_{3} \mathrm{OH}\right]+[\mathrm{HCHO}]+[\mathrm{HCOOH}]+\left[\mathrm{CO}_{2}\right]$

$\left[\mathrm{Cl}^{-}\right]^{*}=\left[\mathrm{CH}_{3} \mathrm{Cl}\right]+\left[\mathrm{Cl}^{-}\right]$

$\left[\mathrm{Br}^{-}\right]^{*}=\left[\mathrm{CH}_{3} \mathrm{Br}\right]+\left[\mathrm{Br}^{-}\right]$

Also,

$\left[\mathrm{H}^{+}\right]=10^{-\mathrm{pH}}$

$\left[\mathrm{e}^{-}\right]=10^{-\mathrm{pE}}$

The ratio of the equilibrium concentrations of the non-master species to the master species are then determined through mass action equations. For example, consider the reaction,

$$
\mathrm{CH}_{3} \mathrm{OH}(\mathrm{aq})+\mathrm{H}_{2} \mathrm{O} \rightarrow \mathrm{CO}_{2}(\mathrm{aq})+6 \mathrm{H}^{+}+6 \mathrm{e}^{-}
$$

Because the activity of water is taken to be unity, we may write the mass action equation as,

$$
\frac{\left[\mathrm{CO}_{2}(\mathrm{aq})\right]\left[\mathrm{H}^{+}\right]^{6}[\mathrm{e}]^{6}}{\left[\mathrm{CH}_{3} \mathrm{OH}\right]}=\mathrm{K}_{\mathrm{eq}}=10^{-4.619}
$$


Therefore, we can express the virtual $\left[\mathrm{CH}_{3} \mathrm{OH}\right]$ as a function of the master species concentrations by,

$$
\left[\mathrm{CH}_{3} \mathrm{OH}\right]^{*}=\frac{\left[\mathrm{CO}_{2}(\mathrm{aq})\right]^{*}\left[\mathrm{H}^{+}\right]^{6}\left[\mathrm{e}^{-}\right]^{6}}{\mathrm{~K}_{\mathrm{oq}}}
$$

We proceed to solve mass action cquations such as this for all of the non-master species present. This yields the relative, or virtual, concentrations of all of the species, but not the absolute concentrations, as mass must be conserved. To correct for this, we convert the virtual concentrations into absolute concentrations by using a normalization factor $v$. To calculate $v$ for a given component, we first take the sum of the total virtual concentration of the component. Thus,

$$
x=\sum_{-1}^{s} \mu_{i, 0}\left[s_{i}\right]
$$

where $\left[s_{i}\right]$ is the virtual concentration of species $s$ which contains component $i$, and $\mu_{1,}$ is the stoichiometry of component $t$ in species $s$. For example, for carbon in this study,

$x=\left[\mathrm{CH}_{3} \mathrm{Cl}\right]^{*}+\left[\mathrm{CH}_{3} \mathrm{Br}\right]^{*}+\left[\mathrm{CH}_{4}\right]^{*}+\left[\mathrm{CH}_{3} \mathrm{OH}\right]^{*}+[\mathrm{HCHO}]^{*}+[\mathrm{HCOOH}]^{*}+\left[\mathrm{CO}_{2}\right]^{*}$

But we know the initial amount of total carbon, or any other component, that is present, thus we can define the normalization factor $v$ such that

$v=\frac{\text { total initial carioon }}{x}$

We then multiply all of the species containing carbon by $v$ to obtain an estimate of their absolute concentrations. The same process is followed for chlorine and bromine. 
If only one element is present (other than $\mathrm{H}$ and $\mathrm{O}$ ), this scheme will yield the correct solution directly, without iteration. If other elements are present, lowever, the above procedum: (following the definition of the master species) must be performed several times until all of the species concentrations are satisfied to within a specified convergence tolerance.

Additionally, once the kinetics equations are solved, reactions that are assumed to take place instantaneously, such as the speciation of $\mathrm{CO}_{2}$ into $\mathrm{H}_{2} \mathrm{CO}_{3}, \mathrm{HCO}_{3}^{-}$, and $\mathrm{CO}_{3}^{2-}$, as well as $\mathrm{HCOOH}$ into $\mathrm{HCOO}^{-}$, can be calculated after the kinetics equations are solved, using this scheme.

We have already emphasized that KINETRAN assumes constant $\mathrm{pH}$ and Eh values at a given location throughout the simulation. It is possible to circumvent this restriction by simply inserting a charge balance and an electron balance equation into the above iteration scheme and treating $\left[\mathrm{H}^{+}\right]$and $\left[\mathrm{e}^{-}\right]$as dependent varlables. This is actually quite easy to do but is not appropriate to implement for two reasons. The first is strictly chemical: introducing this feature will cause the $\mathrm{pH}$ and Eh of the system to depend entirely on the degradation of the organic species present, and not at an un the mineral assemblage and the inorganic species present. In almost every conceivable scenario, this is probably a very poor assumption. Secondly, additional computational features such as Newton-Raphson iteration schemes would need to be incorporated in order to assure convergence of the solution, unnecessarily increasing the complexity and workload of the computer program.

\subsubsection{Calculation of Parameters}

Once the final equilibrium concentrations for all species of interest in the system have been calculated on the basis of the equilibrium constants and the initial concentrations, the 
kinetic coefficients of the reverse reactions can be determined using the scheme outlined in section 2.1

Because all the reactions that are allowed to take place under the control of first-order kinetics are completely user-defined, it is somewhat arbitrary as to the direction in which a reaction is written. Using the equilibrium constraint, the model determines the correct rate constant for the reverse reaction. In general, however, most reactions will have a dominant direction initially if they are far from equilibrium, and the kinetic rate constant for this forward reaction is usually the most well-known, so it is convenient to use this as the preferred direction.

Recall that in order to implicitly solve the simultaneous reaction problem, we defined a time-averaging parameter, $\lambda_{\text {in }} \mathrm{A}$ separate value for $\lambda$ must be determined for every reaction, forward and backward. This is easily accomplished by setting up an indexing system for $\lambda$ and using (10) to directly estimate it from the rate constant for the reaction and the time step $\Delta t$.

It is possible that in many situations, the kinetic coefficients for various reactions will not be cunstant but may depend, for example, on the number of microbes present. The present version of the KINETRAN model does not directly consider this possibility. However, these phenomena could be handled by inserting conditional statements into the program that allow the kinetics parameters to vary with time or with other controlling factors such as microbe populations.

\subsubsection{Assembling the Matrix of Equations}

Once the reverse-direction reaction rates and $\lambda$-parameters have been calculated, it is rela-

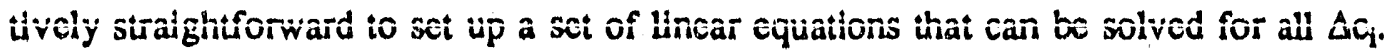


We know that among all of the aqueous species present in the system, a certain number of reactions will take place. For any given species over a given time step, there will be sink terms, where the species is destroyed in some reactions, and source terms, where it is created in others. If we look back at our example from section 2.1 , we note that the reaction $A \rightarrow B$ destroys $A$ and creates $B$, while the reverse reaction $B \rightarrow A$ likewise destroys $B$ and creates $A$. A separate equation analogous to $(9 a)$ can be written for $\Delta c_{i j}$ for every reaction $j$ that involves species $i$. We define $\Delta c_{i}$ to be a positive quantity when it is produced in a reaction, and negative when consumed. Thus, if we write all the reactions of interest proceeding in the initially dominant direction, then for a given species $i$, there will be $J_{r}$ reactions in which it is a reactant that is destroyed, and $J_{p}$ reactions in which it is a generated as a product. If we define $s_{i}$ as species $l$ and $s_{m j}$ as the complementary species that is produced or destroyed, depending on reaction direction, with species $i$ in reaction $j$, then we have, when $i$ is a reactant,

$$
\mu_{i j} s_{i} \rightarrow \mu_{m j} s_{m j}
$$

for $j=1,2,3, \ldots, J_{r}$ where $\mu_{i, j}$ and $\mu_{m j}$ refer to the respective stoichiometric coefficients. When $i$ is written as the product of a reaction, then

$$
\mu_{m j^{j}} s_{m j^{j}} \rightarrow \mu_{i j} s_{i}
$$

where $j^{\prime}=1,2,3, \ldots, J_{p}$. Taking all possible reactions into account, we find,

$$
\begin{gathered}
\Delta c_{i}=\Delta t \sum_{j=1}^{J_{1}} \frac{\mu_{i j}}{\mu_{m, j}} k_{j, r}\left[c_{m j}^{0}+\lambda_{j, r} \Delta c_{m j}\right]-k_{j, r}\left[c_{i}^{0}+\lambda_{j, r} \Delta c_{i}\right]+ \\
\Delta t \sum_{j^{\prime}=1}^{J_{p}} \frac{\mu_{i j^{\prime}}}{\mu_{m j^{\prime}}} k_{j^{\prime}, s}\left[c_{m j^{\prime}}^{0}+\lambda_{j^{\prime}, s} \Delta c_{m j^{\prime}}\right]-k_{j^{\prime}, r}\left[c_{i}^{0}+\lambda_{j^{\prime}, \Delta} \Delta c_{i}\right]
\end{gathered}
$$


Here, $c_{i}$ and $c_{m j}$ refer to the concentrations of $s_{i}$ and $s_{m}$, respectively. The subscripts $f$ and $r$ refer to the forward and reverse reactions, respectively.

The equation presented above is written for each species $i$ present in the system. It summarizes the changes in concentration of species $i$ due to production in reverse reactions, destruction in forward reactions, production in forward reactions, and destruction in reverse reactions, respectively. Because of the unknown terms present in each of these equations, the $\Delta c_{m}$ values, the system of equations is implicit and must be solved through the use of matrix algebra. In order to accomplish this, the set of equations in the form given above are written in matrix form so that

$$
\left[A_{i, m}\right]\left[\Delta c_{i}\right]=\left[B_{i}\right]
$$

We define the terms of this matrix in the following manner. Let the total number of reactions thit occur in the system, between all of the species present, be $N$, so that $n=1,2,3, \ldots, N$. Also, when referring to any of these reactions, we introduce a variable $d$ such that $d=1$ for the forward reaction and $d=2$ for the reverse reaction. It can be shown, through algebraic manipulation for our expression for $\Delta \mathrm{c}_{\mathrm{i}}$, that, for $i=m$,

$$
A_{i, m}=\Delta t\left[-\sum_{n=1}^{N} k_{n(i, \pi, 1), d} \lambda_{z(i, m), d}\right]-1
$$

where $k_{n(i m), d)}=k_{n, l}$, if $l$ is written as a reactant in reaction $n$

$=k_{n, 2}$, if $i$ is written as a product in reaction $n$

$=0$, if $i$ is not involved in reaction $n$. 
$\lambda_{n(L, m), d}$ is subscripted in a manner analogous to $k$.

For $i \neq m$,

$$
\begin{aligned}
A_{i, m} & =\frac{\mu_{i, n(i, m)}}{\mu_{m, n(i, m)}} \Delta t k_{n(i, m), 2} \lambda_{m(i, m), 2} \text { if } i \text { is a reactant in reaction } n \text { with } m \\
& =\frac{\mu_{i, n(1, m)}}{\mu_{m, n(i, m)}} \Delta t k_{n(i m), 1} \lambda_{m(i, m), 1}, \text { if } i \text { is a product in reaction } n \text { with } m \\
& =0, \text { if } i \text { does not react with } m .
\end{aligned}
$$

$\mu_{i, n(1, m)}$ and $\mu_{m, n(i, m)}$ refer to the respective stoichiometric coefficients of species $i$ and $m$ in reaction $\mathrm{n}$.

The "known" vector $B_{i}$ is a function of the initial conditions. Here, we define $B_{i}$ as,

$$
B_{i}=\Delta t\left[\sum_{n=1}^{N} k_{n(i, m), d}\right] c_{i}^{0}-\sum_{n=1}^{N} B_{n(1, m)}^{\prime} c_{m}^{0}
$$

where $k_{n(i, m), d}=k_{n, 1}$ if $i$ is a reactant in reaction $n$

$=k_{n, 2}$, if $i$ is a product in reaction $n$

$=0$, if $i$ is not involved in reaction $n$.

$B_{n(i, m)}^{\prime}=\frac{\mu_{i, n(i, m)}}{\mu_{m, n(i, m)}} \Delta t k_{n(i, m) 2}$, if $i$ is a reactant in reaction $n$ with $m$

$=\frac{\mu_{i, n(i, m)}}{\mu_{m, n(i, m)}} \Delta t k_{n(i, m), 1}$, if $i$ is a product in reaction $n$ with $m$ 
$=0$, if $i$ does not react with $m$.

$c_{i}^{0}$ and $c_{m}^{0}$ refer to the concentrations of species $i$ and $m$ at the beginning of time step $\Delta t$.

Eventually, after determining all of the terms according to the above procedure, we develop an $i \times i$ matrix of linear equations, the unknowns being $\Delta c_{i}$ and all of the other quantities, such as the kinetic coefficients, $\lambda$-parameters, and the initial values of $c_{i}^{0}$ and $c_{m}^{0}$ having been already caiculated. The system of linear equations can then be conveniently solved by using an appropriate matrix solver.

Other species that take part in the given set of chemical reactions, but which are not included in the above formulation, are accounted for by usirig mass balance constraints after the matrix is solved. For example, for chloride,

$$
\Delta c_{(c)}=-\sum_{m^{\prime}=1}^{M^{\prime}} \mu_{m^{\prime}, C} \Delta c_{m^{\prime}}
$$

where $M^{\prime}$ represents the number of species containing chlorine atoms, and $\mu_{m ;}, \mathrm{l}$ is the stoichiometric coefficient for the number the chlorine atoms that are freed or taken up by species $\mathrm{m}^{\prime}$ during reaction. The same approach is used for other species present, such as $\mathrm{Br}^{-}$. Since the $\mathrm{pH}$ and Eh are fixed at constant values, changes in $\left[\mathrm{H}^{+}\right]$and $[\mathrm{e}]$ as a result of the kinetically-controlled reactions need iot be considered.

\subsection{The Transport Equation}

The kinetic rate equations described above have to be incorporated in the chemical transpon equations. Ẅe now present these equaiions îor a muibipie species aqueous sysiem. Fớ 
convenience, we write these equations for a discrete elemental volume $l$ communicating with its neighbors $m$, where $m=1,2,3, \ldots, M$. The complete equation describing chemical transport includes expressions for advection, molecular diffusion, hydrodynamic dispersion, adsorption, and source terms. Therefore, for species $i$,

$$
\sum_{m=1}^{M} q_{1, m} A_{L, m} c_{L, m}^{i}+\sum_{m=1}^{M} n D_{d}^{i} \frac{\Delta c_{L m}^{i}}{x_{L, m}} A_{L, m}+\sum_{m=1}^{M} n D_{H}^{i} \frac{\Delta c_{L m}^{i}}{x_{L, m}} A_{L, m}+G_{l}^{i}=n V_{B, a} R^{i} \frac{\Delta c^{i}}{\Delta t}
$$

Here, the first term on the left describes solute transport due to advection, where $q_{1, m}$ is the volumetric fluid flux per unit area (darcy velocity) between $l$ and $m$ normal to the interface between them, $A_{1, m}$ is the interfacs area, and $\tau_{L, m}^{i}$ is the average concentration of species $i$ at the interface of the two volume elements.

The second and third terms on the left respectively describe molecular diffusion and hydrodynamic dispersion. Here, $D_{d}$ and $D_{H}$ are the diffusion and dispersion coefficients and $n$ is the porosity of the material. The expression $\Delta c_{1, m}^{i} / x_{1, m}$ is simply the concentration gradient of species $i$ between $l$ and $m$ approximated according to the finite difference philosophy. When material heterogeneities are involved, the harmonic mean is used to obtain the spatiallyaveraged value for the one parameter. For example, for the diffusion coefficient,

$$
D_{d}=\frac{x_{1}+x_{m}}{\frac{x_{1}}{D_{d}}+\frac{x_{m}}{D_{d, m}}}
$$

where $x_{1}$ and $x_{m}$ refer to the respective distances from the nodal points to the interface and $D_{d, 1}$ and $D_{d m}$ refer to the respective diffusion coefficients for the two elements.

The final term on the left side of (12), $G_{1}^{i}$, is the source/sink term, which is an expression 
for net generation or destruction of species $i$ in volume element $l$. This quantity is generally determined directly from evaluation of (11). However, if extemal sources or sinks for species $i$ exist, they must also be included in this term. This includes mass-balance corrections to account for the creation of new cell mass tiaterial for microbe populations that may participate in biodegradation processes. The source/sink term is a crucial part of the KINETRAN algorithm, as this is the variable that provides the coupling between the transport and transformation equations.

Focusing on the right-hand-side of (12), the quantity $V_{B \perp}$ is the bulk volume of element $l$. The total change in concentration of species $i$ during $\Delta t$ is given by $\Delta \mathrm{c}^{\mathrm{i}}$. This is the temporal variation of concentration of the species in volume element $l$ and should not be confused with $\Delta c_{L, m}^{i}$ on the left-hand-side, which represents the spatial variation.

The variable $\mathrm{R}$ refers to the retardation coefficient, which is defined as

$$
\mathbf{R}^{i}=1+\frac{P_{b} K_{d}^{i}}{n}
$$

Here, $\rho_{b}$ is the dry bulk density of the matrix material and $K_{d}^{i}$ is the distribution coefficient for species $i$. This expression describes the effect of adsorption on species $i$. Thus, adsorption influences the behavior of species $i$ only by restricting its movement; no change in its chemical behavior is inferred. The altemative to this approach would be to include adsorption as part of the source/sink term. This would have implications for the chemistry of species $i$, as it would no longer be allowed to react in the aqueous phase. It is probable that a technique for handling adsorption that is a hybrid of these two approaches would be the most realistic, but until more data are available on piecisely how sorbed species behave chemically, implementing such an approach in the model would be premature. 
The numerical modeling of the chemical transport portion of the KINETRAN algorithm reduces to solving (12) separately for every species in the system, for each volume element, over every time step. The equation is solved explicitly; that is, the advective, diffusive and dispersive fluxes are calculated using the initial values of concentrations for each time step in place of the time-averaged values. At the end of the time step, $c_{i}$ is updated with $\Delta c_{i}$. In order to avoid unphysical oscillations, the explicit method must use time steps that are smaller than a critical time step. We state here, omitting the proof (Edwards, 1972 and Rasmuson et al., 1982) that

$$
\Delta \mathrm{t}_{, \text {critical }}=\frac{\sum \text { Capacitance }}{\sum \text { Conductance }+\sum_{\text {upstream }} \text { Advectance }}=\frac{\mathrm{nV}_{\mathrm{B}, \mathrm{R}} \mathrm{R}}{\sum \mathrm{U}_{\mathrm{l,m}}+\sum_{\text {upetream }} \mathrm{F}_{1, \mathrm{~m}}}
$$

where $U_{L, m}=n\left[D_{d}+D_{H}\right] A_{L, m} / D_{L, m}$ and $F_{L, m}$ is the flux into $l$ from $m$, where $m$ is upstream from l. Advectance and conductance refer to the ability of the bounding surface of a volume element to advect and conduct solute into the element, respectively. The capacitance is simply the volume of fluid within the element times the retardation factor $R$. It is also of passing interest to mention here that the ratio of advectance to conductance,

$$
\frac{\sum_{\text {upstream }} F_{L m}}{\sum U_{1, m}}
$$

is the generalized Peclet number for the volume element (Rasmuson et al., 1982).

Note that in the present work we first solve the transport equation and then the source/sink terms according to (11), volume element by volume element. This procedure is analogous to the two-step procedure employed by Narasimhan et al. (1986) and Liu and 
Narasimhan (1989b) in solving redox-driven transport problems. In principle, we have a choice of solving the transport equation either by small time steps or without any restrictions on the time step if we use implicit methods. However, in order to minimize potential errors in temporal integration, we decided to use conservatively small time steps in accordance with the use of the explicit (forward-differencing) method. It is likely that we may be able to use larger values for $\Delta t$ in conjunction with an implicit solution of the transport problem without much loss of accuracy. To what extent we can relax the size of the time step is as yet to be clearly understood. 


\section{CHAPTER 3: APPLICATION TO A HYPOTHETICAL PROBLEM}

In order to assess the capabilities of KINETRAN, we apply the model to a hypothetical problem involving the simultaneous infiltration and chemical transformation of two halogenated hydrocartons, and their decay products, through a one-dimensional soil column. We first examine the batch chemistry of such a system, and then proceed to solve the combined transporttransformation problem.

\subsection{Batch Simulation}

We first apply only the chemical transformation module of KINETRAN to the hypothetical problem presented in section 1.1. Transport of the various species involved is not considered. Using the same initial species concentrations, we fix the Eh at +0.1 Volts, the $\mathrm{pH}$ at 7.0 , and the temperature at $25^{\circ} \mathrm{C}$. The purpose of this exercise is to show how the concentrations of the various species involved evolve through time as compared to the instantaneous equilibrium case.

Possible pathways for the transformation of the methyl halide pollutants, as well as those of the secondary transient species, are shown in Figure 3.1. The set of reactions representing these transformations are shown in Table 3.1, along with the kinetic coefficients for the forward reactions. Almost all of these rate constants are, of course, estimated; but we believe that they will be more or less reasonable under some field conditions. For example, the rate constants for the two hydrolysis reactions are actual experimental values which seem to be constant over the neutral $\mathrm{pH}$ range at constant temperature (Mabey and Mill). However, hydrolysis is not the primary means of degradation for methyl chloride, although it usually is for 
methyl bromide. Neither is reduction to methane, which, although it is thermodynamically favored even at an Eh of +0.1 Volts, usually requires assistance from anaerobic microbes, which would not be found abundantly under these conditions. Thus, the microbially-mediated oxidation of methyl chloride to formaldehyde might be considered the important reaction (Vogel et al.). If we assume that methyl chloride and methyl bromide are converted into formaldehyde by microbes at roughly the same rate, then the rate constant for this reaction for methyl chloride might lie between the hydrolysis rate constants for the two methyl halides. Using this type of logic, the hypothetical rate constants presented in Table 3.1 were generated.

As mentioned, methane is actually thermodynamically favored over $\mathrm{CH}_{3} \mathrm{Cl}$ and $\mathrm{CH}_{3} \mathrm{Br}$ even at this Eh. Methane should also form as a result of equilibration with methyl alcohol, as $\mathrm{CH}_{4}$ and $\mathrm{CH}_{3} \mathrm{OH}$ will have nearly the same equilibrium concentrations under these conditions, although they will be extremely small. Nevertheless, from experience one would not often expect to find much methane produced under these relatively oxidizing conditions. Because of this, we suppress methane accumulation by specifying very slow rates of production and very rapid oxidation of methane to $\mathrm{CO}_{2}$. Similarly, formic acid is not often mentioned as a common species in such situations, thus we accelerate its destruction by allowing it to oxidize to carbon dioxide rapidly as well. A "real-world" explanation for this might be the presence of microorganisms in the soil which are capable of metabolizing these substances.

Methyl bromide and methyl chloride, depicted in Figure 3.2, show simple exponential decay. This is because neither is being produced directly in any forward reactions, and the reverse reaction rates for the cegradation reactions of the two are exceedingly small. In Figure 3.3, the secondary organic species show more complex behavior, however. The concentrations of methane and formic acid, and particularly methyl alcohol and formaldehyde, show a rapid 
increase initially as they are produced through degradation reactions. However, as the primary pollutant concentrations begin to fall off, the secondary organic species begin to be destroyed (i.e. oxidation to $\mathrm{CO}_{2}$ ) faster than they are produced, thus explaining their transient behavior as shown in the plot. The concentration of total aqueous $\mathrm{CO}_{2}$ rises steadily over time, as one would expect.

The free halogen ions, $\mathrm{Cl}^{-}$and $\mathrm{Br}^{-}$, show concentrations that do not vary significantly after 50 days or so (Figure 3.2), We believe this observation, along with the constant pH-Eh assumption, helps justify the reasoning that these reactions are approximately first-order in both directions, as postulated in section 2.1 .

\subsection{Combined Transport and Transformation Effects}

\subsubsection{Problem Definition}

We now apply the whole KINETRAN model to a hypothetical problem involving the simultaneous transport and chemical transformation of two halogenated hydrocarbons through a one-dimensional soil column. The species considered for this problem are the same set that we have used as an example throughout this thesis, as listed in section 2.3.1.

The physical configuration of the problem is depicted in Figure 3.4. A one-dimensional soll column 2 meters in depth with a cross-sectional area of $1 \mathrm{~m}^{2}$ is divided into 10 equal volume elements. A constant, uniform fluid flux, representing infiltrating rainwater, flows toward the bottom at a rate of 0.508 meters/year, or, volumetrically, $1.611 \times 10^{-8}$ meters $^{3} /$ second. The column consists of a homogeneous material with a porosity of 0.25 , a neutral $\mathrm{pH}$ of 7.0 , and a mildly oxidizing Eh of +0.1 Volts. The effective diffusion 
coefficients for all species are assumed to be equal to $1 \times 10^{-10}$ meters $2 /$ second and the longltudinal dispersivities 0.1 meter. Adsorption is neglected for this simulation so $K_{d}=0$ for all species. The column is assumed to be fully saturated with fluid at all times. The column is under isothermal conditions at $25^{\circ} \mathrm{C}$. A constant time step of 10 days is used for the simulation, with the total simulation time set at 100 days.

Initially, $\left[\mathrm{CH}_{3} \mathrm{Cl}\right]$ and $\left[\mathrm{CH}_{3} \mathrm{Br}\right]$ occur at equal concentrations of $10^{-3}$ moles/iter in the uppermost two volume elements of the column, representing a spill. Throughout the column, and in the inflitrating rainwater entering the top of the column, background total $\left[\mathrm{CO}_{2}(\mathrm{aq})\right]$ is $10^{-3}$ moles/iter, $[\mathrm{Cl}]$ is $10^{-3}$ moles/iter, and $[\mathrm{Br}]$ is $10^{-10}$ moles $/ 1$ iter. All other species considered, throughout the entire column, occur at initally zero concentrations.

\subsubsection{Simulation Results}

The concentration profiles of methyl chloride after 20 days and 100 days are shown in Figure 3.5 and 3.6, respectively. Also shown for comparison are results pertaining to transport without transformation. Figure 3.5 shows that the two profiles are fairly similar after 20 days, as not enough time has elapsed for the material to degrade significantly. After 100 days, however, much of the methyl chloride has been transformed into other species. The profile for the reactive case shows a front that is much less sharp than for the non-reactive case. This is reasonable, since the material will degrade more quickly where it is more abundant (near the 0.8 meter depth mark). Incidentally, integration under the reactive transport profile curves showed that the total amount of $\mathrm{CH}_{3} \mathrm{Cl}$ present after a given time is consistent with that predicted in the batch simulation. This is important as it indicates that mass is conserved through the kinetics-transport coupling in the program, a necessary condition for iniemả mâaủiemaautical 
consistency,

The profles for methyl bromide are shown in Figures 3.7 and 3.8. It behaves similarly, although it degrades much faster, being significantly transformed after just. 20 days. For the 100-day profile shown in Figure 3.8, a log scale had to be used for the concentration because the reactive and non-reactive cases could not be plotted $t$ gether effectively with a linear scale.

Reactive transport profiles for the secondary, or transient organic species are shown in Figures 3.9 and 3.10. Clearly, methyl alcohol and formaldehyde are the most important primary degradation products for these two methyl halides, which is consistent with what was found in the literature (Mabey and Mill (1978); Vogel et al. (1987)). Figure 3.10 shows that after 100 days, the level of $\mathrm{CO}_{2}$ near the center of the column has risen measurably above background levels, which one would expect as the hydrocarbon species are progressively oxidized.

\subsubsection{Reactive Hydrocarbon Transport in the Presence of a Reducing Layer}

As an additional part of the study, we modified the problem definition so that a layer of reducing material was introduced in the soil matrix below 0.8 meters depth. The same initial conditions as described earlier were used, except that the Eh in nodes 5 through 10 was set to -0.3 Volts. The reaction kinetics within this zone were also modified (sce Table 3.2 ). Instead of $\mathrm{CO}_{2}$ (aq) being piesent in background concentrations, dissolved methane was present instead, at the same concentration. The results of this simulation are depicted in Figures 3.11 and 3.12 .

As seen from Figure 3.11, after 20 days methyl alcohol and formaldehyde have formed in the oxidizing zone, but have not yet reached the reducing layer. A generally sharp redox front is maintained at the 0.8 meter depth mark, although a small amount of $\mathrm{CO}_{2}$ can be detected in the reducing zone. Because of advection and dispersion, it has been transported into this zone 
slightly faster than it can be reduced. Methane, on the other hand, must travel upstream in order to inflltrate the oxidizing zone, thus it is assisted only by diffusive processes, and is opposed by advection. As a result, methane is transported upstream at a rate slower than its oxidation rate in the oxidizing zone, so we do not see the corresponding "tongue" of methane In this zone the way we see it for $\mathrm{CO}_{2}$ in the reducing zone.

It is seen from Figure 3.12 that the methane and carton dioxide profles after 100 days are similar to those at 20 days, except that they show a greater-than-background concentration where the peak amounts of infiltrating pollutants occur, as shown in Figures 3.6 and 3.8. The methyl alcohol profle closely resembles the profile for the homogeneous case shown in Figure 3.10, thus showing that the reducing zone seems to have no effect on it. This is because alcohol is produced in this system primarlly by the hydrolysis of the two methyl halides, and these reactions do not involve electron transfer, hence are independent of the prevalling redox state. Formaldehyde, on the other hand, seerns to show a slight asymmetry in its concentration profile. It is likely that this results from formaldehyde being generated mainly in the oxidizing, zone, so the HCHO present in the reducing zone has not been produced there. Rather, it was transported there from the oxidizing zone above and has not yet had enough time to degrade into other species.

It must be emphasized that the results described above are derived strictly from the simulation of a hypothetical scenario which is not based on any particular contamination problem that may exist in the field. It would certainly be encouraging to find quantitative data in the literature that would be useful for validating the above simulations as good approximations of the real world. However, such data are quite scarce, and often contain too much uncertainty about the physical and chemical characteristics of the systems they describe. Thus, for now, we 
must be content with attempting to verify the model by showing that it produces credible, internally consistent results. 
Table 3.1

Degradation Reactions for Methyl Chloride and Methyl Bromide at $\mathrm{pH}=7.0$ and $\mathrm{Eh}=+0.1$ Volts

\begin{tabular}{|c|c|c|c|}
\hline Reaction & Type & $\begin{array}{l}\text { Half-llfe* } \\
\text { (days) }\end{array}$ & $\begin{array}{l}k_{\text {forward }} \\
\left(\sec ^{-1}\right)\end{array}$ \\
\hline $\mathrm{CH}_{3} \mathrm{Cl} \rightarrow \mathrm{CH}_{4}$ & reduction & 10000 & $8.02 \times 10^{-10}$ \\
\hline $\mathrm{CH}_{3} \mathrm{Cl} \rightarrow \mathrm{CH}_{3} \mathrm{OH}$ & hydmolysis & 338 & $2.37 \times 10^{-8}$ \\
\hline $\mathrm{CH}_{3} \mathrm{Cl} \rightarrow \mathrm{HCHO}$ & oxidation & 100 & $8.02 \times 10^{-8}$ \\
\hline $\mathrm{CH}_{3} \mathrm{Br} \rightarrow \mathrm{CH}_{4}$ & reduction & 10000 & $8.02 \times 10^{-10}$ \\
\hline $\mathrm{CH}_{3} \mathrm{Br} \rightarrow \mathrm{CH}_{3} \mathrm{OH}$ & hydrolysis & 20 & $4.09 \times 10^{-7}$ \\
\hline $\mathrm{CH}_{3} \mathrm{Br} \rightarrow \mathrm{HCHO}$ & oxidation & 100 & $8.02 \times 10^{-8}$ \\
\hline $\mathrm{CH}_{3} \mathrm{OHI} \rightarrow \mathrm{CH}_{4}$ & reduction & 10000 & $8.02 \times 10^{-10}$ \\
\hline $\mathrm{CH}_{3} \mathrm{OH} \rightarrow \mathrm{HCHO}$ & oxidation & 100 & $8.02 \times 10^{-10}$ \\
\hline $\mathrm{HCHO} \rightarrow \mathrm{HCOOH}$ & oxidation & 200 & $4.01 \times 10^{-38}$ \\
\hline $\mathrm{CH}_{4} \rightarrow \mathrm{CO}_{2}$ & oxidation & 10 & $8.02 \times 10^{-7}$ \\
\hline $\mathrm{CH}_{3} \mathrm{OH} \rightarrow \mathrm{CO}_{2}$ & oxidation & 100 & $8.02 \times 10^{-8}$ \\
\hline $\mathrm{HCHO} \rightarrow \mathrm{CO}_{2}$ & oxidation & 100 & $8.02 \times 10^{-8}$ \\
\hline $\mathrm{HCOOH} \rightarrow \mathrm{CO}_{2}$ & oxidation & 10 & $8.02 \times 10^{-7}$ \\
\hline
\end{tabular}

- See Appendix A for the complete reactions, as well as their equilibrium constants.

- Nole that the kinetic dela presented here, with the exception of the two hydrolysis reactions (Mabey and Mill, 1978), are completely artificial and are used for demonstration purposes only. Such dati are not to be used in evaluating the fate of any of the apecies mentioned for any real contamination site. 
Table 3.2

Degradation Reactions for Methyl Chloride and Methyl Bromide at $\mathrm{pH}=7.0$ and $\mathrm{Eh}=-\mathbf{0 . 3}$ Volts

\begin{tabular}{|l|c|c|c|}
\hline \multicolumn{1}{|c|}{ Reaction* } & Type & $\begin{array}{c}\text { Half-life } \\
\text { (days) }\end{array}$ & \multicolumn{1}{c|}{$\begin{array}{c}\mathbf{k}_{\text {forward }} \\
\left(\mathrm{sec}^{-1}\right)\end{array}$} \\
\hline $\mathrm{CH}_{3} \mathrm{Cl} \rightarrow \mathrm{CH}_{4}$ & reduction & 100 & $8.02 \times 10^{-8}$ \\
$\mathrm{CH}_{3} \mathrm{Cl} \rightarrow \mathrm{CH}_{3} \mathrm{OH}$ & hydrolysis & 338 & $2.37 \times 10^{-8}$ \\
$\mathrm{CH}_{3} \mathrm{Cl} \rightarrow \mathrm{HCHO}$ & oxidation & 10000 & $8.02 \times 10^{-10}$ \\
$\mathrm{CH}_{3} \mathrm{Br} \rightarrow \mathrm{CH}_{4}$ & reduction & 100 & $8.02 \times 10^{-8}$ \\
$\mathrm{CH}_{3} \mathrm{Br} \rightarrow \mathrm{CH}_{3} \mathrm{OH}$ & hydrolysis & 20 & $4.09 \times 10^{-7}$ \\
$\mathrm{CH}_{3} \mathrm{Br} \rightarrow \mathrm{HCHO}$ & oxidation & 10000 & $8.02 \times 10^{-10}$ \\
$\mathrm{CH}_{3} \mathrm{OH} \rightarrow \mathrm{CH}_{4}$ & reduction & 100 & $8.02 \times 10^{-8}$ \\
$\mathrm{HCHO} \rightarrow \mathrm{CH}_{3} \mathrm{OH}$ & reduction & 100 & $8.02 \times 10^{-8}$ \\
$\mathrm{HCHO} \rightarrow \mathrm{HCOOH}$ & oxidation & 10000 & $4.01 \times 10^{-10}$ \\
$\mathrm{CO}_{2} \rightarrow \mathrm{CH}_{4}$ & reduction & 10 & $8.02 \times 10^{-7}$ \\
$\mathrm{CH}_{3} \mathrm{OH} \rightarrow \mathrm{CO}_{2}$ & oxidation & 10000 & $8.02 \times 10^{-10}$ \\
$\mathrm{HCHO} \rightarrow \mathrm{CO}_{2}$ & oxidation & 10000 & $8.02 \times 10^{-10}$ \\
$\mathrm{HCOOH} \rightarrow \mathrm{CO}_{2}$ & oxidation & 10000 & $8.02 \times 10^{-10}$ \\
\hline
\end{tabular}

- See Appendix A for the complete reactions, as well as their equilibrium conitants.

- Nole that the kinetic dalu presented here, with the exception of the two hydrolysis reactions (Mabey and Mill, 1978), are completely artificial and are used for demonstration purposes only. Such data are not to be used in evaluating the fate of any of the ppecie: mentioned for any real contemination sten 


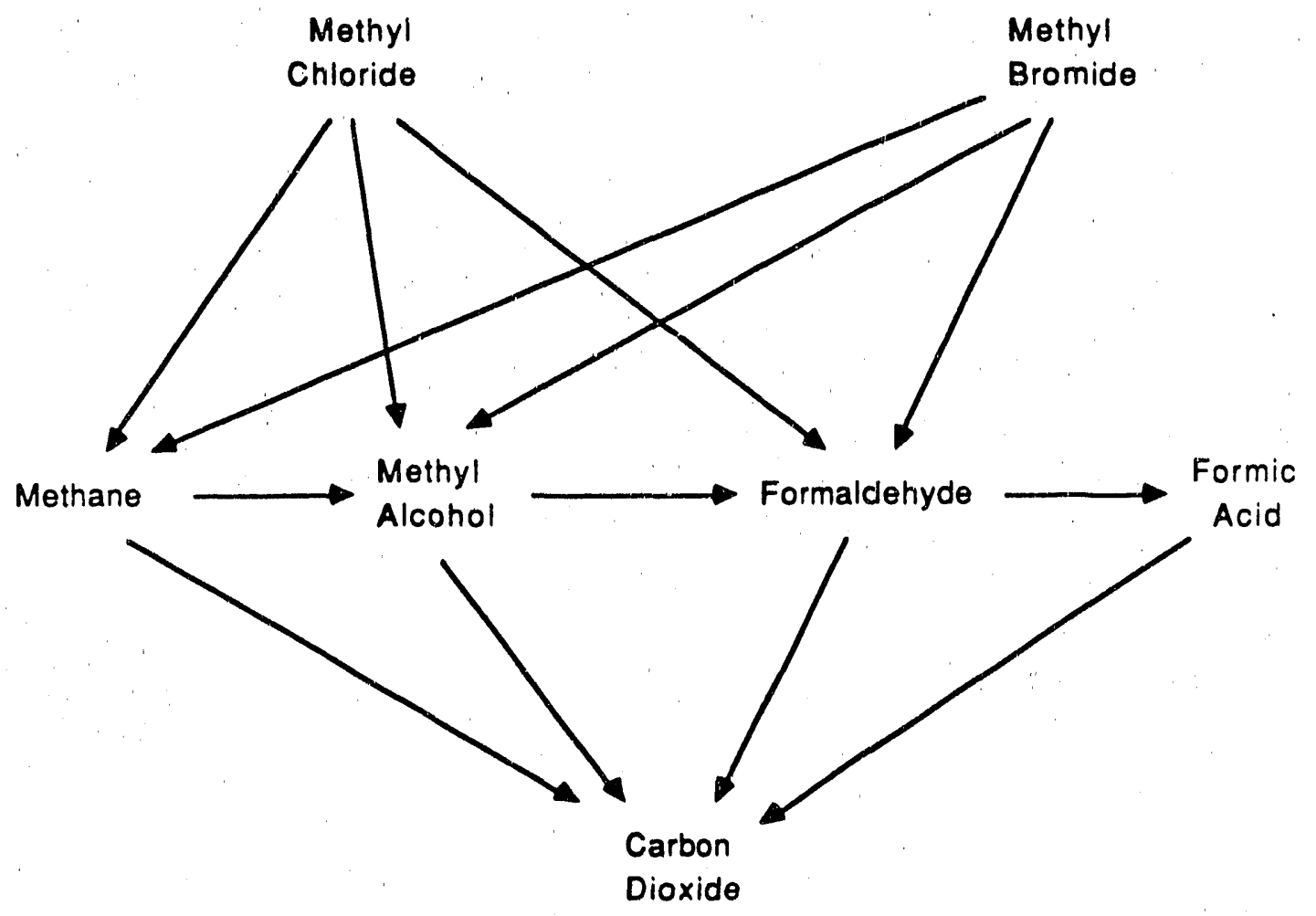

Figure 3.1. Possible pathways for the degradation of methyl chloride and methyl bromide under oxidizing conditions. 


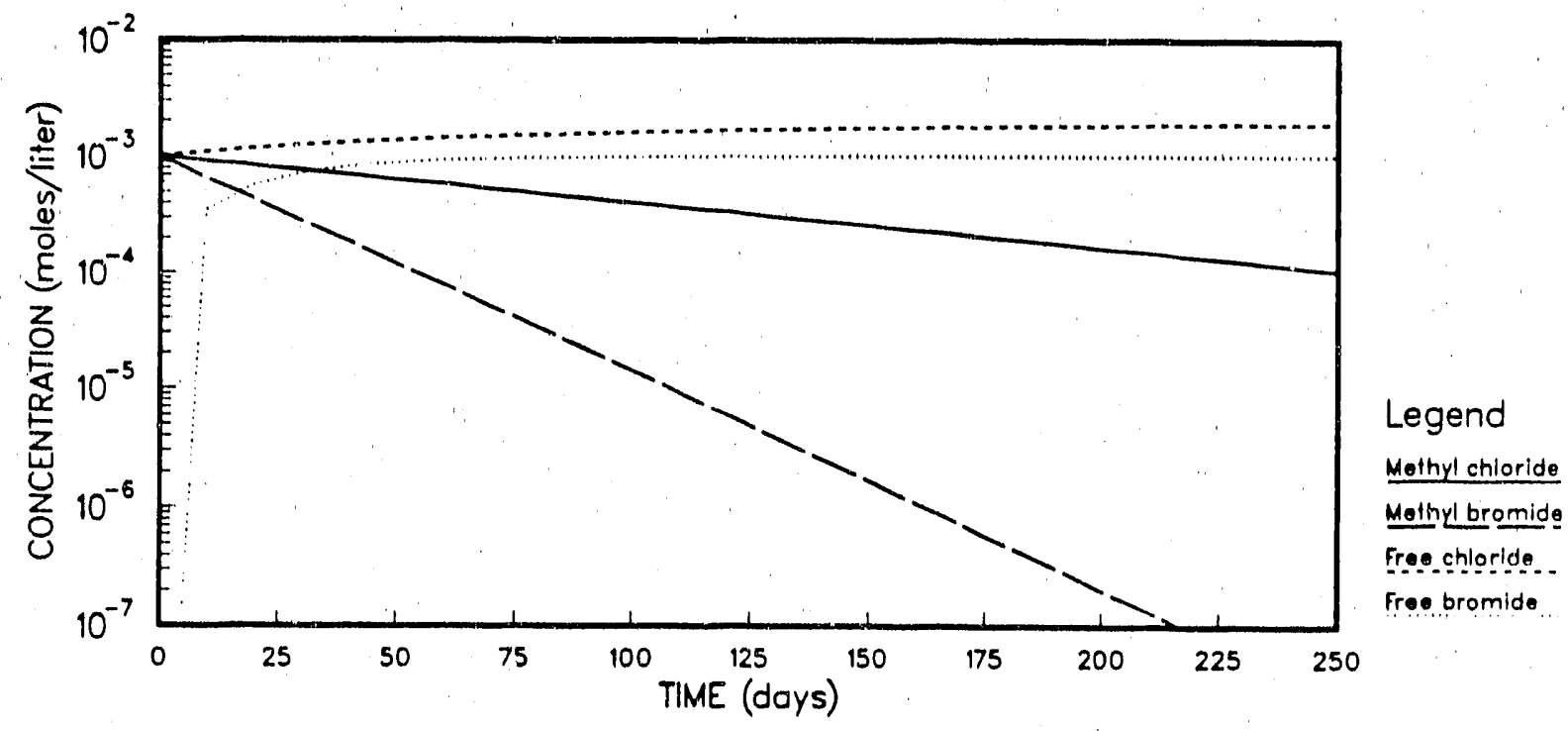

Figure 3.2. Batch simulation concentrations of methyl chloride and methyl bromide, along with the free halogen ions, as a function of time.

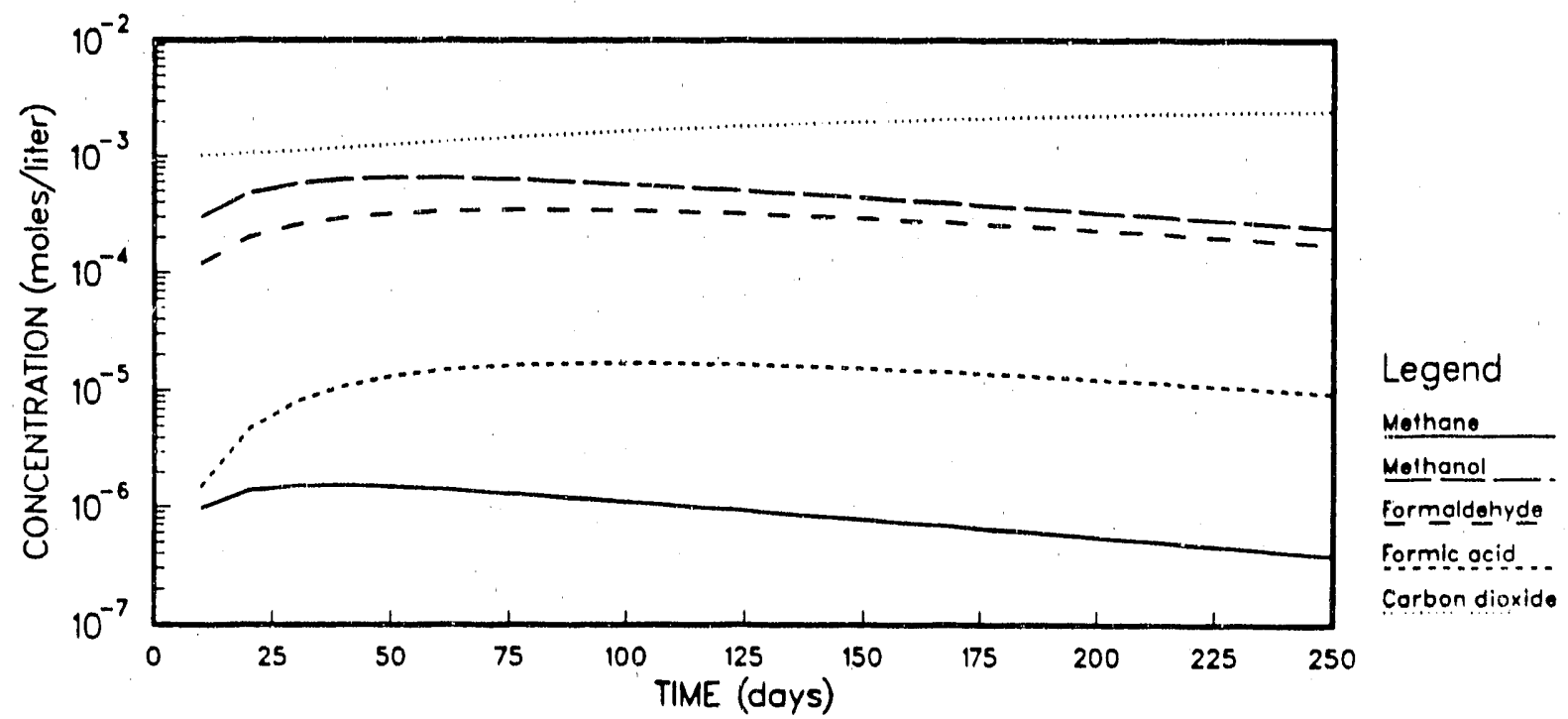

Figure 3.3. Batch simulation concentrations over time of the secondary species produced by the degradation of the two methyl halides. 


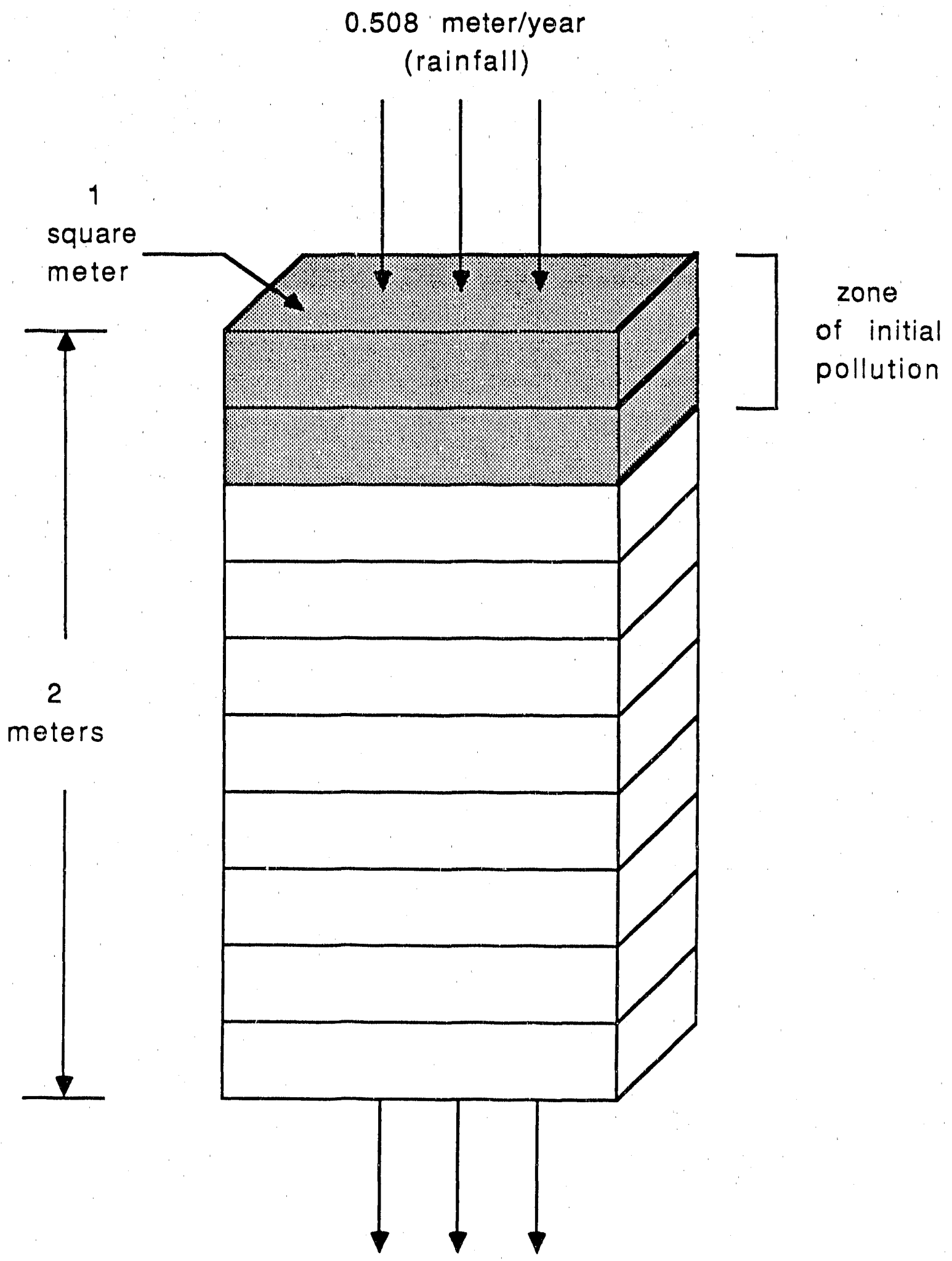

Figure 3.4. Physical configuration for the hypothetical soil or rock column used for the example simulation. 


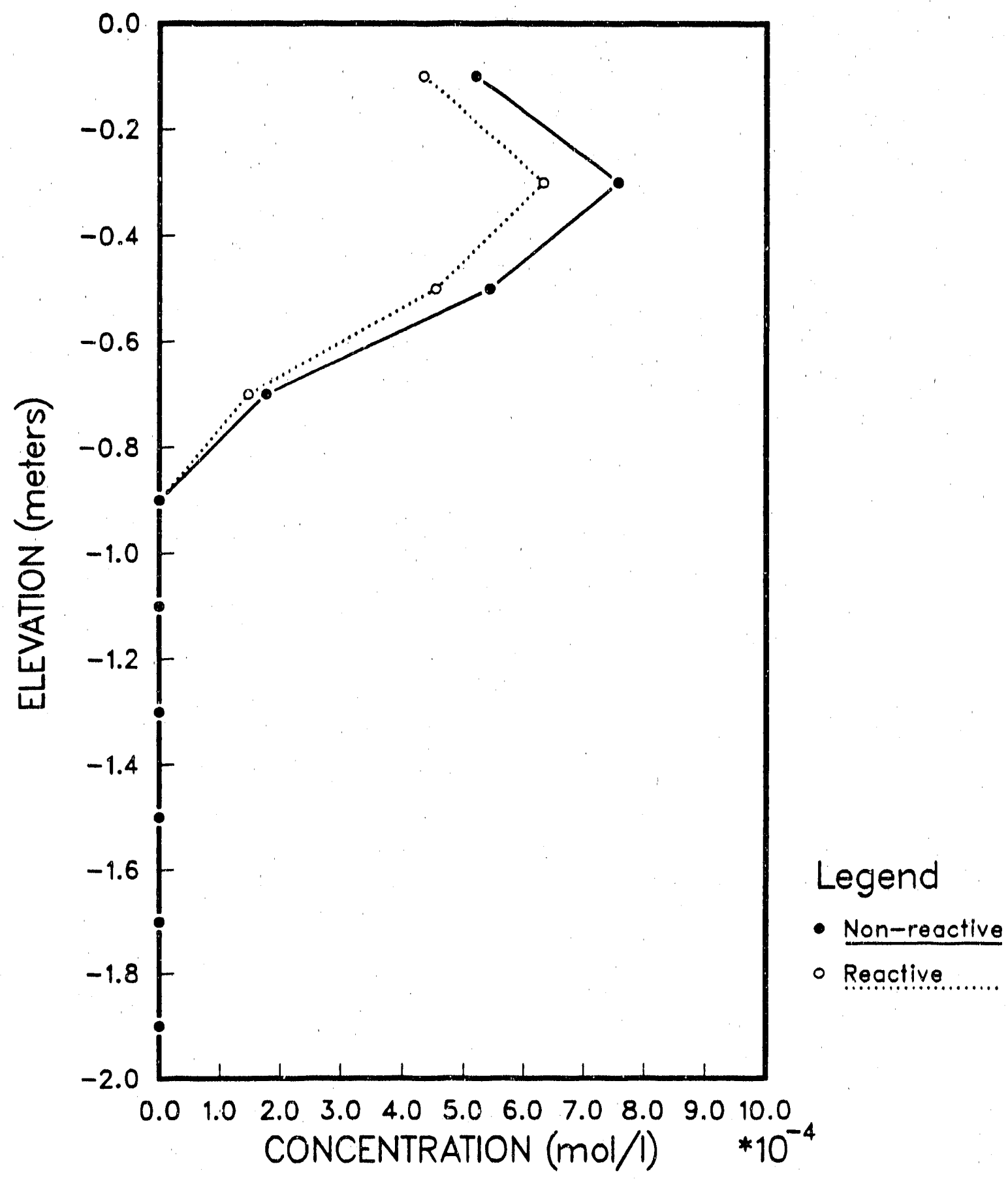

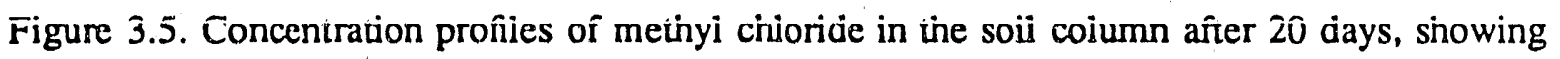
the reactive and non-reactive cases. 


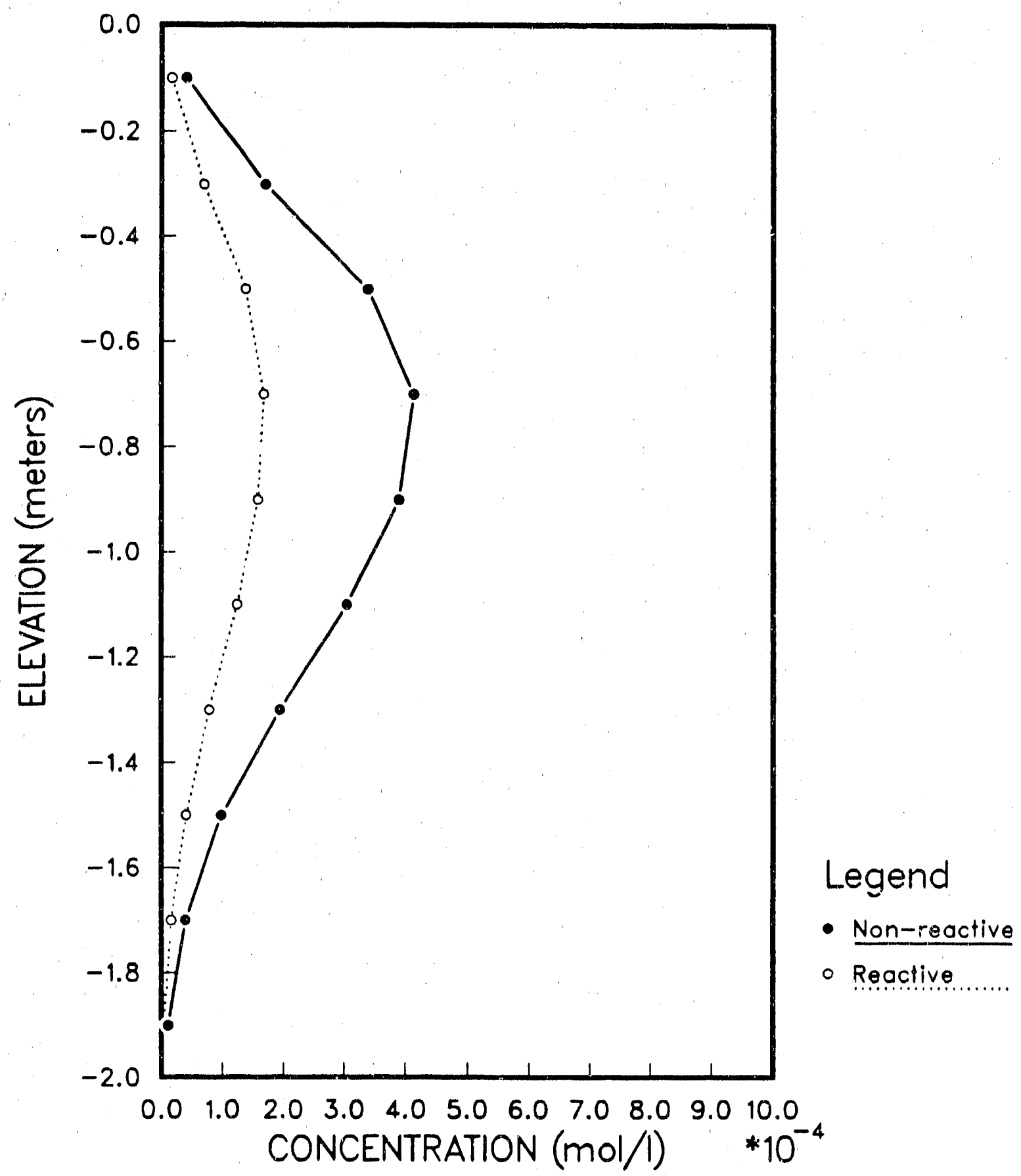

Figure 3.6. Concentration profiles of methyl chloride in the soil column after 100 days, showing reactive and non-reactive cases. 


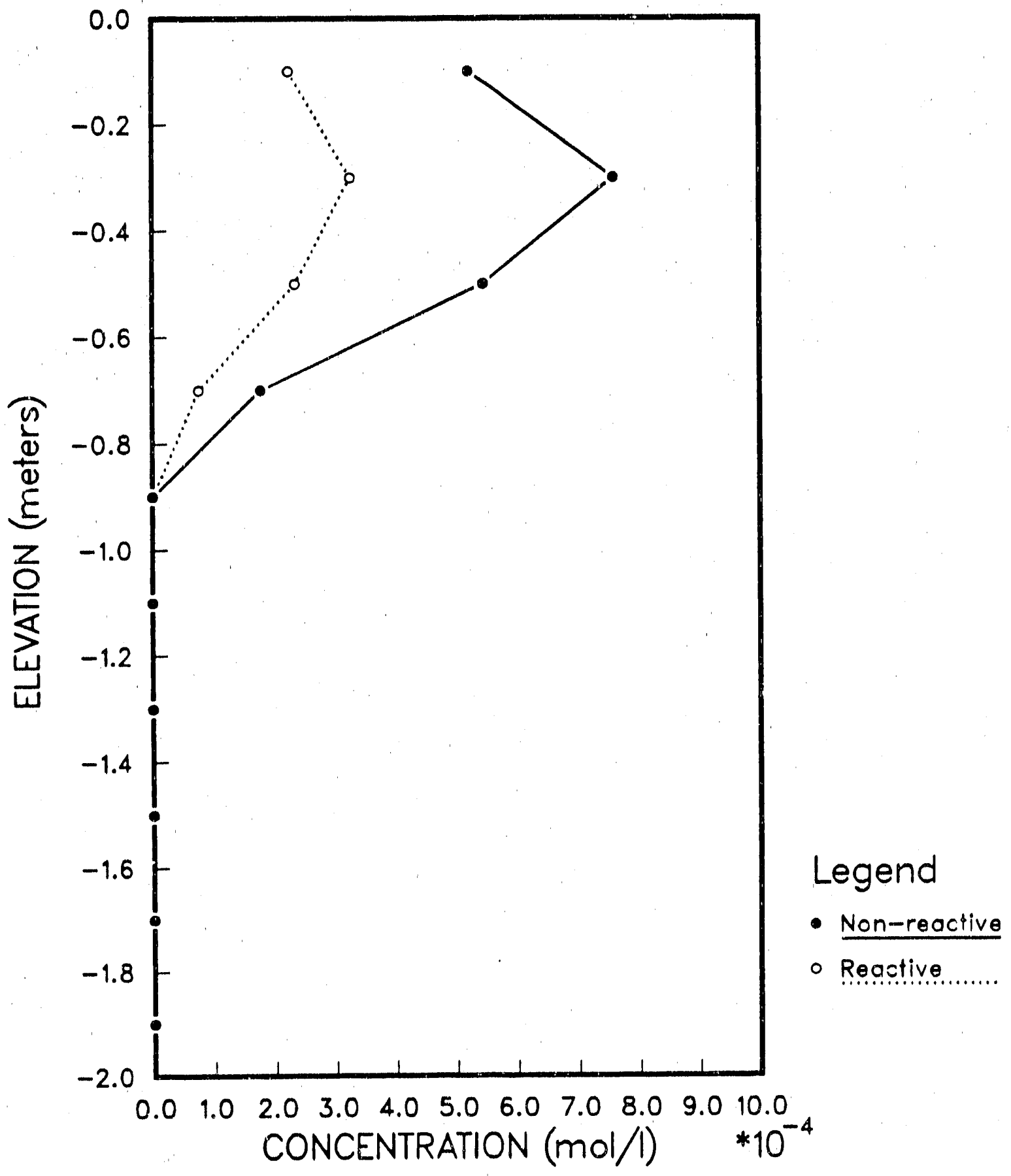

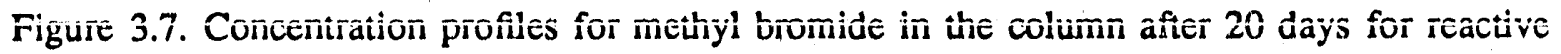
and non-reactive cases. 


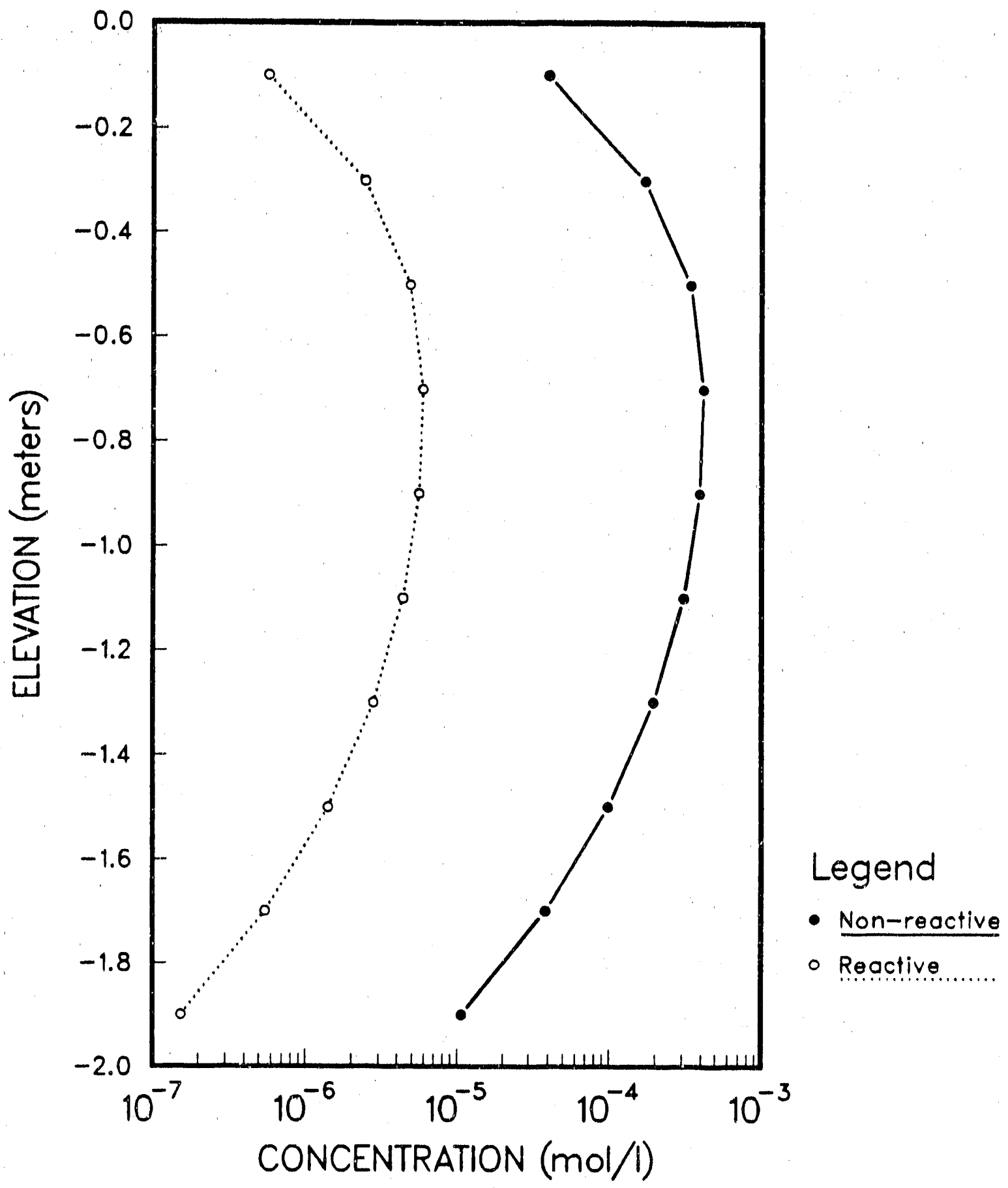

Figure 3.8. Concentration profiles for methyl bromide in the column after 100 days for reactive and non-reactive cases. 


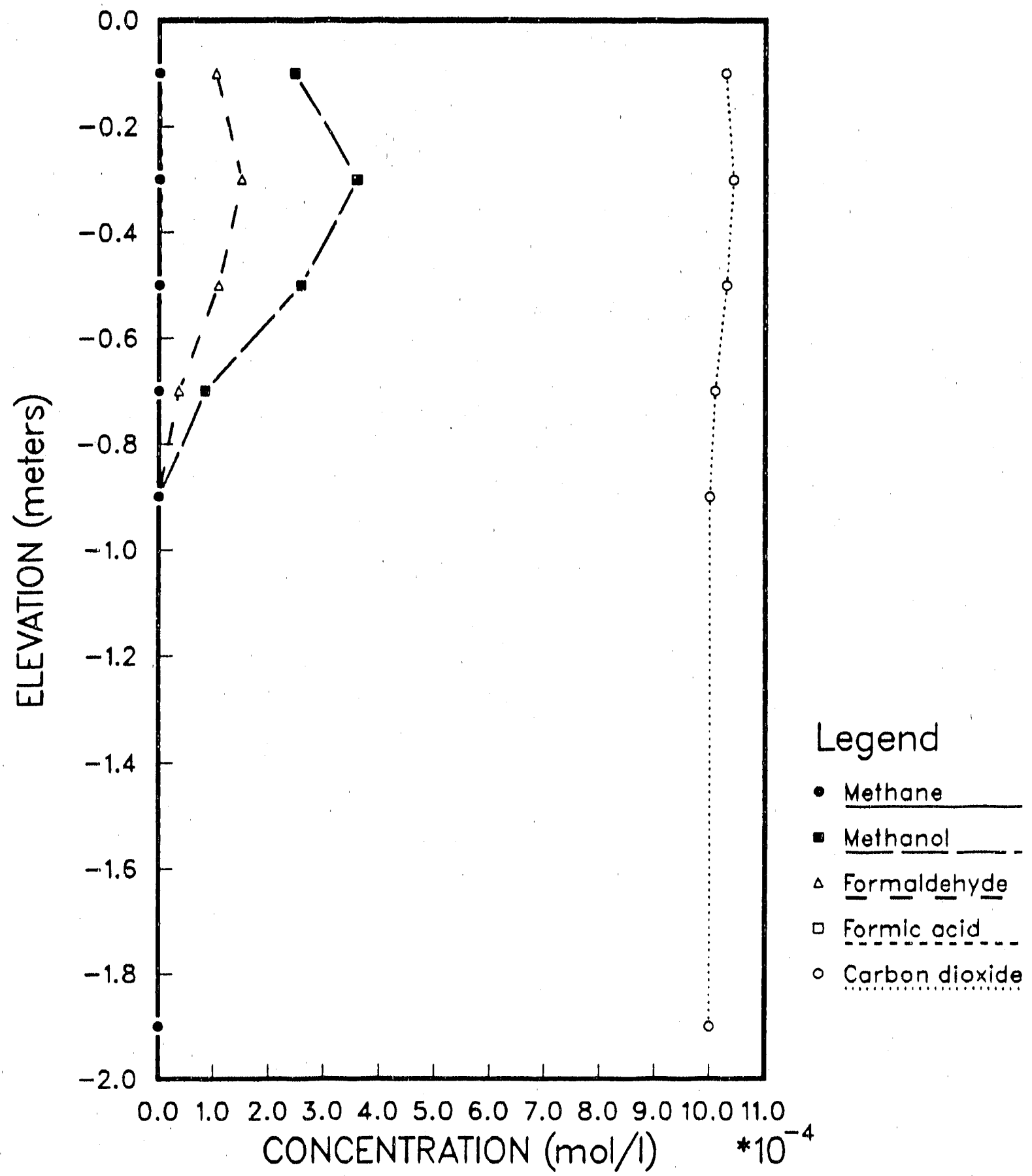

Figure 3.9. Reactive transport profiles for the secondary species in the soil column after 20 days. 


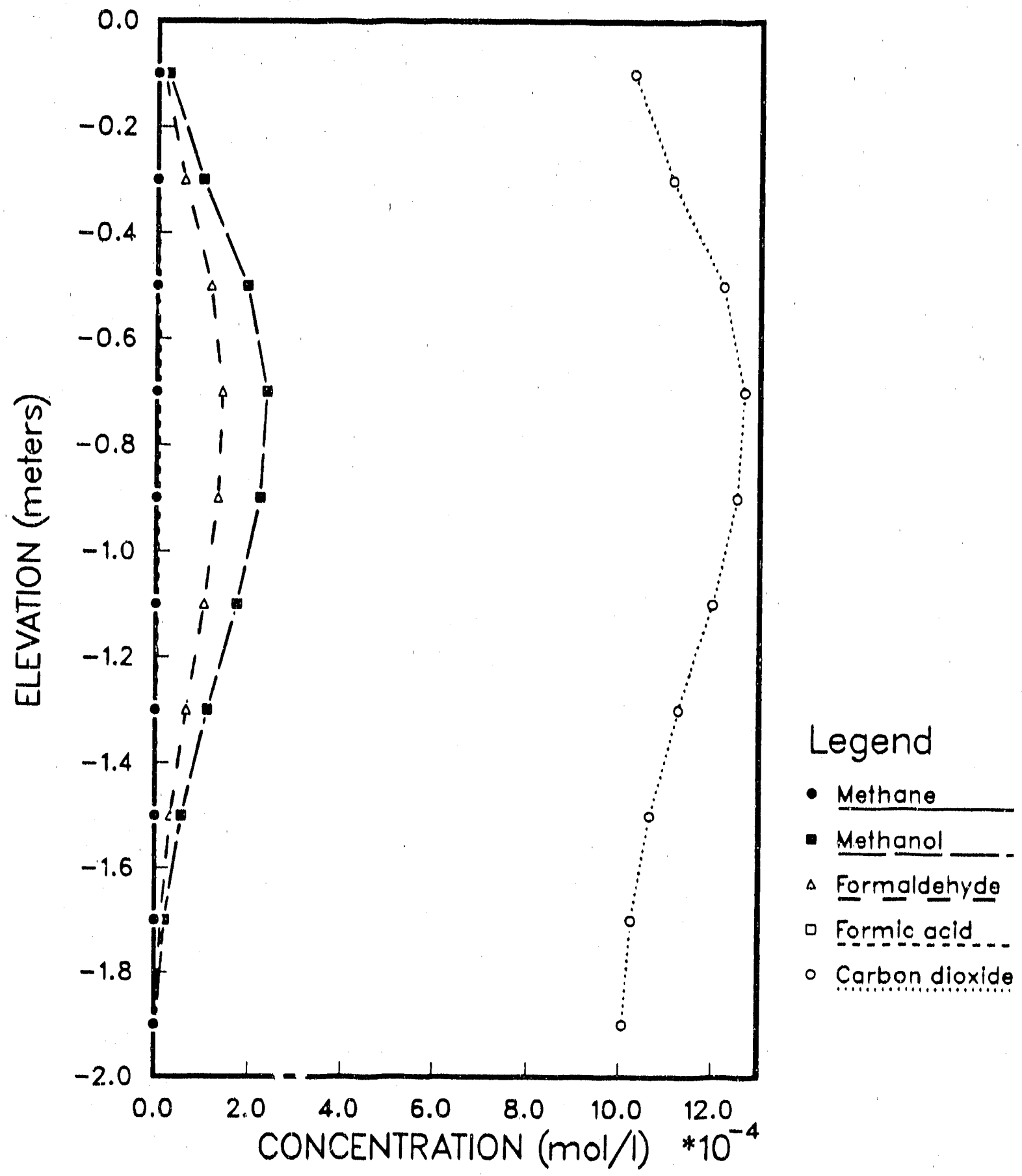

Figure 3.10. Reactive transport profiles for the secondary species after 100 days have elapsed. 


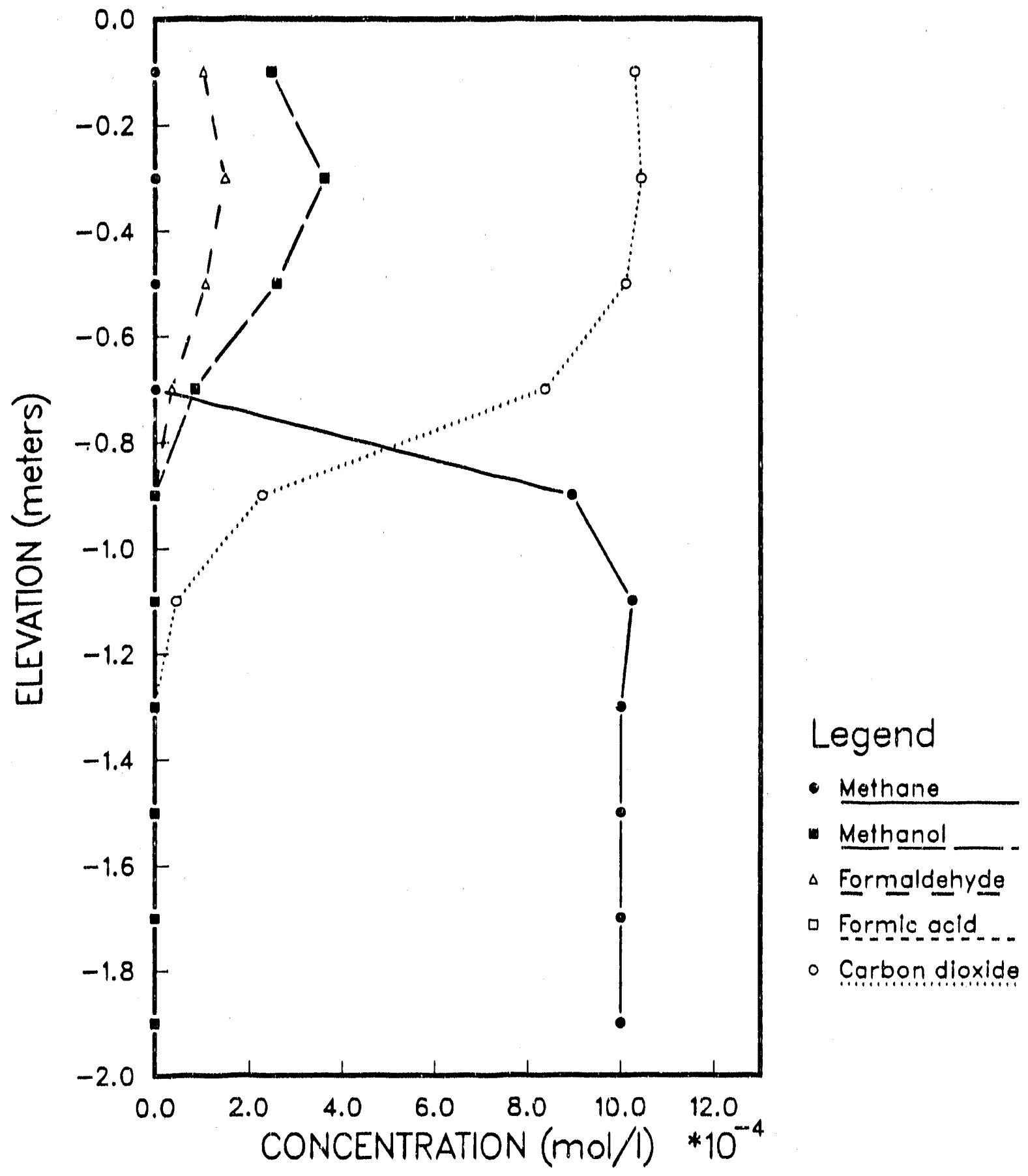

Figure 3.11. Reactive transport profiles of the degradation products of the methyl halides in the prestince of a réduciñg iàyer; $t=20$ days. 


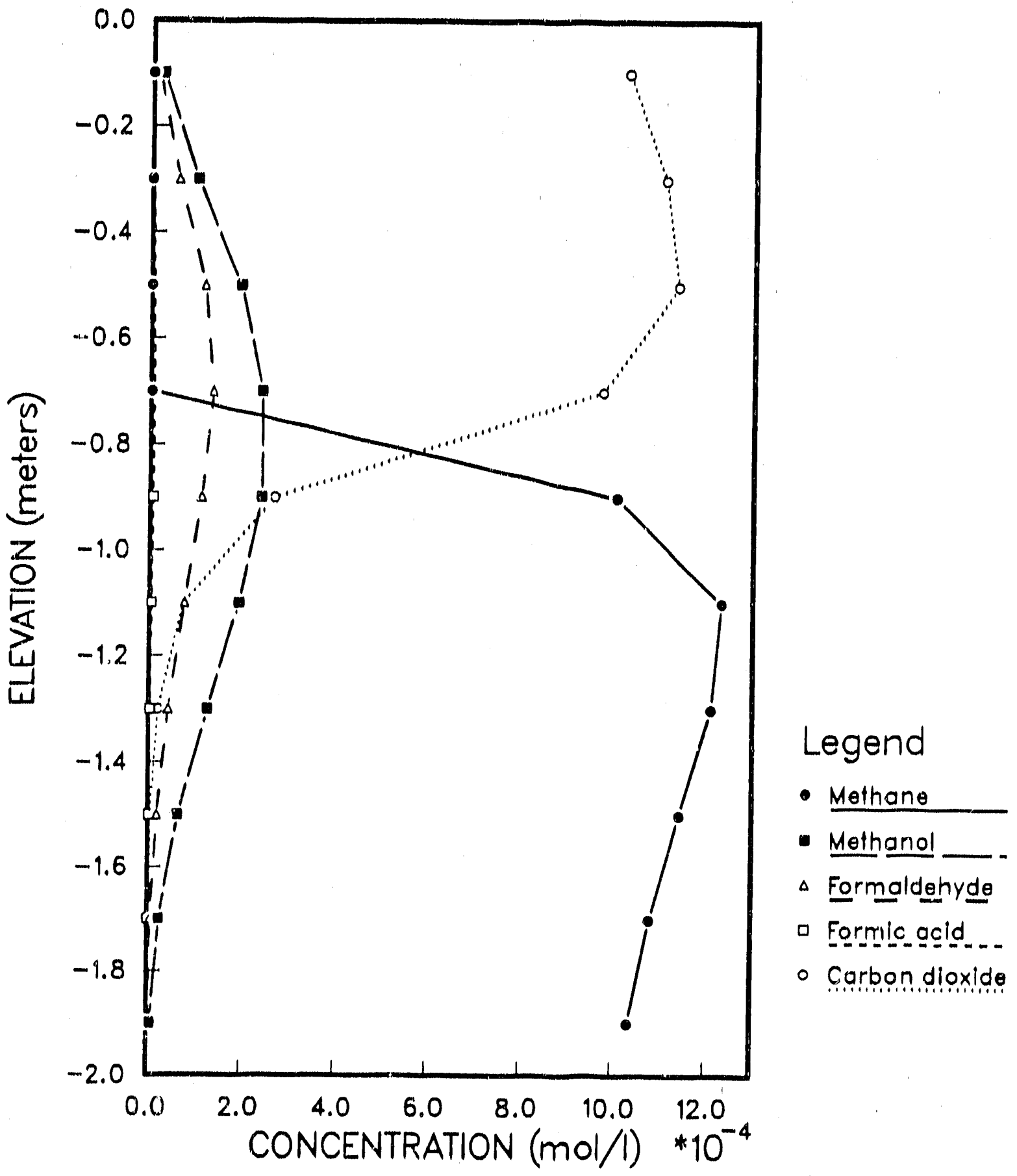

Figure 3.12. Reactive transport profiles of the secondary species in the soil column containing à ređuicing layer, $\hat{i}=i \hat{i} 0 \hat{~ d a y s . ~}$ 


\section{CHAPTER 4: MODEL VERIFICATION}

Model verification involves the assessment of the mathematical consistency of a numerical model. This may be accomplished through a comparison with an analytical solution to a given problem, or a comparison with the results of another numerical model which is designed to accomplish a similar task. Model validation involves the comparison of modeling results with actual experimental data, a much more difficult task. We attempt to partially validate the KINETRAN model in the next chapter.

In this section, we are concemed with model verffication. Because analytical solutions for the type of problems KINETRAN considers do not exist, we must be satisfied by verifying its intemal mathematical consistency. We assess this for both the chemical and the transport features of the simulator.

\subsection{Hypothetical Equilibration of Formic Acid with Carbon Dioxide}

A simple way to test whether or not the kinetics model is performing in a credible fashion is to allow the reactionis discussed in the previous chapter to evolve until the entire system is at equilibrium and to compare the results at equilibrium with the calculated final equilibrium state of the system. However, a comparison of Figures 3.2 and 3.3 with Figures 1.1 and 1.2 shows that this may take a very long time to occur. A simpler test must therefore be devised. From Figure 1.2, we note that at $E h=+0.1$ Volts, formic acid maintains an extremely small but finite concentration value in the presence of $1.2 \times 10^{-3}$ moles/liter of total dissolved $\mathrm{CO}_{2}$. In fact, from the reaction

$$
\mathrm{HCOOH} \rightarrow \mathrm{CO}_{2}(\mathrm{aq})+2 \mathrm{H}^{+}+2 \mathrm{e}^{-}
$$


we can write the mass action relationship

$$
\frac{\left[\mathrm{CO}_{2}(\mathrm{aq})\right]\left[\mathrm{H}^{+}\right]^{2}\left[\mathrm{e}^{-}\right]^{2}}{[\mathrm{HCOOH}]}=10^{2427}
$$

From this expression, one can calculate that under these conditions, $[\mathrm{HCOOH}]=1.868 \times 10^{-23}$ moles/iter. This is obviously an almost trivial number; it certainly could never be measured in the fleld. However, the model insists that this be a finite quantity in order that the mass action constraint to be satisfied.

Thus, if we take the kinetics simulator by itself, give it an initial $\mathrm{pH}$ of 7.0 and an Eh of +0.1 Volts, along with $\left[\mathrm{CO}_{2}\right]=1.2 \times 10^{-3}$ moles/liter, all other species concentrations being zero, then this hypothetical equilibrium value for $[\mathrm{HCOOH}]$ should be eventually achieved. As seen from Figure 4.1, this is precisely what the model calculates. $\mathrm{HCOOH}-\mathrm{CO}_{2}$ equilibrium is achieved after about 100 days. The use of (10) frorn section 2.2 to calculate the $\lambda$-parameter was very successful; the plot shows a smooth approach to the equilibrium value. No oscillations occur, and the model does not overestimate or underestimate the equilibrium value to any measurable degree. This gives us confidence that the kinetics algorithm in KINETRAN is functioning correctly.

\subsection{Verification of the Transport Model}

A comparison of the performance of the transport module used in KINETRAN against a modified version of the well-established chemical/heat transport program TRUMP (Edwards, 1972) was performed in order to test the internal consistency of the transport model. Using the initial conditions described for the hypothetical problem in the previous chapter, both programs 
simulated the non-reactive transport of methyl chloride. Results from the two models, shown compared in Figure 4.2, indicate excellent agreement between the models. 


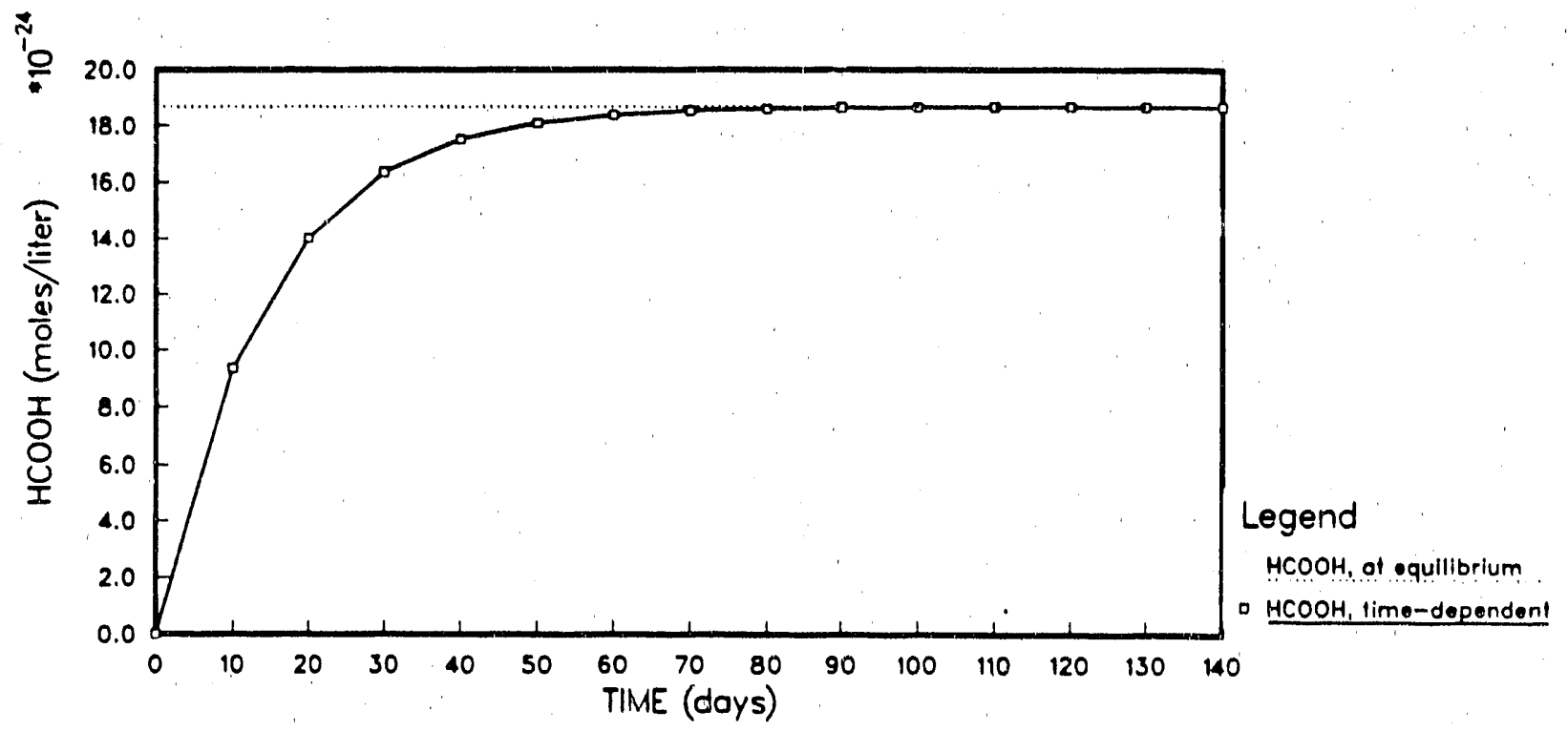

Figure 4.1. Hypothetical equilibration of formic acid with carbon dioxide over time. 


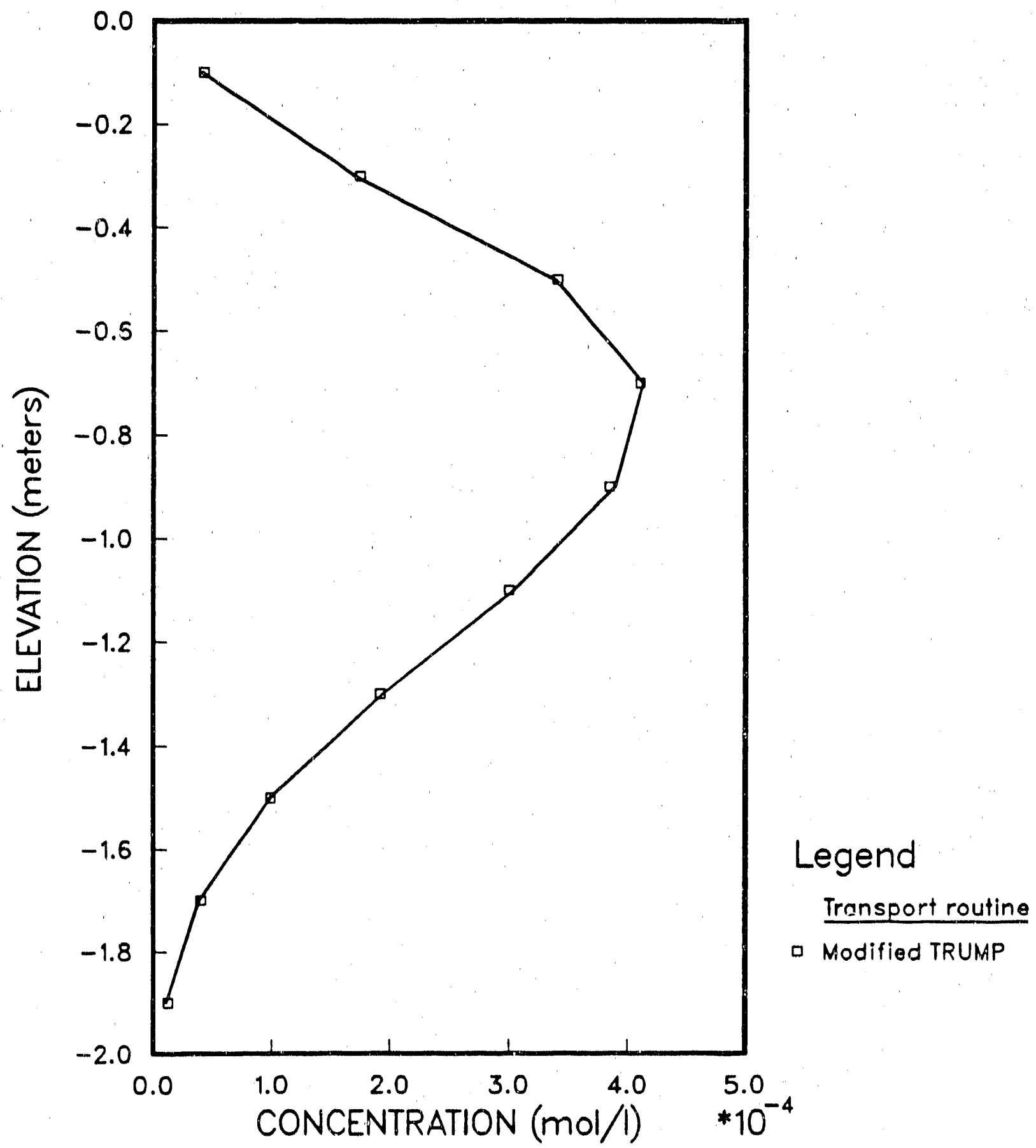

Figure 4.2. Comparison of the transport module in KINETRAN with the results from the chemical/heat transport program TRUMP. 


\section{CHAPTER 5: APPLICATION TO A FIELD PROBLEM}

We choose to test the applicability of KINETRAN to actual field problems by comparing its simulated results against data derived from a large-scale field experiment performed at the Canadian Forces Base at Borden, Ontario in 1986 by workers from Stanford University and the University of Waterloo (Curtis et al., 1986, Freyberg, 1986, MacKay et al., 1986, Roberts et al., 1986, and Sudicky, 1986). This data was chosen for the model assessment exercise because: (1) hydrologic conditions at the site had been extensively studied and quantified, with the aquifer being relatively homogeneous with a uniform, steady groundwater flow, (2) location of the source of contamination and time of introduction of pollutants was quantifiable, along with initial concentrations of the pollutants, and (3) spatial sampling density for the contaminant plumes was high enough for an adequate comparison with modeling results.

The results of our study demonstrate that the KINETRAN model is indeed applicable to real contamination sites and may prove to be of value in predicting the spatial and temporal extent of contamination.

\subsection{Problem Definition}

\subsubsection{Overview of the Borden Experiment}

One of the principal objectives of the Borden experiment was to evaluate the fatc of selected organic contaminants in groundwater under field conditions (MacKay et al. (1986)). In the experiment, five halogenated hydrocarbons (carbon teirachloride, hexachloroethane, tetrachloroethylene, oromoform, and 1,2-dichlorobenzene) along with two inorganic tracers 
(chloride and bromide) were injected in known quantities into a sandy aquifer over a 15-hour period. For approximately three years, the concentrations of these materials were measured in the downstream groundwater flow direction by an extensive monitoring network, yielding data on both the transport and transformation behavior of these materials at the site.

Analysis of the behavior of the plumes by Freyberg (1986) indicates very little spreading in the vertical direction or transverse to the groundwater flow direction. All of the plumes behave essentially as ellipsoids that grow more and more elongate in the direction coincident with the fluid flow. Because of this, solute transport at the Borden site can be approximated as one-dimensional and with only a horizontal component.

\subsubsection{Chemical Characteristics}

The results of the Borden experiment were interpreted by Roberts et al. in terms of the mass balance of the organic species present. Retardation coefficients, determined according to the technique described above, were used to estimate the total mass of a given organic species from the measured aqueous concentration. Discrepancies in the total mass of a species in the system were interpreted as evidence for transformation of the species. Simple first-order decay constants were assigned to the halogenated hydrocartons that showed evidence of degradation. Daughter products produced in the degradation reactions, and reactions between the initial contaminants, or with the subsequent decay products, were not addressed. As the major focus of this work, we consider the latter possibilities in detail, and use the scenarios generated to offer possible explanations for the observations, including some unexplained discrepancies.

The possible decay schemes of the halogenated hydrocarbons used in the Borden study are variable and quite complex. We do not expect to be able to include in our simulation 
every possible reaction and every possible transient daughter species that may be produced. Instead, we focus our attention on a small number of most likely degradation reactions, both abiotic and biologically-mediated, which produce species that may be of potential environmental significance.

Table 5.1 lists the original contaminants along with the decay products considered. Table 5.2 lists the initial concentrations of the contaminants in the $12 \mathrm{~m}^{3}$ of solution injected into the aquifer. The $\mathrm{pH}$ of the aquifer is assumed to remain constant at 7.6 (MacKay et al., 1986). The local Eh of the groundwater near the Borden site was found to vary considerably in an earlier study by Nicholson et al. (1983). For the area used in the experiment, we chose an Eh value that seemed to represent the best mean value; +0.3 Volts (moderately oxidizing). Nicholson et al. concluded that the Eh in the Borden aquifer was likely to be buffered by the $\mathrm{Fe}^{2+}-\mathrm{Fe}^{3+}$ redox couple, so we assume that the degradation of the organic contaminants, particularly in such low concentrations, has no significant effect on the Eh.

The decay scheme of greatest significance in our modeling study is the breakdown of hexachloroethane. Hexachloroethane degrades through a complex series of reductive dehalogenation reactions to form, as end products, either ethane or ethylene. Vogel et al., (1987) list this series as involving up to 17 different species/isomers. We utilize a simplified version of this scheme (Figure 5.1). The transformation of hexachloroethane into tetrachloroethylene is definitely a significant reaction (Vogel et al., (1987)), occurring as a result of both abiotic and biologically-mediated processes. As we discuss shortly, this reduction reaction may take place even under seemingly oxidizing conditions. Subsequently, tetrachloroethylene transforms through further reductive dehalogenation to trichloroethylene, dichloroethylene, vinyl chloride, and finally ethylene and carbon dioxide (under oxidizing conditions). We consider 
dichloroethylene to exist as a transient species in the system only in an implicit sense; that is, we bypass it in the simulation. This is because dichloroethylene exists as three possible isomers (cis -, trans -, and 1,1-dichloroethylene) and their explicit presence would add needless complexity to the simulation (Barrio-Lage et al., 1986), considering the lack of data on their presence. Trichloroethylene and vinyl chloride are of interest here, as trichloroethylene was indeed detected in the system, and vinyl chloride is a potent human carcinogen.

The other possible degradation pathway for hexachloroethane degradation is through a series of chloroethane isomers to ethane itself. Again, we do not explicitly consider the array of isomers and reactions involved, and instead approximate the whole process as a transformation of hexachloroethane to ethane. There is considerable evidence that this degradation pathway for hexachloroethane is not of particular significance in the Borden experiment, as we shall discuss later.

The ethane produced in this pathway is transformed into ethylene via simple oxidation or is converted into ethanol through hydrolysis. Ethylene is eventually oxidized to $\mathrm{CO}_{2}$, as is ethanol, either directly or through intermediate species such as acetaldehyde and acetic acid (Hart, (1987), Vogel et al., (1987)).

Figure 5.2 illustrates the possible reductive dehalogenation of carbon tetrachloride to methane. Unlike the case for hexachloroethane degradation, none of the intermediate species for the transformation of this compound were initially present nor were measured during the course of the experiment. As a result, we treat the whole process as a single step, and choose to ignore the intermediate species. Bromoform, the brominated equivalent of chloroform, is treated analogously. The degradation of the final pollutant, 1,2-dichlorobenzene, is probably exceedingly complex, involving many intermediate species and isomers, such as chlorophenols, 
catecols, and so forth, none of which were quantified in the experimental data. Thus, its degradation is treated is a transformation to either methane or carbon dioxide.

Figure 5.3 illustrates the reactions that are explicitly handled by the model for these three substances. Among the possibilities, all three may be reduced to methane or oxidized to $\mathrm{CO}_{2}$. In addition, bromoform and carbon tetrachloride may be transformed via hydrolysis to methanol. Finally, methane itself is oxidized to methanol, which is in turm oxidized (directly or indirectly) to carbon dioxide.

The hypothetical equilibrium concentrations of all of the species considered as a function of Eh are shown in Figures 5.4 and 5.5. These calculations are based on a list of equilibrium reactions (Table 5.3), the initial concentrations of the contaminants in the injection solution, a $\mathrm{pH}$ of 7.6, and a temperature of $20^{\circ} \mathrm{C}$. All of the species listed, except of course total $\mathrm{CO}_{2}$. have effective equilibrium concentrations of zero because of their thermodynamic instability under oxidizing conditions. The figures are useful, however, in that they provide some insight into which species are stable with respect to other species. For example, Vogel et al., (1987) state that progressively more chlorinated hydrocarbons are increasingly oxidized and thus are increasingly susceptible to reduction. Figure 5.4 shows that this can be inferred from the relative stabilities of the chlorinated ethanes and ethenes present in the system. Hexachloroethane is less stable than tetrachloroethylene, which is less stable than trichloroethylene and vinyl chloride, at the Eh-value of the Borden site. Thus, the sequence of reductive dehalogenation reactions mentioned earlier for these species is favored, at least thermodynamically, at an Eh of +0.3 Volts. Therefore, illustrations such as Figures 5.4 and 5.5 are useful in determining directions for degradation reactions under prevailing conditions if these are not known a priori.

Knowledge of which degradation reactions are favorable is, by itself, insufficient for 
modeling the system; the first-order rate constants must be quantified as well. In some cases, rates for degradation reactions in systems of environmental interest, particularly for abiotic hydrolysis reactions, follow general values from one system to the next. (Mabey and Mill, (1978)). However, in the vast majority of instances, reaction rates are highly system-dependent and must be determined empirically, directly from the data. This problem is due largely to the actions of microorganisms, which are capable of greatly accelerating the breakdown of organic chemicals (Vogel et al., (1987)), but whose behavior at any one site usually cannot be predicted a priori.

\subsubsection{Simulation Rate Constants}

Roberts et al., (1986) provide estimates of the first-order decay constants of hexachloroethane, bromoform, and 1,2-dichlorobenzene in the Borden experiment, and assume that tetrachloroethylene and carbon tetrachloride showed no evidence of degradation at the site. As discussed above, we present a more complex interpretation of the system chemistry. The degradation reactions are presented in Table 5.4. We now discuss the logical basis for he assignment of the reaction rate constants.

Analysis of the total mass balance data for the organic species in the Borden experiment yielded a rate constant of $0.02 \mathrm{day}^{-1}$ for hexachloroethane. As was mentioned, there are two possible degradation pathways for this compound. From the literature (Vogel et al., (1987)), indications are that the transformation of hexachloroethane to tetrachloroethylene may be the most important reaction. There is convincing evidence from the experimental data that this is indeed the case at the Borden site. Analysis of the concentration data for tetrachloroethylene suggest that $c / c_{0}$ ranges significantly greater than unity, but less than approximately 1.5 , over 
the course of the experiment. Thus, a source for this extra material must exist, and the only likely source is hexachloroethane. In addition, small amounts of trichloroethylene were detected during the experiment (Freyberg, 1989), and its likely source has to be tetrachloroethylene. The initial concentration ratio, in menles/liter, of hexachloroethane to tetrachloroethylene is approximately 0.47 . Since all of the hexachloroethane is transformed during the course of the experiment, we assign a rate constant for the transformation of hexachloroethane to tetrachloroethylene approximately equal to the hexachloroethane decay constant. The decay rate assigned for the tranisformation of hexachloroethane directly to ethane is therefore quite small. The rate constant for the transformation of tetrachloroethylene to trichloroethylene is then estimated through a history-matching scheme with the data. As we discuss later, this interpretation seems to explain the apparently inomalous behavior of tetrachloroethylene in the system.

It is possible that a transformation reaction may take place between tetrachloroethylene and carbon tetrachloride (Vogel et al., (1987)). Under the conditions of the experiment, carbon tetrachloride is favored thermodynamically. Nevertheless, the transformation of tetrachloroethylene into carbon tetrachloride involves the addition of chloride ions onto two hydrocarbon molecules. Such a reaction would probably be extremely slow in an environment such as the Borden site because microorganisms tend to do the opposite; they remove halogens from hydrocarbons. Thus, this reaction, if it occurs, is assumed to have a very long half-life.

The numerical rate constants for these degradation reactions are approximated through the relationship,

$$
\frac{\Delta c_{\mathrm{HCE}}}{\Delta \mathrm{t}}=-\mathrm{k}_{\mathrm{PCE}}[\mathrm{HCE}]+-\mathrm{k}_{\text {ethane }}[\mathrm{HCE}]+-\mathrm{k}_{\mathrm{CTET}}[\mathrm{HCE}] \approx-\mathrm{k}_{\text {tolal }}[\mathrm{HCE}]
$$


A similar scheme is used to quantify the degradation of carbon tetrachloride and bromoform. Roberts et al, (1986) calculate a decay rate constant of 0.003 day $^{-1}$ for bromoform. A rate constant is not provided for carbon tetrachloride; however, we found that a reasonable fit to the data resulted from the assignment of a very small rate constant for its degradation.

Although a simplified decay scheme (Figure 5.3) can be outlined for the degradation of these two compounds, the decisions regarding the significance of each of the reactions are rather difficult. This is because data regarding the presence of the possible decay products for these materials in the Borden experiment are not available. Thus, we seek only to be able to simulate the temporal evolution of the parent species concentrations, and analyze the hypothetical behavior of the daughter species produced.

We can make a few reasonable guesses concerning which reactions may be dominant in the decay scheme of carbon tetrachloride and bromoform. For example, the hydrolysis reactions that produce methanol from the two halogenated methanes are probably insignificant, as Mabey and Mill, (1978) state that the half-lives for abiotic hydrolysis of these two under environmental conditions is on the order of hundreds to thousands of years.*

Vogel et al., (1987), in a summary of experimental work involving biodegradation studies, state that carbon tetrachloride may be transformed into either carbon dioxide or chloroform, even under anaerobic condiuons. Bromoform would be expected to behave in an analogous manner. As a further complication, Roberts et al., (1986) suggest the possibility of isolated pockets of anaerobic conditions existing in an otherwise presumably oxidizing aquifer. Thus, whether these materials degrade at the Borden site via reductive dehalogenation, such as with the hexachloroethane-tetrachloroethylene-vinyl chloride scheme, or through simple

\footnotetext{
- Recent work by Jeffers and Wolfe (1989) suggest that the hydrolysis half-life of carbon tetrachloride may in fact be much shorter than previously suspected. This is clearly an area where more research is needed.
} 
oxidation via formaldehye and formic acid, is definitely an open question. Because of the presumed oxidizing conditions, we assume for modeling purposes that the preferred degrada. tion pathway is simply transformation to $\mathrm{CO}_{2}$. Utilizing a relationship such as Equation (13), we assign very small rate constants to the reactions trunsforming the two halogenated methanes to methanol and methane. This is done in order to analyze the hypothetical behavior of methane and metilanol in the system.

Roberts et al., (1978) calculate a decay constant for 1,2-dichlorobenzene of 0.004 day $^{-1}$. We have already alluded to the complex nature of the degradaiton of 1,2-dichlorobenzene. Again, we assume that this material is transformed directly into $\mathrm{CO}_{2}$, with only a small amount converted to methane. This is probably reasonable, since 1,2-dichlorobenzene is not heavily chlorinated hence not heavily oxidized, and thus is probably not particularly susceptible to reduction. Roberts et al. state, in fact, that they suspect that this material is indeed most readily degradable under aerobic (oxidizing) conditions.

The remaining reactions in the system, which include the degradation of vinyl chloride and all reactions not involving halogenated hydrocarbons, are assigned half-lives of approximately 100 days for modeling purposes. We believe that this is an appropriate assumption, given the lack of relevant data from the site, and that for most of these reactions this should be accurate within an order of magnitude.

\subsubsection{Transport Characteristics}

The Borden experiment was performed in a relatively homogeneous sandy aquifer. The hydraulic conductivity of the aquifer ranges from $5 \times 10^{-5}$ to $2 \times 10^{-4} \mathrm{~m} / \mathrm{sec}$, with a geometric mean of $7.2 \times 10^{-5} \mathrm{~m} / \mathrm{sec}$ (Sudicky, 1986). The annual mean horizontal hydraulic gradient is 
calculated by Sudicky to be 0.0043 . The mean porosity is given as 0.33 , with a coefficient of variation of 0.05 (Mac Kay et al., (1986)). These values imply a steady-state pore fluid velocity of approximately $0.081 \mathrm{~m} /$ day.

Careful measurements of the spatial variability of the concentrations of the two inorganic tracers, $\mathrm{Cl}^{-}$and $\mathrm{Br}^{-}$, showed no evidence that these two species had undergone any adsorption. That is, $c / c_{0}$ did not depart significantly from unity over the course of the experiment. As a result, plotting the position of the centers of mass of the tracer plumes as a function of time should also yield a value for the pore fluid velocity. These calculations yielded an average velocity of $0.091 \mathrm{~m} /$ day (MacKay et al.). This is in reasonable agreement with the value calculated from the hydraulic gradient, and is probably more accurate, given the greater uncertainties in determining average values for the hydraulic conductivity, potential gradient, and porosity. Thus, for our modeling study, we choose the latter value, which corresponds to a darcy velocity of $3.5 \times 10^{-7} \mathrm{~m} / \mathrm{sec}$.

Quantification of dispersivities for large-scale field tests is always difficult due to departures from the standard Fickian model and scale-dependencies. The Borden site is no exception. It is beyond the scope of our study to analyze the phenomenon of plurne dispersion in detail, as this is covered extensively by Freyberg (1986). We wish only to extract a single dispersivity value from the data in order to use it in the transport model, which assumes that dispersion is Fickian in nature. Freyberg (1986) conclude that the longitudinal dispersivity of the aquifer asymptotically approaches $0.49 \mathrm{~m}$ over the three-year time span of the expieriment. Sudicky et al. (1983) report a lower value, listing the apparent dispersivity of the same aquifer to be $0.08 \mathrm{~m}$ following a small-scale field test. In order to partially offset the problem of numerical dispersion in our simulation (see section 5.2.2.3 and Appendix B), we choose to use 
the latter (smaller) value. Transverse dispersivity is not quantified in the Borden experiment, and we ignore it as well, considering the one-dimensional nature of the problem. Effective diffusion coefficients for all species are assumed to be $1 \times 10^{-10} \mathrm{~m}^{2} / \mathrm{sec}$.

Data from the Borden site show that the center of masses of the organic contaminant plumes lagged significantly behind those of the tracers, the difference becoming increasingly apparent as the experiment proceeded in time. Roberts et al. interpreted this as clear evidence that the organic species were being retarded as a result of adsorption. The retardation coefficient for a given species $\boldsymbol{l}$ is defined by the velocity ratio with respect to a non-adsorbing solute,

$$
R_{i}=\frac{v_{C^{-1}}}{v_{i}}
$$

Curtis et al. (1986) performed laboratory experiments designed to duplicate the adsorptive behavior of the materials on the Borden aquifer. They found that the materials were indeed adsorbing on the sand grains, probably due to the hydrophobicity of the halogenated hydrocarbons. Apparently, each of the materials produced linear, reversible isotherms consistent with an equilibrium adsorption model.

Further analysis of the Borden site data indicated, however, that the contaminant plumes did not obey constant retardation coefficients but instead showed time-dependent retardation. Roberts et al. suggested a number of possibilities to account for this, but stated that the most likely was that diffusion rate limitation resulted in a slow approach to equilibrium, so that in the relationship

$$
R_{i}=1+\frac{P_{b} K_{d}^{i}}{n}
$$


the distribution coefficient of species $\ell, \mathbf{K}_{d}$, slowly increases over time. Using regression analysis, power curves were fit to the experimental data to express solute velocity as a function of time (see Table 5.5). The retardation coefficients were determined from the calculated velocities and (14).

The same retardation relationships are used in the modeling study for the initial contaminants present. Among the secondary species produced, trichloroethylene and vinyl chloride are assumed to obey the same velocity equation as tetrachloroethylene. The remaining species, ethane, ethylene, ethanol, methanol, methane, and $\mathrm{CO}_{2}$ are all assumed to have retardation factors of unity.

The goal of the transport portion of the simulation is to couple the chemical transformation simulation capability of KINETRAN with a solute transport model, and to be able to reproduce some of the features of the Borden experiment, at least in a qualitative manner.

Our emphasis for this modeling study is primarily focused on the reactive transport features of the problem, such as, for example, the spatial variability in concentration of two reacting species subject to differing degrees of retardation. As a result, we feel that it is beyond the scope of this study to attempt to precisely' simulate the configuration of the various contaminant plumes through the use of a detailed three-dimiensional mesh. Such a match can usually be achieved tnrough the use of history-matching schemes and appropriate weighting functionss This type of study has been performed many times in the past using varlous chemical transpoit models, and simply repeating such work for the Borden experiment would not prove to be of great scientific significance. Rather, the purpose of this study is to investigate the applicability of the KINETRAN model to a site where complex chemical transformations may be occurring, thus the computational effort at this level is focused on solving the chemical problems. 
Bearing this purpose in mind, we choose to model the transport of the contaminant plumes through the use of a relatively simple one-dimensional grid (see Figure 5.6). If the cross-sectional area of such a mesh is large enough, the small amount of transverse dispersion that did occur in the original experiment will not be a factor in the simulation, and thus mass balance errors that would result from the one-dimensional approximation are avoided. The use of a coarse mesh greatly reduces the computational effort needed to solve the reactive transport problem at the expense of some spatial resolution. However, the use of coarse meshes for strongly advective systems often leads to numerical dispersion problems. We investigate this phenomenon further in Appendix B.

The initial concentrations of the contaminants in the volume element representing the initial injection plume are shown in Table 5.6 (in moles $/ \mathrm{m}^{3}$ ). These concentrations were determined by dividing the original total mass of each contaminant in the $12 \mathrm{~m}^{3}$ injection plume (calculated from Table 5.2) by its molecular weight and dividing the resulting quantity (total moles) by the pore volume of the node $\left(132 \mathrm{~m}^{3}\right)$. The concentration of $\mathrm{CO}_{2}$ is assumed to be initially constant throughout the system, including groundwater infiltrating the column. The background concer ation of $\mathrm{Cl}^{-}$in the groundwater at the Borden site was measured by Nicholson et al., (1983)to be 1-3 mg/, clearly negligible compared to the injected tracer concentration, $892 \mathrm{mr}^{\top}$.

\subsection{Simulation Results}

\section{5.j.i. B. Batch Simuiation}

Using the contarninant concentrations in the initial solution, along with the $\mathrm{pH}$, Eh, and 
$\left[\mathrm{CO}_{2}\right]$ presented above, and the degradation reactions, we first apply the chemical transformation module of the KINETRAN simulator to solving the batch (non-transport) problem, using a 10-day time step, over a 700-day period. The goal of this exercise is to see how well the model, and our interpretation of the system, match the estimated total masses of the organic compounds as given by Roberts et al.

The total masses of the organic compounds in the experimental data were determined by integrating the concentration profiles over the entire snil column. We could have followed an aralogous procedure by summing up the concentrations of the various species over all of the volume elements. However, because conditions throughout the simulated soil column do not vary (pH, Eh, and forward reaction rates), solving for the changes in total mass of the species as if they were all in a static batch system will yield virtually identical results. One would expect a discrepancy between the two methods only if the reverse reactions are significant, as the rates of mariy of these reactions depend on the chloride and bromide concentrations which are spatially and temporally variable. However, because of thermodynamic constraints at this pH and Eh, none of the reverse reactions, as listed in Table 5.4, are of significance. In fact, comparison of the batch simulation degradation curves for the initial contaminants with those determined by summation of the reactive transport profiles (discussed shortly) yielded no appreciable differences.

The advantage of first solving the batch system problem is that it can yield first-order kinetic parameters as part of a history matching scheme that may be used later in the reactive transport problem, saving a considerable amount of computational effort. This is because for a system of $i$ species, after $N$ time steps, only $N i \times i$ matrices need to be solved in order to determine the changes in total mass. If the reactive transport curves are to be used, then $N M$ 
$i \times i$ matrices must be solved, where $M$ is the number of nodes, in addition to solving the transport equations. Clearly, using the latter method to fit the correct degradation parameters would be much more difficult and time-consuming.

Because the first-order decay constants presented by Roberts et al. were derived for the total masses of the organic compounds in the system, and not just for the mass in solution, we treat the batch simulation as if all species are totally dissolved in the aqueous phase. Thus, adsorption is viewed in the context of this model as strictly a tran mrt phenomenon, with no implications for the transformation behavior of a given organic species within a given volume element. The alternative approach, dealing with transformation chemistry exclusively in the aqueous phase, implies that species adsorbed on the solid phase are not subject to degradation, which may not be true at all. Furthermore, because the retardation coefficients for the organic species in this problem are not constant, this would make determination of first-order decay constants quite difficult. Therefore, the method used for this simulation is more computationally suitable for history-matching schemes.

Figures 5.7 through 5.13 illustrate the behavior of the total mass of the organic compounds in the system. Bromoform and 1,2-dichlorobenzene show simple first-order decay curves in Figures 5.7 and 5.8, respectively. Neither is being produced in any significant reactions, and both are being degraded, primarily into $\mathrm{CO}_{2}$. Although there is considerable scatter in the experimental data, the agreement of the simulated results is good. Note that the scatter for bromoform, and to a degree 1,2-dichlorobenzene, lies preferentially above the simulated decay curve. Roberts et al. suggest that there may be a slight time lag in the decay process during which time microcrganisms that play a part in the transformation become established. In each of these figures, adjustment of the simulated decay curves for a 100-day time lag shows 
better agreement with the experimental results.

Figure 5.9 shows the behavior of carbon tetrachloride. Roberts et al., (1986) state that they firid no evidence for the transformation of carbon tetracliloride and hence provide no first-order decay constant. We assign a very small decay constant to carbon tetrachloride in order to achieve a slightly better fit to the data (see Table 5.4). The effect of this is rather subthe, the decay curve appearing as more of a gently sloping line than an exponential curve.

Hexachlorothane and tetrachloroethylene are depicted in Figures 5.10 and 5.11, respectively. Again, hexachloroethane shows simple exponential decay, with the curve fitting the data quite well, in this case without evidence of a decay time-lag (also reported by Roberts et al.). The behavior of tetrachloroethylene is more complex, however. According to our interpretation of the chemical phenomena occurring in this system, as discussed in section 5.1.2, tetrachloroethylene is produced from the degradation of hexachloroethane. Therefore, its concentration increases for the first 150 days or so until the hexachloroethane is depleted, then the tetrachloroethylene concentration decreases as a result of subsequent transformation to trichloroethylene. The curve generated by KNNETRAN, based on these assumptions, is reconcilable with the data plotted in Figure 5.11, although one may argue that scatter in the experimental data allows us the liberty to do this. However, there is indeed evidence based on observations of Roberts et al., that tetrachloroethylene may in fact be both produced and consumed in the system. For example, calculations of the total mass in the system based on synoptic data indicate that, for tetrachloroethylene, $1.05 \leq \mathrm{c} / \mathrm{c}_{0} \leq 1.23$ over the course of the experiment, within a 95\% confidence interval. Additionally, calculations of Roberts et al. involving integration of the breakthrough curves for tetrachloroethylene at three sampling points indicate that $1.18 \leq \mathrm{c} / \mathrm{c}_{0} \leq 1.48$ within a $95 \%$ confidence interval. The latter values were measured earlier in 
the experiment when the plume was passing by three monitoring points located relatively close to the source. The fact that these values appear to be larger than the former ones conforms very well with the modeling prediction that the tetrachloroethylene concentration rises initially and then begins to fall off. This finding strongly suggests that the assumption of tetrachloroethylene as chemically inert (no source term or decay constant) might perhaps be overly simplistic, and that our interpretation may have considerable merit.

Figure 5.12 illustrates the transient behavior of hexachloroethane and tetrachloroethylene as compared to the hypothetical behavior of trichloroethylene and vinyl chloride. The concentrations are given in total mass (grams) of the species in the system. The detection limit for these data in the experimental study occurred at around 0.05 grams (Roberts et al.).

Trichloroethylene appears in the system as a result of the degradation of tetrachloroethylene, although not in easily measured amounts. According to Freyberg (1989), traces of trichlorocthylene were indeed found during the Borden experiment, supporting, at least qualitatively, our hypothetical results. As shown by Figure 5.12, vinyl chloride also occurs in the system in a pattern similar to trichloroethylene, from which it is derived. However, the concentrations of this material are even smaller. Thus, although it is likely that vinyl chloride appeared in the real system, its concentrations would have probably been too minute to detect.

The hypothetical transient behavior of the secondary organic species are shown in Figure 5.13. These species are produced through a variety of oxidation and reduction reactions, as well as hydrolysis reactions. The concentrations of these species, as modeled by the simulator,

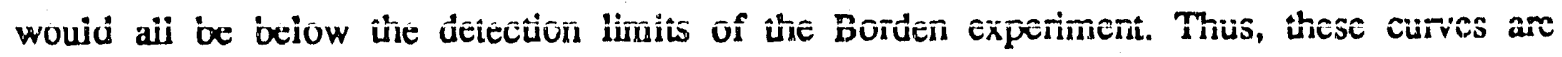
speculative, but they do suggest interesting, and entirely plausible, possibilities. 
Ethane is produced through a long series of reduction reactions that replace the chlorine atoms of hexachlomethane with hydrogen atoms. These are approximated as a single reaction for modeling purposes (see section 5.1.2). Because we assert that the primary degradation product of hexachloroethane is tetrachloroethylene, and not ethane, ethane is produced in only very small amounts, and is rapidly oxidized to ethylene or directly to $\mathrm{CO}_{2}$, or is converted via hydrolysis to ethanol. From the figure, we see that ethanol appears as a result of this in small concentrations, as it too is oxidized to $\mathrm{CO}_{2}$. Methane and methanol show analogous behavior, but at somewhat higher concentrations. This is because methane is produced by more sources, namely the reduction of carbon tetrachloride, bromoform, and 1,2-dichlorobenzene. Ethylene behaves differently from the other species; it is produced initially principally by the oxidation of ethane, and later on by the reduction and dechlorination of vinyl chloride. Its concentration begins to level off near 700 days, when its subsequent oxidation to $\mathrm{CO}_{2}$ begins to dominate.

\subsubsection{Transport Simulation}

\subsubsection{Centers of Mass of Contaminant Plumes}

The centers of mass of each of the plumes of the five o.iginal contaminants, along witt the chloride tracer, are depicted in Figures 5.14 through 5.19. The curves for the simulated results were dirived by using a linear interpolation for the concentration values between the nodal points. Numerical integration was used to evaluate,

$$
\bar{x}_{i}=\int \frac{x d c_{i}}{c_{i}}
$$


where $x_{i}$ and $c_{i}$ are the center of mass and the concentration of species $i$, respectively. The centers of mass calculated in this manner from the simulated concentration profiles are compared with the experimental data of Roberts et al. In general, the agreement between the two is good. There is a slight discrepancy between the simulated and observed results in the more strongly sorbed species, however, most notably with hexachloroethane (Figure 5.19). This is most likely due to the presence of the upstream node and the linear interpolation of the concentration profiles between nodes, leading to a negative bias for the centers of mass for more highly adsorbed species. Nevertheless, strongly sorbed species such as hexachloroethane do not advance very far during the simulation anyway, so the error mentioned above is not of great importance. Thus, in general, we see that the use of a relatively coarse, one-dimensional mesh to simulate this problem does not adversely affect the accurate location of the centers of mass of the plumes, at least over the distance and time scales used.

\subsubsection{Breakthrough Curves}

Roberts et al. presented the results of time series samplings (breakthrough curves) for the five original contaminants and the chloride tracer from three different monitoring points in their study. We decided against attempting to directly duplicate these quantitative results with KINETRAN for two reasons. The primary reason was that the monitoring points were all in relatively close proximity to the injection point (within 5 meters), were located at different depths, and were not colinear when projected onto a horizontal plane. Attempting to simulate the breakthrough curves under such a scenario would have required the use of a very fine, three-dimensional mesh and small time steps for accurate time-s,ries sampling. Because the distance and time scales we chose to model for this system are much larger, such fine 
discretization would have been computationally cumbersome. Secondly, presenting a more intractable difficulty, the precise configuration of the initial contaminant plume immediately following injection could not be well enough constrained for modeling purposes.

Instead, we choose to attempt to duplicate the time-series results in a more qualitative manner. Owing to our coarse mesh, we sample the breakthrough curves of chloride, carbon tetrachloride, and tetrachloroethylene at a distance of 10 meters from the injection site and compare the shapes of the curves qualitatively with the curves for the same species at the monitoring points. Again, because of the discrete nature of the simulation, space and time intervals are not fine enough to accurately determine the breakthrough curves simply by plotting relative concentrations at a given location verses time. Thus, the breakthrough curves must be determined by an indirect method.

The determination is as follows. At any given cross-sectional plane through the onedimensional column, at any given time, the solute flux of a particular species over the last time interval is given by the change in concentration of that species downstream over that time interval (assuming the species has not been significantly chemically transformed during the time interval). Under conditions of steady solute flux, the flux will be proportional to the concentration, hence the breakthrough curves can be estimated.

The breakthrough curves, determined by this method, are shown in Figure 5.20. Qualitatively, these match the experimental breakthrough curves quite well (see Roberts et al., (1986)). Chloride, which is not adsorbed at all, arrives first and shows a relatively sharp pulse. Carbon tetrachloride, with an average retardation factor of around 2, arrives later and shows a pulse that is much less sharp. Finally, tetrachloroethylene, with an average retardation factor of around 4, arrives last and show, a pulse that is even less sharp than carbon tetraclloride. In 
fact, after 375 days, the tetrachloroethylene concentration is just peaking, while cartion tetrachloride is already diminishing and most of the chloride has long since passed through. The experimental data of Roberts et al. is very similar, although the peaks of all three species are sharper, with that of chloride being a virtual spike. This: anost likely due to the proximity to the source. The simulated breakthrough curves, measured at over twice the distance from the initial pulse, are less sharp because dispersion has had more time to smear out the solute fronts.

Integration under the chloride curve, the conservative tracer, yields a value of $c / c_{0}$ of 0.97, indicating that this indirect method for breakthrough curve determination is probably a reasonably good approximation. Integration under the carbon tetrachloride and tetrachloroethylene curves is not meaningful because a significant amount of flux is still occurring at 10 meters after 375 days. For carbon tetrachloride, after 375 days, transformation has led to $c / c_{0}=0.93$, so the carbon tetrachloride breakthrough curve is probably reasonably accurate as well.

The tetrachloroethylene curve, however, is only very approximately correct, because of its complex chemistry in the system. After 375 days, $c / c_{0}=1.25$ due to the assumption that tetrachloroethylene is produced through the degradation of hexachloroethane. This production occurs mainly in the upstream direction, since hexachloroethane is more is more strongly adsorbed than tetrachloroethylene. Downstream, tetrachloroethylene is destroyed more rapidly because production does not balance its transformation into trichloroethylene. As a result, using changes in the downstream concentration of tetrachloroethylene to determine the flux turough the cross-sectional area at 10 meters probably introduces considerable error, so the tetrachloroethylene curve must be viewed as only a rough qualitative guicle. 


\subsubsection{Dispersion}

The concentration versus distance profiles for the non-reactive chloride tracer are shown in Figure 5.21. Dispersion of the chloride plume over time as it advances in the downstream direction is evident. MacKay et al. report field evidence for the dispersion of the chloride tracer, and the organic contaminants as well, at the Borden site. The plumes all became more and more ellipsoidal as they migrated away from the injection site, with their major axes aligned with the direction of groundwater flow.

As we have shown in the previous section, the simulated centers of mass of the contaminant plumes agree fairly well with field measurements. This observation, coupled with the qualitative agreement between the two concerning dispersion of the contaminant plumes, leads us to believe that our transport model is in reasonable agreement with the field observations, at least qualitatively, within the limited scope of this study. The modeling results do show somewhat more dispersion than was measured in the experiment, however. This is almost certainly the result of numerical (non-physical) dispersion which results from the use of a relatively coarse mesh and full upstream weighting. Numerical dispersion can be reduced by using a finer mesh (see Appendix B) and by carefully adjusting the upstream weighting function to values less than 1.0 , but this greatly increases the computation effort required, as more nodes must be used and smaller time steps must be taken. In addition, decreasing the upstream weighting function often leads to non-physical oscillations about the solute front, particularly in dominantly advective systems, such as the one we are concerned with. 


\subsubsection{Reactive Transport Results}

The concentration versus distance profles for several of the species that undergo significant chemical transformation are depicted in Figures 5.22 through 5.26.

Figure 5.22 shows the concentration profile of bromoform over time. In comparing this figure with Figure 5.21, two features are immediately apparent. One is the retardation of bromoform in the soil column, evidenced by the fact that the plume does not advance nearly as far downstream as the chloride plume in the same amount of time. Secondly, the area under the profile curve becomes progressively smaller over time as a result of transformation. Because the rate of transformation is proportional to the concentration, the species degrades faster in the region of the profile with the highest concentration, the result being that the concentration profiles appear to be even more dispersed than would be expected as time progresses. This feature is itself somewhat suppressed by the effects of retardation, however.

The reactive transport profiles of the chlorinated hydrocarbons involved in the decay chain of hexachloroethane are shown in Figures 5.23 through 5.26. In each of these graphs, the concentration, given in grams per liter of soil (bulk concentration), is only a relative term used for comparative purposes. This is because these concentrations are averaged over each entire volume element and will usually be much smaller than the real values, as in reality the plume would be concentrated locally within the volume blocks.

Figure 5.23 shows the concentration profile of hexachloroethane over time. The species would be expected to behave in a manner analogeus to that of bromoform: the transport of both are retarded with respect to chloride, and both show transformation behavior that may be described as first-order decay processes. The graph shows, however, that hexachi roethane is so strongly retarded that it is essentially not transported at all; it simply degrades in place, pri- 
marily into tetrachloroethylene. In fact, among the organic species initially injected in the system, hexachloroethane shows the greatest increase in its retardation factor over time (see section 5.1.3).

The concentration profiles of the next member of the decay series, tetrachloroethylene, are depicted in Figure 5.24. The behavior of this material in the simulated system is relatively complex. As a whole, the total concentration of tetrachloroethylene in the system increases initially as a result of the degradation of hexachloroethane, peaking at around 150 days. After that time, the concentration of the parent material becomes too low to balance the loss of tetrachloroethylene through transformation into trichlomethylene, and the overall concentration begins to decline.

These processes due not occur at uniform rates throughout the column. Because hexachloroethane is adsorbed more strongly than tetrachloroethylene, production of tetrachloroethylene may dominate degradation, at least initially, near the injection source, while the opposite case may be true further downstream. One might expect that the result of this would be a suppression of plume dispersion. When the time-dependent retardation factors for both hexachloroethane and tetrachloroethylene are taken into consideration as well, it becomes evident that the curves shown in Figure 5.24 are exceedingly difficult to interpret. In situations where these effects may be even more pronounced, the suggestion here is that one must use extreme caution when attempting to calculate, and interpret, retardation coefficients from data such as these.

Figures 5.25 and 5.26 show the concentration profiles of trichloroethylene isit vinyl chloride, respectively. Both of these species ari accumed to obey the same retardation relationship as tetrachloroethylene. The curves generally mirror the behavior of the tetrachloroethylene 
profles, as vinyl chloride is produced through the transformation of trichloroethylene, which is in tum produced though the degradation of tetrachloroethylene. Vinyl chloride and trichloroethylene do not build up concentrations as high as tetrachloroethylene because these species too are degraded, with the final end products being ethylene and $\mathrm{CO}_{2}$. 
Table 5.1

Organic Species, Borden Simulation

\begin{tabular}{|l|l|l|}
\hline \multicolumn{1}{|c|}{ Species } & Abbreviaton & Formula \\
\hline hexachloroethane & $\mathrm{HCE}$ & $\mathrm{C}_{2} \mathrm{Cl}_{6}$ \\
tetrachloroethylene & PCE & $\mathrm{C}_{2} \mathrm{Cl}_{4}$ \\
trichloroethylene & TCE & $\mathrm{C}_{2} \mathrm{HCl}_{3}$ \\
vinyl chloride & VC & $\mathrm{C}_{2} \mathrm{H}_{3} \mathrm{Cl}$ \\
carbon tetrachloride & $\mathrm{CTET}$ & $\mathrm{CCl}_{4}$ \\
bromoform & $\mathrm{BROM}$ & $\mathrm{CHBr}_{3}$ \\
1,2-dichlorobenzene & $1,2-\mathrm{DCB}$ & $\mathrm{C}_{6} \mathrm{H}_{4} \mathrm{Cl}_{2}$ \\
methane & & $\mathrm{CH}_{4}$ \\
methanol & & $\mathrm{CH}_{3} \mathrm{OH}$ \\
ethang & & $\mathrm{C}_{2} \mathrm{H}_{6}$ \\
$\mathrm{C}_{2} \mathrm{H}_{5} \mathrm{OH}$ \\
$\mathrm{C}_{2} \mathrm{H}_{4}$ \\
$\mathrm{CO}_{2}$ \\
\end{tabular}


Table 5.2

Initial Contaminant Concentrations in Injection Plume

\begin{tabular}{|l|l|}
\hline \multicolumn{1}{|c|}{ Species } & Conc.(g/liter)* \\
\hline $\mathrm{C}_{2} \mathrm{Cl}_{6}$ & $2.00 \times 10^{-5}$ \\
$\mathrm{C}_{2} \mathrm{Cl}_{4}$ & $3.00 \times 10^{-5}$ \\
$\mathrm{C}_{2} \mathrm{HCl}_{3}$ & 0.0 \\
$\mathrm{C}_{2} \mathrm{H}_{3} \mathrm{Cl}$ & 0.0 \\
$\mathrm{CCl}_{4}$ & $3.10 \times 10^{-5}$ \\
$\mathrm{CHBr}_{3}$ & $3.20 \times 10^{-5}$ \\
$\mathrm{C}_{6} \mathrm{H}_{4} \mathrm{Cl}$ & $3.32 \times 10^{-4}$ \\
$\mathrm{CH}_{4}$ & 0.0 \\
$\mathrm{CH}_{3} \mathrm{OH}$ & 0.0 \\
$\mathrm{C}_{2} \mathrm{H}_{6}$ & 0.0 \\
$\mathrm{C}_{2} \mathrm{H}_{5} \mathrm{OH}$ & 0.0 \\
$\mathrm{C}_{2} \mathrm{H}_{4}$ & 0.0 \\
$\mathrm{CO}_{2}($ total) & $7.69 \times 10^{-2 * *}$ \\
$\mathrm{Cl}^{-}$ & 0.892 \\
$\mathrm{Br}^{-}$ & 0.324 \\
\hline
\end{tabular}

- From Mackay el al. (1986).

- From Nicholson et al. (1983). 
Table 5.3

Equilitration Reactions for Borden Organic Species

\begin{tabular}{|l|r|}
\hline \multicolumn{1}{c|}{ Reaction } & log $\mathrm{K}_{e q}$ \\
\hline $\mathrm{C}_{2} \mathrm{Cl}_{6}+4 \mathrm{H}_{2} \mathrm{O} \rightarrow 2 \mathrm{CO}_{2}+6 \mathrm{Cl}^{-}+8 \mathrm{H}^{+}+2 \mathrm{e}^{-}$ & 97.50 \\
$\mathrm{C}_{2} \mathrm{Cl}_{4}+4 \mathrm{H}_{2} \mathrm{O} \rightarrow 2 \mathrm{CO}_{2}+4 \mathrm{Cl}^{-}+8 \mathrm{H}^{+}+4 \mathrm{e}^{-}$ & 65.36 \\
$\mathrm{C}_{2} \mathrm{HCl}_{3}+4 \mathrm{H}_{2} \mathrm{O} \rightarrow 2 \mathrm{CO}_{2}+3 \mathrm{Cl}^{-}+9 \mathrm{H}^{+}+6 \mathrm{e}^{-}$ & 41.22 \\
$\mathrm{C}_{2} \mathrm{H}_{3} \mathrm{Cl}+4 \mathrm{H}_{2} \mathrm{O} \rightarrow 2 \mathrm{CO}_{2}+\mathrm{Cl}^{-}+11 \mathrm{H}^{+}+10 \mathrm{e}^{-}$ & 1.55 \\
$\mathrm{CCl}_{4}+2 \mathrm{H}_{2} \mathrm{O} \rightarrow \mathrm{CO}_{2}+4 \mathrm{H}^{+}+4 \mathrm{Cl}^{-}$ & 66.17 \\
$\mathrm{CHBr}_{3}+2 \mathrm{H}_{2} \mathrm{O} \rightarrow \mathrm{CO}_{2}+3 \mathrm{Br}^{-}+5 \mathrm{H}^{+}+2 \mathrm{e}^{-}$ & 38.86 \\
$\mathrm{C}_{6} \mathrm{H}_{4} \mathrm{Cl}+12 \mathrm{H}_{2} \mathrm{O} \rightarrow 6 \mathrm{CO}_{2}+2 \mathrm{Cl}^{-}+28 \mathrm{H}^{+}+26 \mathrm{e}^{-}$ & -32.95 \\
$\mathrm{CH}_{4}+2 \mathrm{H}_{2} \mathrm{O} \rightarrow \mathrm{CO}_{2}+8 \mathrm{H}^{+}+8 \mathrm{e}^{-}$ & -21.47 \\
$\mathrm{CH}_{3} \mathrm{OH}+\mathrm{H}_{2} \mathrm{O} \rightarrow \mathrm{CO}_{2}+6 \mathrm{H}^{+}+6 \mathrm{e}^{-}$ & -4.62 \\
$\mathrm{C}_{2} \mathrm{H}_{5} \mathrm{OH}+3 \mathrm{H}_{2} \mathrm{O} \rightarrow 2 \mathrm{CO}_{2}+12 \mathrm{H}^{+}+12 \mathrm{e}^{-}$ & -21.18 \\
$\mathrm{C}_{2} \mathrm{H}_{6}+4 \mathrm{H}_{2} \mathrm{O} \rightarrow 2 \mathrm{CO}_{2}+14 \mathrm{H}^{+}+14 \mathrm{e}^{-}$ & -33.89 \\
$\mathrm{C}_{2} \mathrm{H}_{4}+4 \mathrm{H}_{2} \mathrm{O} \rightarrow 2 \mathrm{CO}_{2}+12 \mathrm{H}^{+}+12 \mathrm{e}^{-}$ & -16.74 \\
\hline
\end{tabular}

Equilibrium constants calculated from Wagman et al. (1968), Dean (1979), and MacKay and Shin (1.981). 
Table 5.4

Degradation Reactions $a \hat{~} \mathbf{p H}=7.6$ and $\mathrm{Eh}=+0.3$ Volts

\begin{tabular}{|c|c|c|}
\hline & $\log K_{\infty}$ & $\begin{array}{l}k_{\text {forwand }} \\
\left(\mathrm{sec}^{-1}\right)\end{array}$ \\
\hline $\begin{array}{l}\mathrm{C}_{2} \mathrm{Cl}_{6}+2 \mathrm{Cl}^{-} \rightarrow 2 \mathrm{CCl}_{4}+2 \mathrm{e}^{-} \\
\mathrm{C}_{2} \mathrm{Cl}_{6}+2 \mathrm{e}^{-} \rightarrow \mathrm{C}_{2} \mathrm{Cl}_{4}+2 \mathrm{Cl}^{-} \\
\mathrm{C}_{2} \mathrm{Cl}_{4}+\mathrm{H}^{+}+2 \mathrm{e}^{-} \rightarrow \mathrm{C}_{2} \mathrm{HCl}_{3}+\mathrm{Cl}^{-} \\
\mathrm{C}_{2} \mathrm{HCl}_{3}+2 \mathrm{H}^{+}+4 \mathrm{e}^{-} \rightarrow \mathrm{C}_{2} \mathrm{H}_{3} \mathrm{Cl}+2 \mathrm{Cl}^{-} \\
\mathrm{C}_{2} \mathrm{H}_{3} \mathrm{Cl}+\mathrm{H}^{+}+2 \mathrm{e}^{-} \rightarrow \mathrm{C}_{2} \mathrm{H}_{4}+\mathrm{Cl}^{-} \\
\mathrm{C}_{2} \mathrm{H}_{6} \rightarrow \mathrm{C}_{2} \mathrm{H}_{4}+2 \mathrm{H}^{+}+2 \mathrm{e}^{-} \\
\mathrm{C}_{2} \mathrm{H}_{3} \mathrm{Cl}+4 \mathrm{H}_{2} \mathrm{O} \rightarrow 2 \mathrm{CO}_{2}+\mathrm{Cl}^{-}+11 \mathrm{H}^{+}+10 \mathrm{e}^{-} \\
\mathrm{C}_{2} \mathrm{H}_{5} \mathrm{OH}+3 \mathrm{H}_{2} \mathrm{O} \rightarrow 2 \mathrm{CO}_{2}+12 \mathrm{H}^{+}+12 \mathrm{e}^{-} \\
\mathrm{CH}_{3} \mathrm{OH}+\mathrm{H}_{2} \mathrm{O} \rightarrow \mathrm{CO}_{2}+6 \mathrm{H}^{+}+6 \mathrm{e}^{-} \\
\mathrm{C}_{2} \mathrm{H}_{6}+\mathrm{H}_{2} \mathrm{O} \rightarrow \mathrm{C}_{2} \mathrm{H}_{5} \mathrm{OH}+2 \mathrm{H}^{+}+2 \mathrm{e}^{-} \\
\mathrm{CHBr}_{3}+\mathrm{H}_{2} \mathrm{O}+\mathrm{H}^{+}+4 \mathrm{e}^{-} \rightarrow \mathrm{CH}_{3} \mathrm{OH}+3 \mathrm{Br}^{-} \\
\mathrm{CCl}_{4}+\mathrm{H}_{2} \mathrm{O}+2 \mathrm{H}^{+}+6 \mathrm{e}^{-} \rightarrow \mathrm{CH}_{3} \mathrm{OH}+4 \mathrm{Cl}^{-} \\
\mathrm{CH}_{4}+\mathrm{H}_{2} \mathrm{O} \rightarrow \mathrm{CH}_{3} \mathrm{OH}^{-}+2 \mathrm{H}^{+}+2 \mathrm{e}^{-} \\
\mathrm{CH}_{4}+2 \mathrm{H}_{2} \mathrm{O} \rightarrow \mathrm{CO}_{2}+8 \mathrm{H}^{+}+8 \mathrm{e}^{-} \\
\mathrm{C}_{2} \mathrm{H}_{6}+4 \mathrm{H}_{2} \mathrm{O} \rightarrow 2 \mathrm{CO}_{2}+14 \mathrm{H}^{+}+14 \mathrm{e}^{-} \\
\mathrm{CHBr}_{3}+3 \mathrm{H}^{+}+6 \mathrm{e}^{-} \rightarrow \mathrm{CH}_{4}+3 \mathrm{Br}^{-} \\
\mathrm{CCl}_{4}+4 \mathrm{H}^{+}+8 \mathrm{e}^{-} \rightarrow \mathrm{CH}_{4}+4 \mathrm{Cl}^{-} \\
\mathrm{C}_{6} \mathrm{H}_{4} \mathrm{Cl}_{2}+20 \mathrm{H}^{+}+22 \mathrm{e}^{-} \rightarrow 6 \mathrm{CH}_{4}+2 \mathrm{Cl}^{-} \\
\mathrm{CCl}_{4}+2 \mathrm{H}_{2} \mathrm{O} \rightarrow \mathrm{CO}_{2}+4 \mathrm{H}^{+}+4 \mathrm{Cl}^{-} \\
\mathrm{C}_{6} \mathrm{H}_{4} \mathrm{Cl}_{2}+12 \mathrm{H}_{2} \mathrm{O} \rightarrow 6 \mathrm{CO}_{2}+2 \mathrm{Cl}^{-}+28 \mathrm{H}^{+}+26 \mathrm{e}^{-} \\
\mathrm{C}_{2} \mathrm{Cl}_{6}+6 \mathrm{H}^{+}+12 \mathrm{e}^{-} \rightarrow \mathrm{C}_{2} \mathrm{H}_{6}+6 \mathrm{Cl}^{-} \\
\mathrm{CHBr}_{3}+2 \mathrm{H}_{2} \mathrm{O} \rightarrow \mathrm{CO}_{2}+3 \mathrm{Br}^{-}+5 \mathrm{H}^{+}+2 \mathrm{e}^{-} \\
\mathrm{C}_{2} \mathrm{H}_{4}+4 \mathrm{H}_{2} \mathrm{O} \rightarrow 2 \mathrm{CO}_{2}+12 \mathrm{H}^{+}+12 \mathrm{e}^{-}\end{array}$ & $\begin{array}{r}-34.83 \\
32.14 \\
24.14 \\
39.66 \\
18.20 \\
-17.24 \\
1.55 \\
-21.18 \\
-4.62 \\
-12.71 \\
43.48 \\
70.78 \\
-16.86 \\
-21.47 \\
-33.89 \\
60.33 \\
87.64 \\
95.89 \\
66.17 \\
-32.95 \\
131.39 \\
38.86 \\
-16.74\end{array}$ & $\begin{array}{l}1.00 \times 10^{-11} \\
2.30 \times 10^{-7} \\
5.00 \times 10^{-9} \\
8.02 \times 10^{-8} \\
8.02 \times 10^{-8} \\
8.02 \times 10^{-8} \\
8.02 \times 10^{-8} \\
8.02 \times 10^{-8} \\
8.02 \times 10^{-8} \\
8.02 \times 10^{-8} \\
2.00 \times 10^{-11} \\
8.02 \times 10^{-11} \\
8.02 \times 10^{-8} \\
8.02 \times 10^{-8} \\
8.02 \times 10^{-8} \\
7.00 \times 10^{-10} \\
8.02 \times 10^{-11} \\
3.00 \times 10^{-10} \\
2.00 \times 10^{-9} \\
4.60 \times 10^{-8} \\
8.02 \times 10^{-10} \\
3.40 \times 10^{-8} \\
8.02 \times 10^{-8}\end{array}$ \\
\hline
\end{tabular}

Equilibrium constants caiculated from Wagman et al. (1968), Dean (1979), and MacKay and Shin (1981). Kinetic rate constants for the five original species injected at the Borden site calculated from the data of Roberts et al. (1986).

- The kinetic dala presented here are completely artificial and are used for demonstration purposes only. Such data are not to be used in evaluating the fate of any of the species mentioned for any real contamination site. 
Table 5.5

Retardation of Original Organic Species

\begin{tabular}{|l|l|}
\hline Species & Velocity Equation* \\
\hline$C^{-}$ & $v=0.117 \mathrm{t}^{-0.045}$ \\
CTET & $v=0.086 \mathrm{t}^{-0.140}$ \\
BROM & $\mathrm{v}=0.082 \mathrm{t}^{-0.148}$ \\
PCE & $v=0.075 \mathrm{t}^{-0.249}$ \\
DCB & $v=0.054 \mathrm{t}^{-0.264}$ \\
HCE & $v=0.046 \mathrm{t}^{-0.301}$ \\
\hline
\end{tabular}

- From Roberts es al. (1986). 
Table 5.6

Initial Contaminant Concentrations for Transport Simulation

\begin{tabular}{|l|l|}
\hline \multicolumn{1}{|c|}{ Species } & Conc.(moles/meter ${ }^{3}$ ) \\
\hline $\mathrm{C}_{2} \mathrm{Cl}_{6}$ & $7.68 \times 10^{-6}$ \\
$\mathrm{C}_{2} \mathrm{Cl}_{4}$ & $1.64 \times 10^{-5}$ \\
$\mathrm{C}_{2} \mathrm{HCl}_{3}$ & 0.0 \\
$\mathrm{C}_{2} \mathrm{H}_{3} \mathrm{Cl}$ & 0.0 \\
$\mathrm{CCl}_{4}$ & $1.83 \times 10^{-5}$ \\
$\mathrm{CHBr}_{3}$ & $1.15 \times 10^{-5}$ \\
$\mathrm{C}_{6} \mathrm{H}_{4} \mathrm{Cl}_{2}$ & $2.05 \times 10^{-4}$ \\
$\mathrm{CH}_{4}$ & 0.0 \\
$\mathrm{CH}_{3} \mathrm{OH}$ & 0.0 \\
$\mathrm{C}_{2} \mathrm{H}_{6}$ & 0.0 \\
$\mathrm{C}_{2} \mathrm{H}_{5} \mathrm{CH}$ & 0.0 \\
$\mathrm{C}_{2} \mathrm{H}_{4}$ & 0.0 \\
$\mathrm{CO}_{2}$ (total) & 1.748 \\
$\mathrm{C}^{-}$ & 2.287 \\
$\mathrm{Br}^{-}$ & 0.369 \\
\hline
\end{tabular}




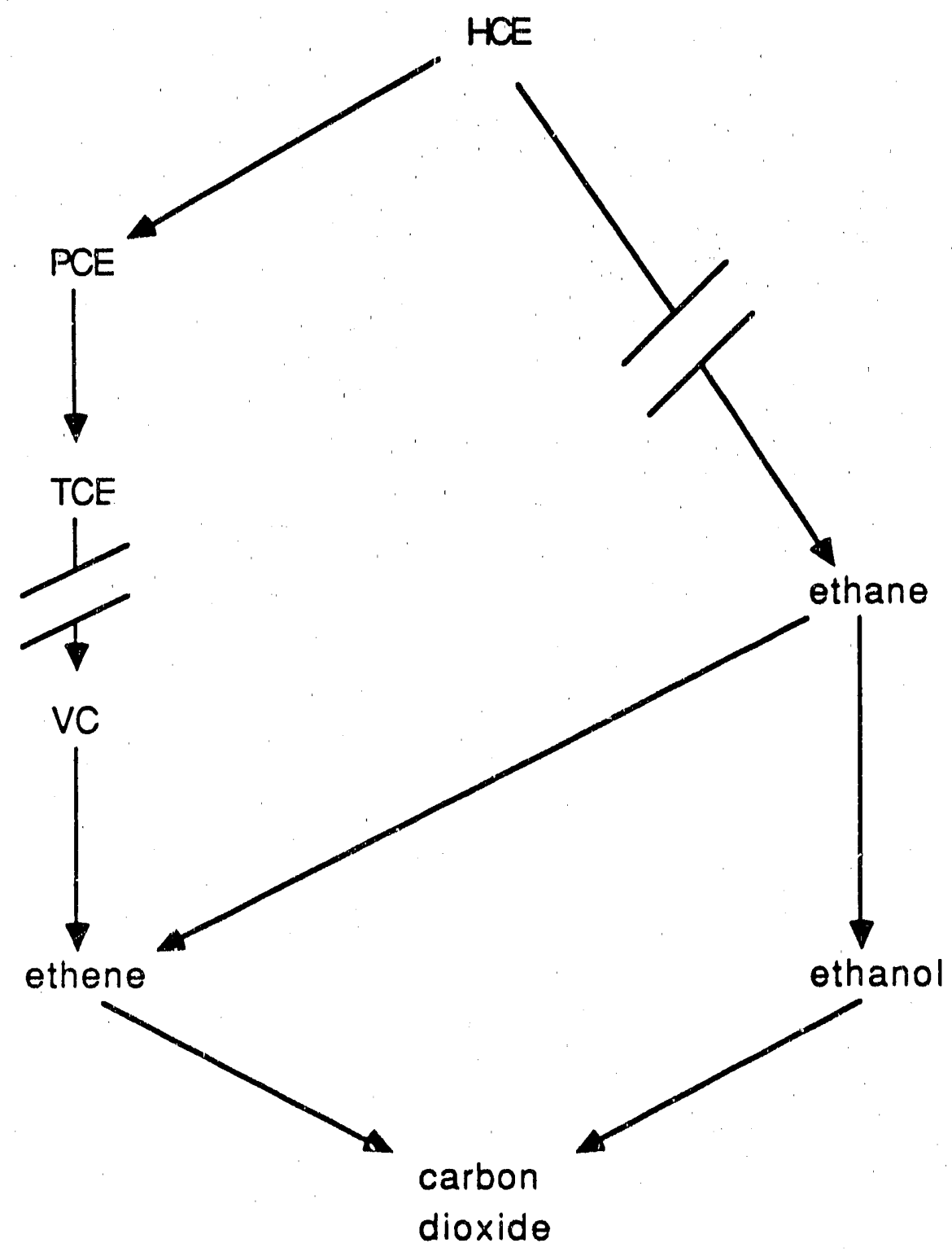

Figure 5.1. Possible degradation pathways for the transformation of hexacliloroethane. 


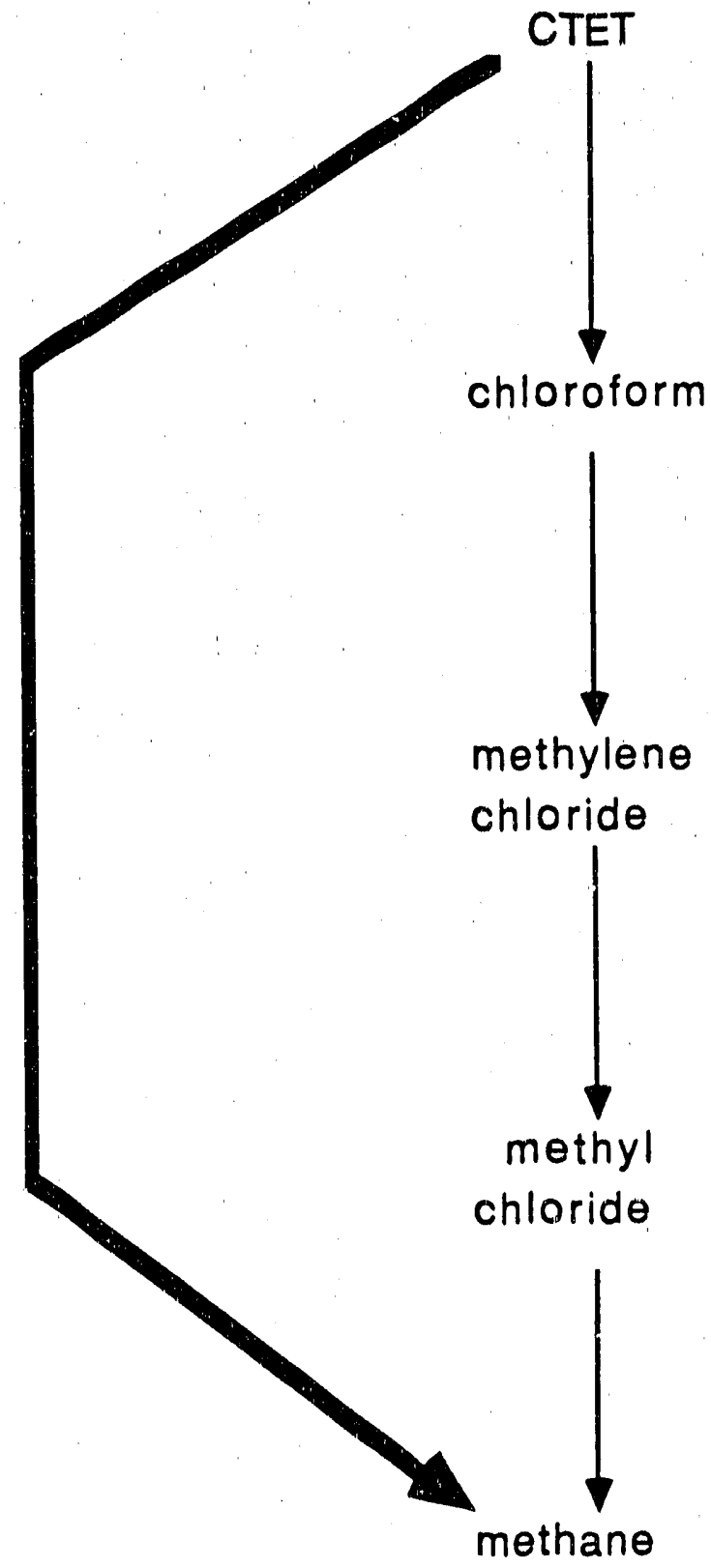

Figure 5.2. Simplified degradation scheme for the reductive dehalogenation of carton tetrachloride. 


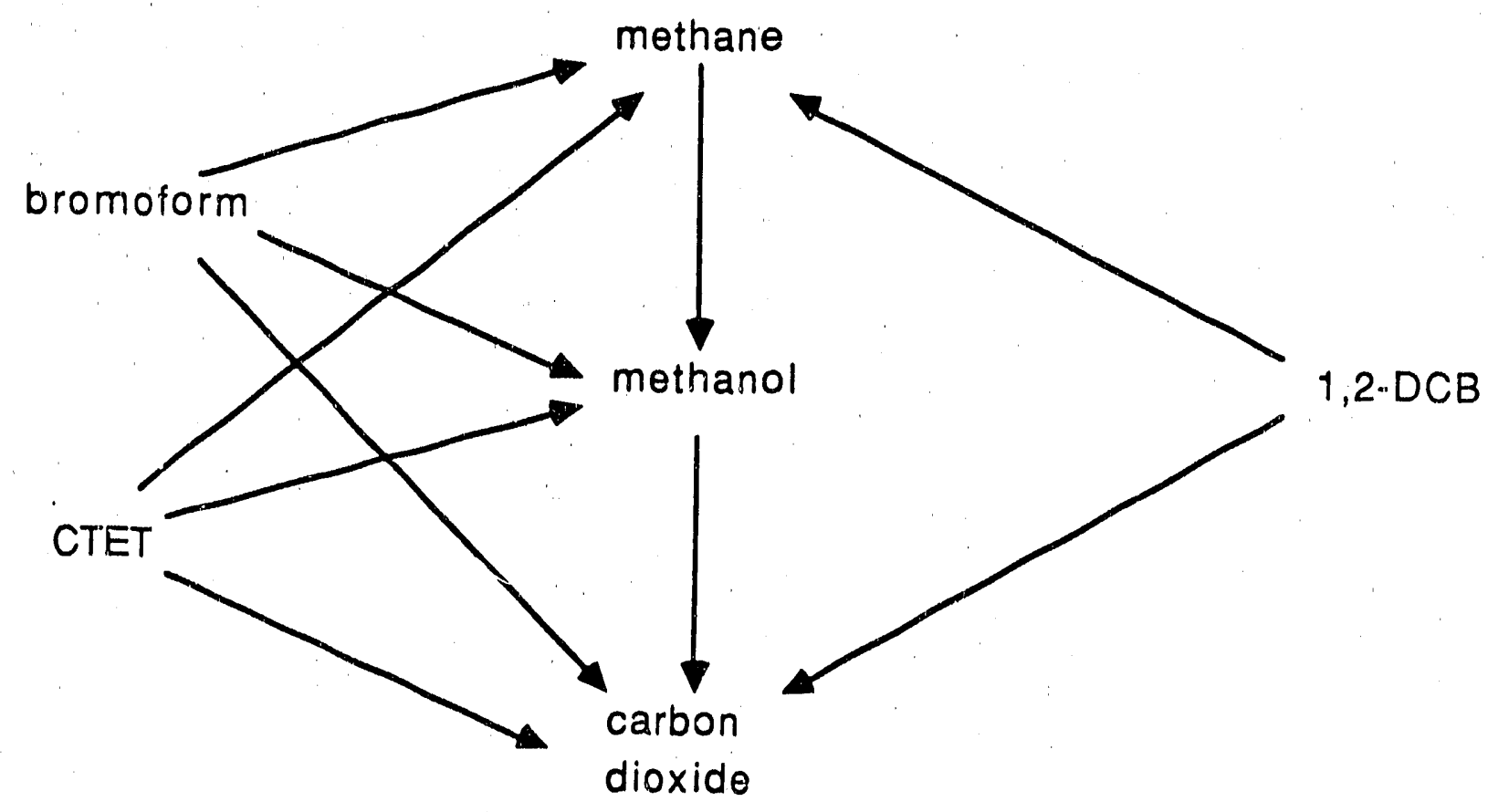

Figure 5.3. Simplified degradation scheme for the degradation of bromoform, carbon tetrachloride, and 1,2-dichlorobenzene. 


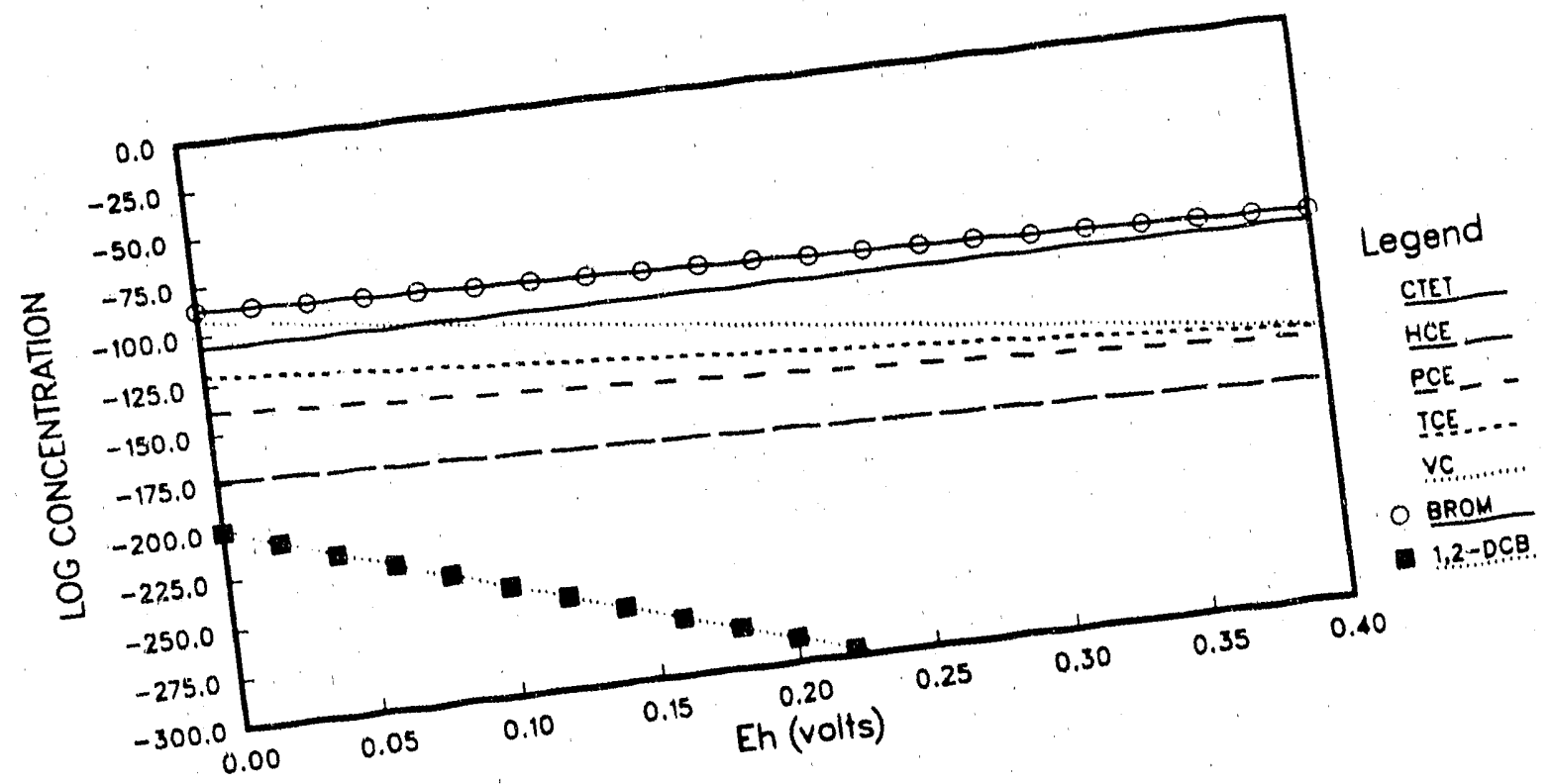

equilibrium concentrations of the chlorinated hydrocarbon species at $\mathrm{pH}=7.6$.

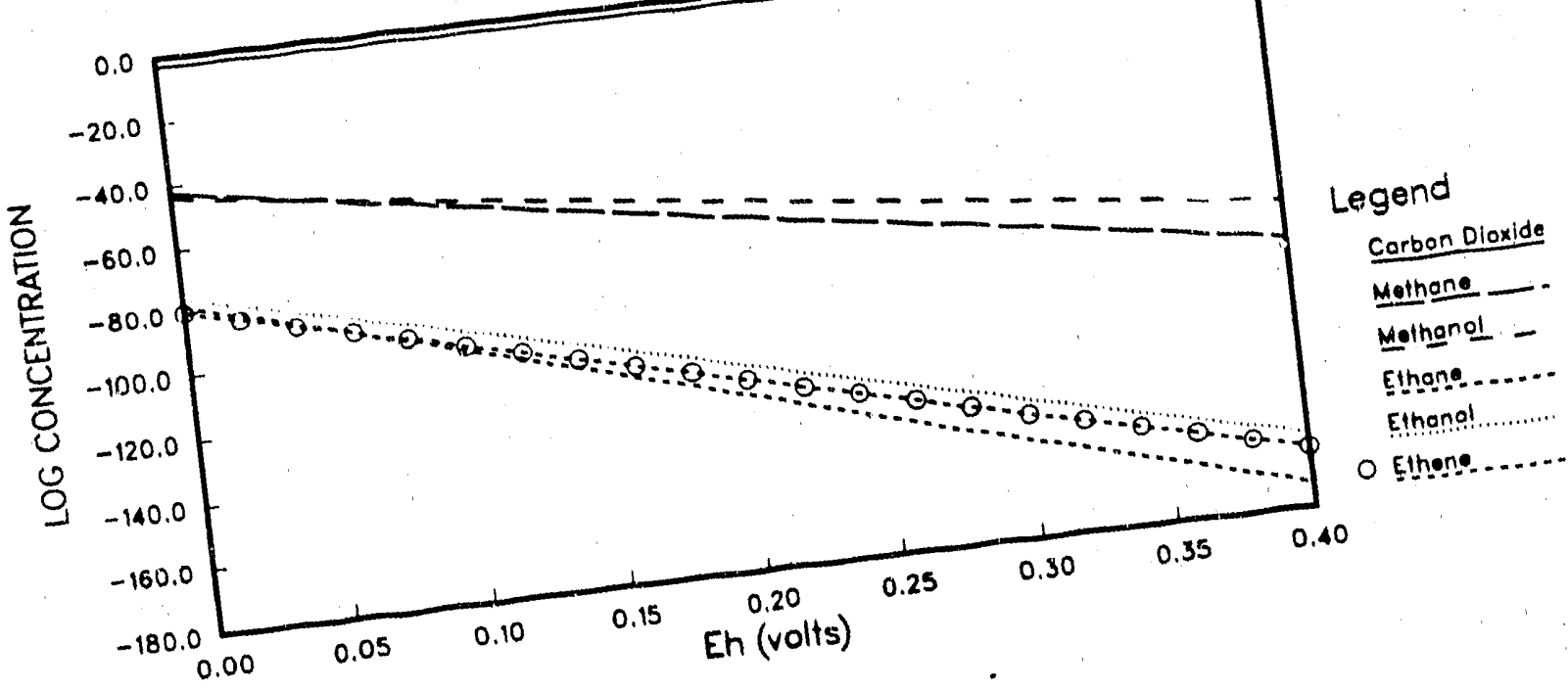

Figure 5.5. Hypothetical equilibrium concentrations of the secondary hydrocarbon species at

$$
\mathrm{pH}=7.6 \text {. }
$$


upstream node

utilized to assess

any upstream diffusion

by strongly retardated

contaminants

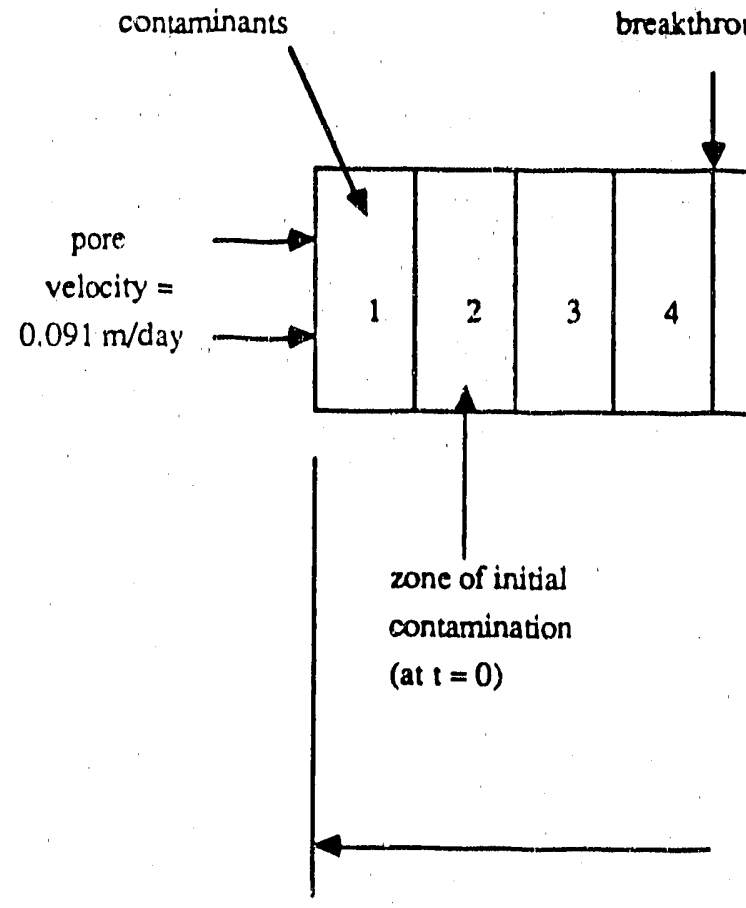

sampling plane

location for

breakthrough curves
$10 \mathrm{~m} \times 10 \mathrm{~m}$

cross-sectional area

40 meters

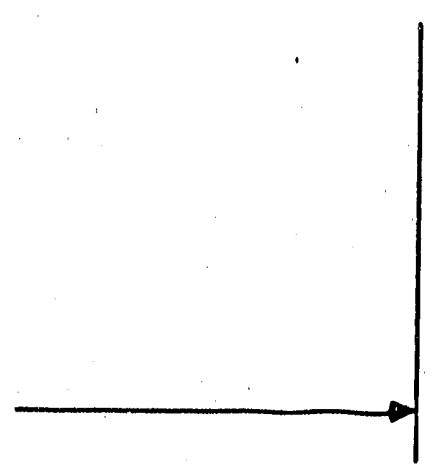

Figure 5.6. Physical configuration of the transport problem. 


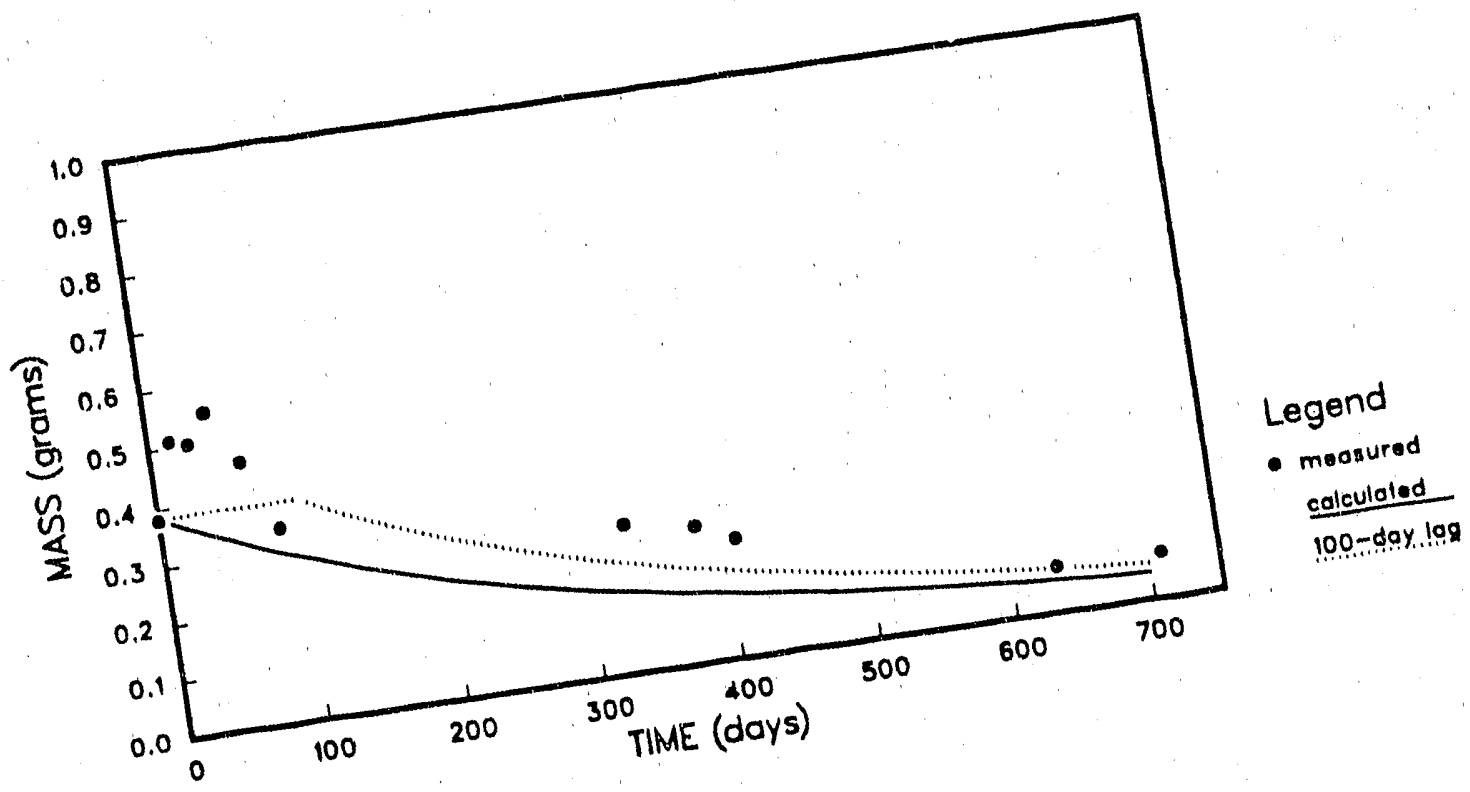

bromoform in the batch simulation over time.

(Experimental data from Roberts et al.. (1986).)

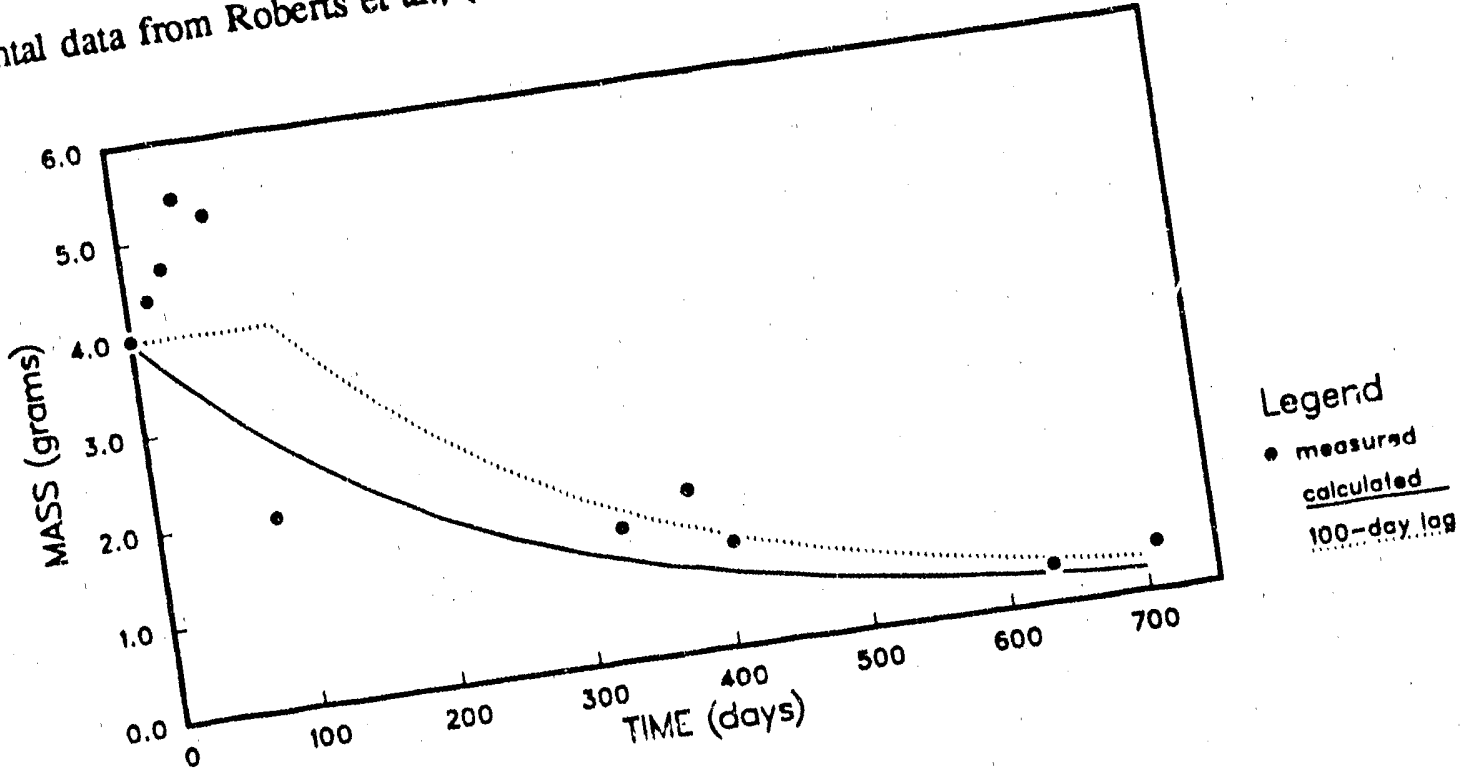

Figure 5.8. Evolution of the total mass of 1,2-dich

the batch simulation over 


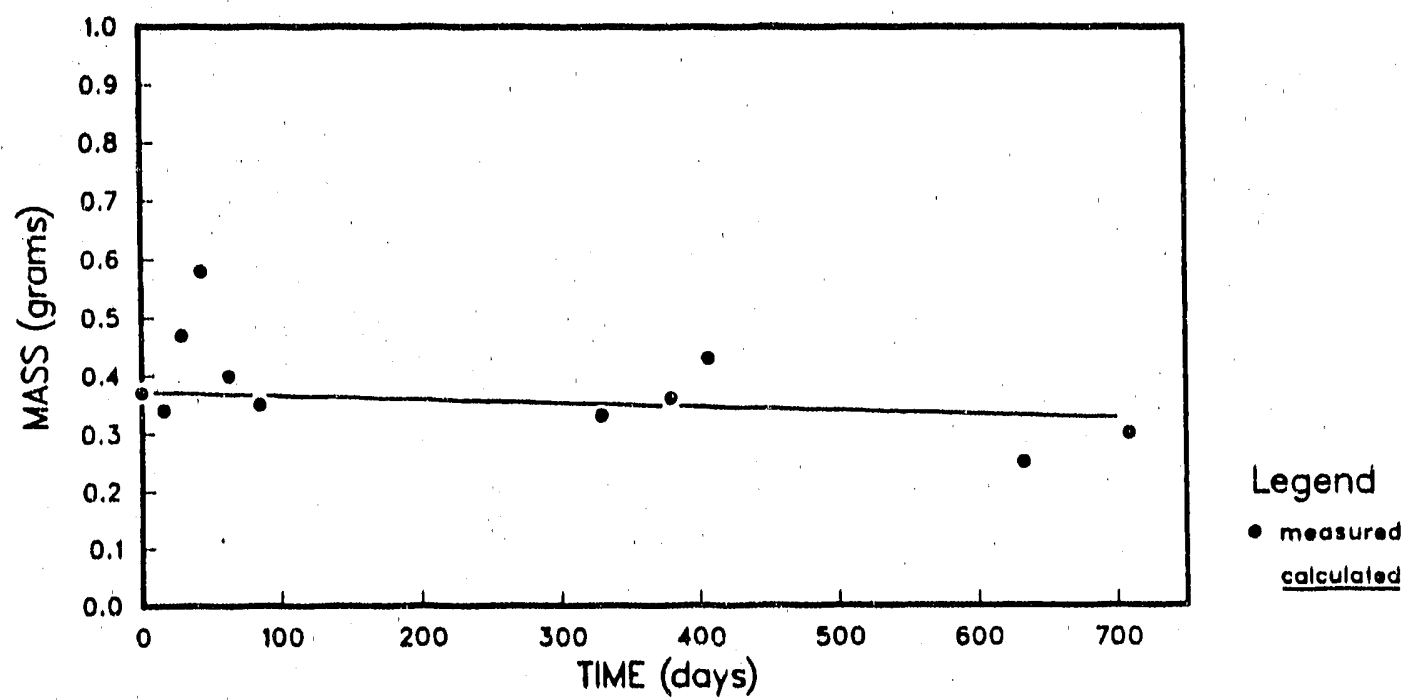

Figure 5.9. Evolution of the Lotal mass of carbon tetrachloride in the batch simulation over time. (Experimental data from Roberts et al., (1986).)

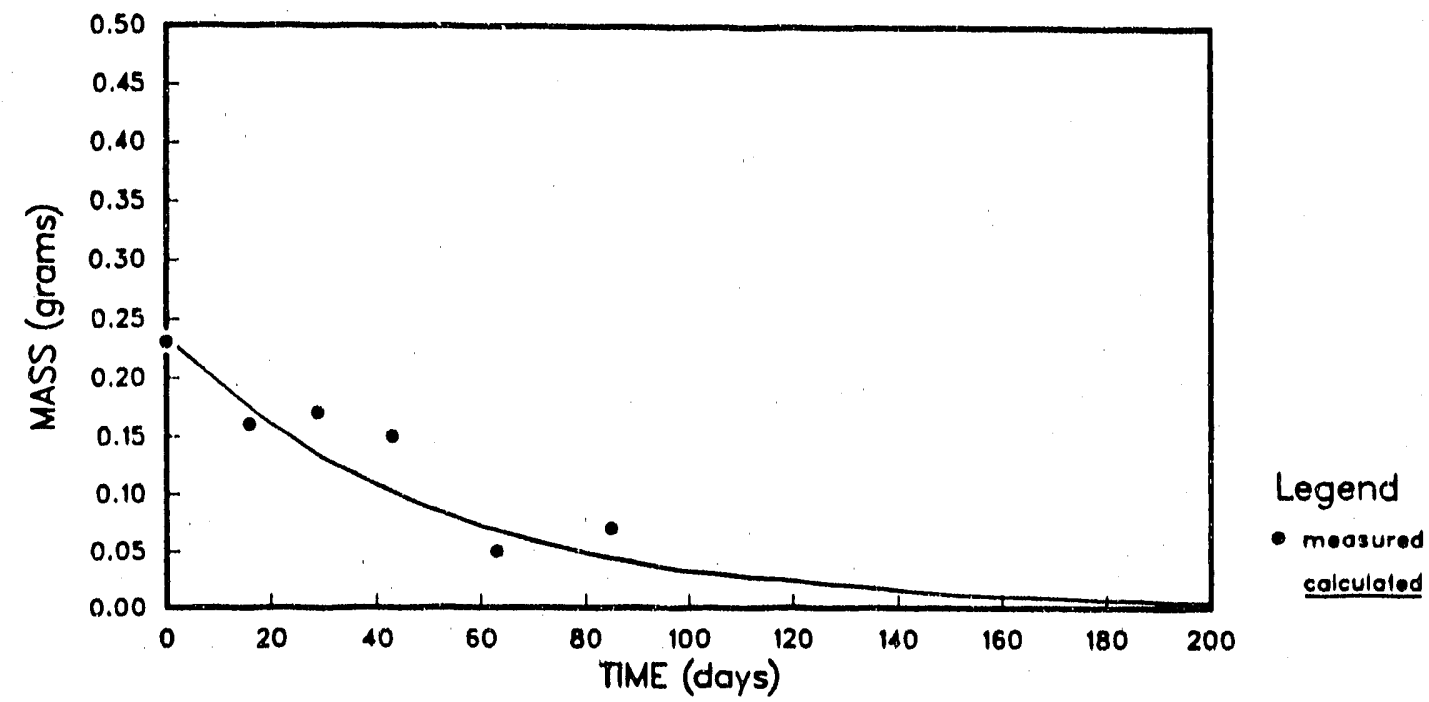

Figure 5.10. Evolution of the total mass of hexachloroethane in the batch simulation over time. (Experimental data from Roberts et al., (1986).) 


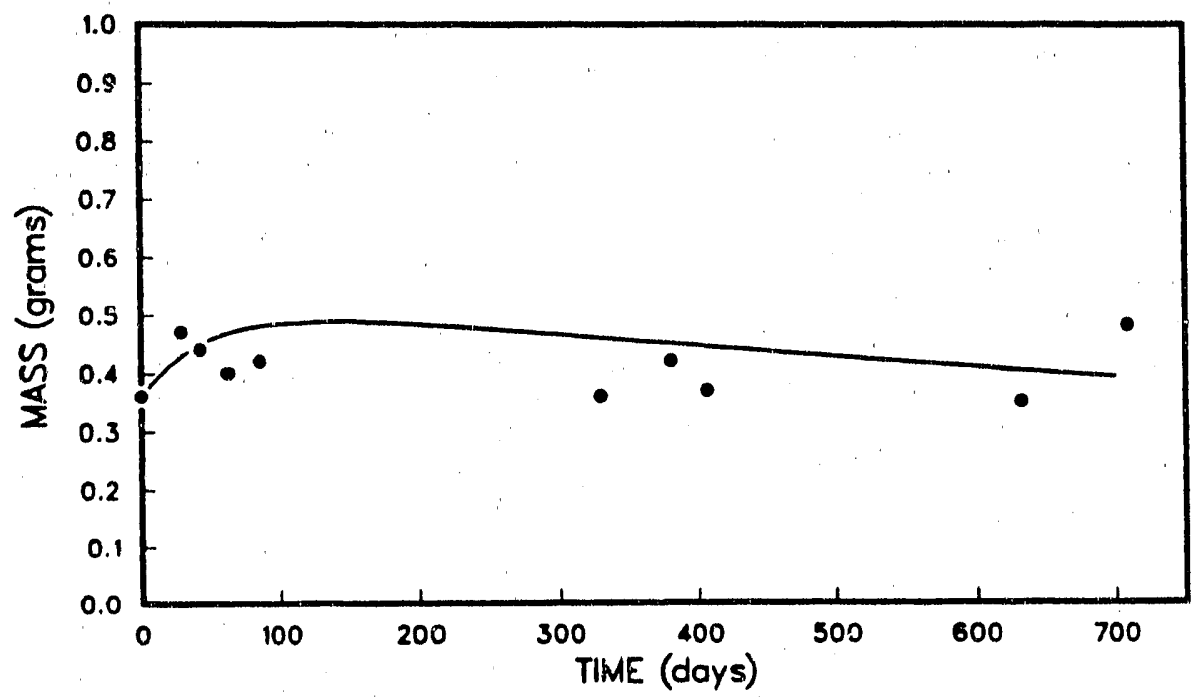

Legend

- meosured

colculoled

Figure 5.11. Evolution of the total mass of tetrachloroethylene in the batch simulation over time. (Experimental data from Roberts et al., (1986).)

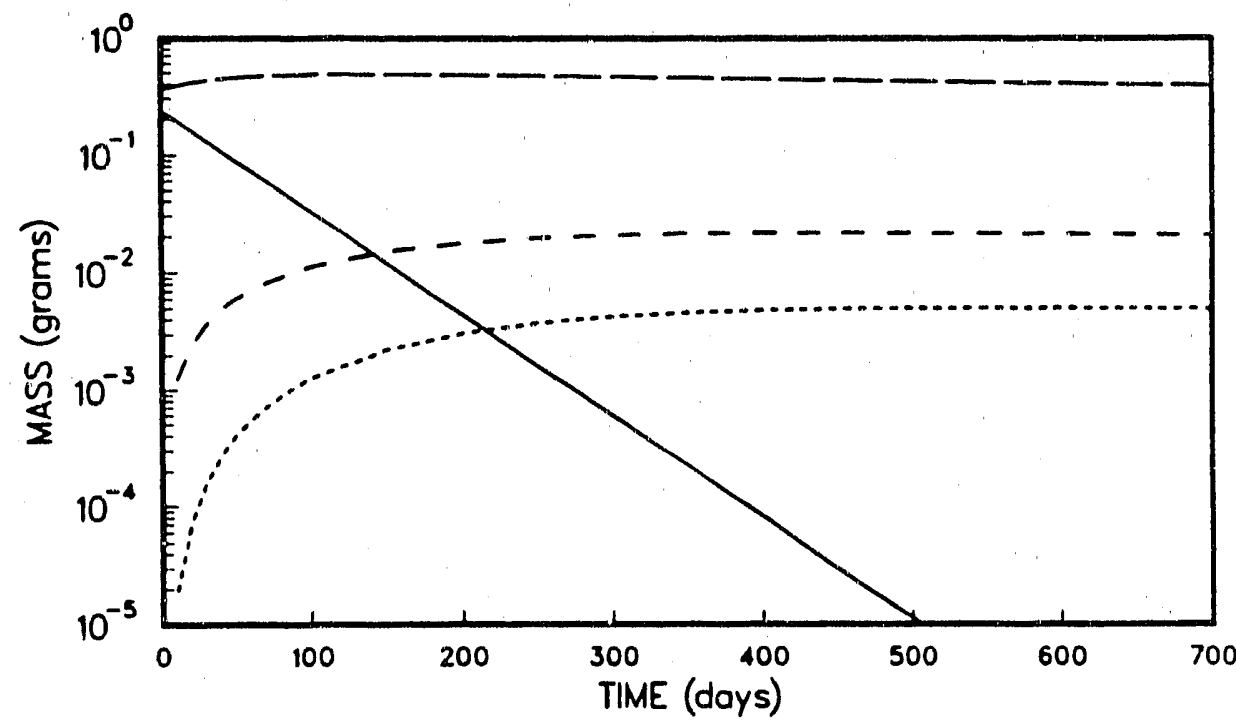

Legend

HCE

PCE

ICE - -

vc.......

Figure 5.12. Comparative temporal evolution of the chlorinated two-carbon hydrocarbons during the batch simulation. 


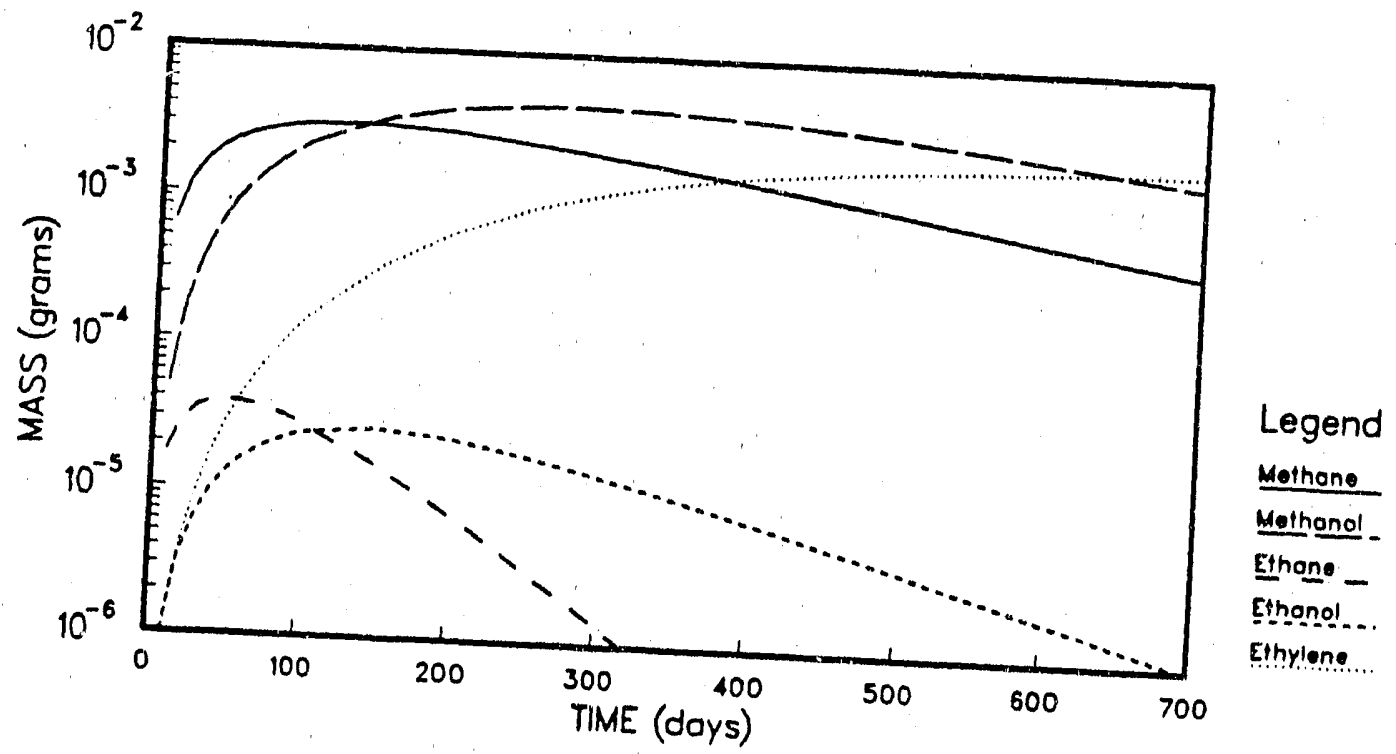
Figure 5.13. Comparative temporal evolution of the secondary hydrocarbons during the batch
simulation. 


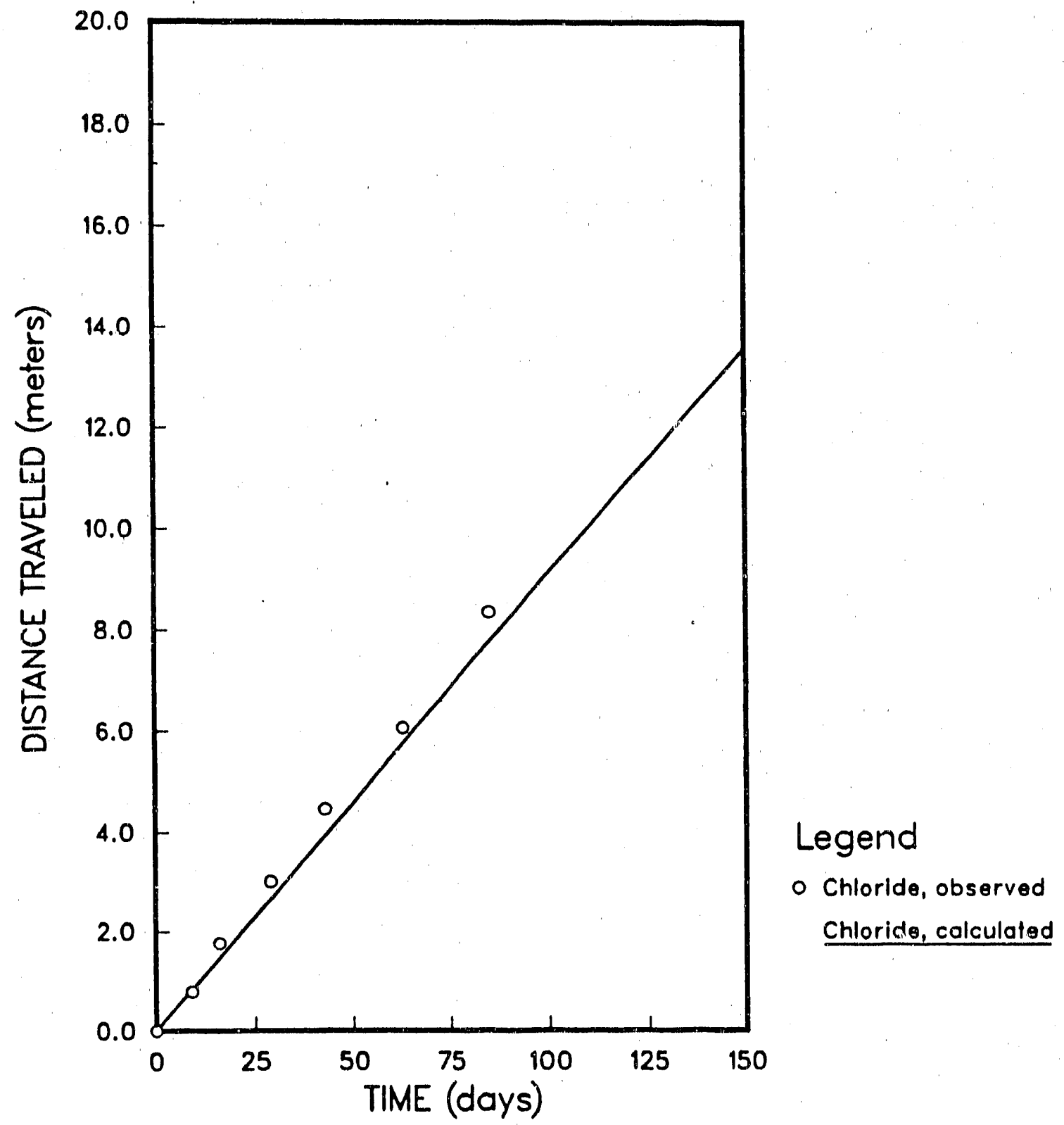

Figure 5.14. Center of mass location of the chloride plume during the transport simulation. (Experimental data from Roberts et al., (1986).) 


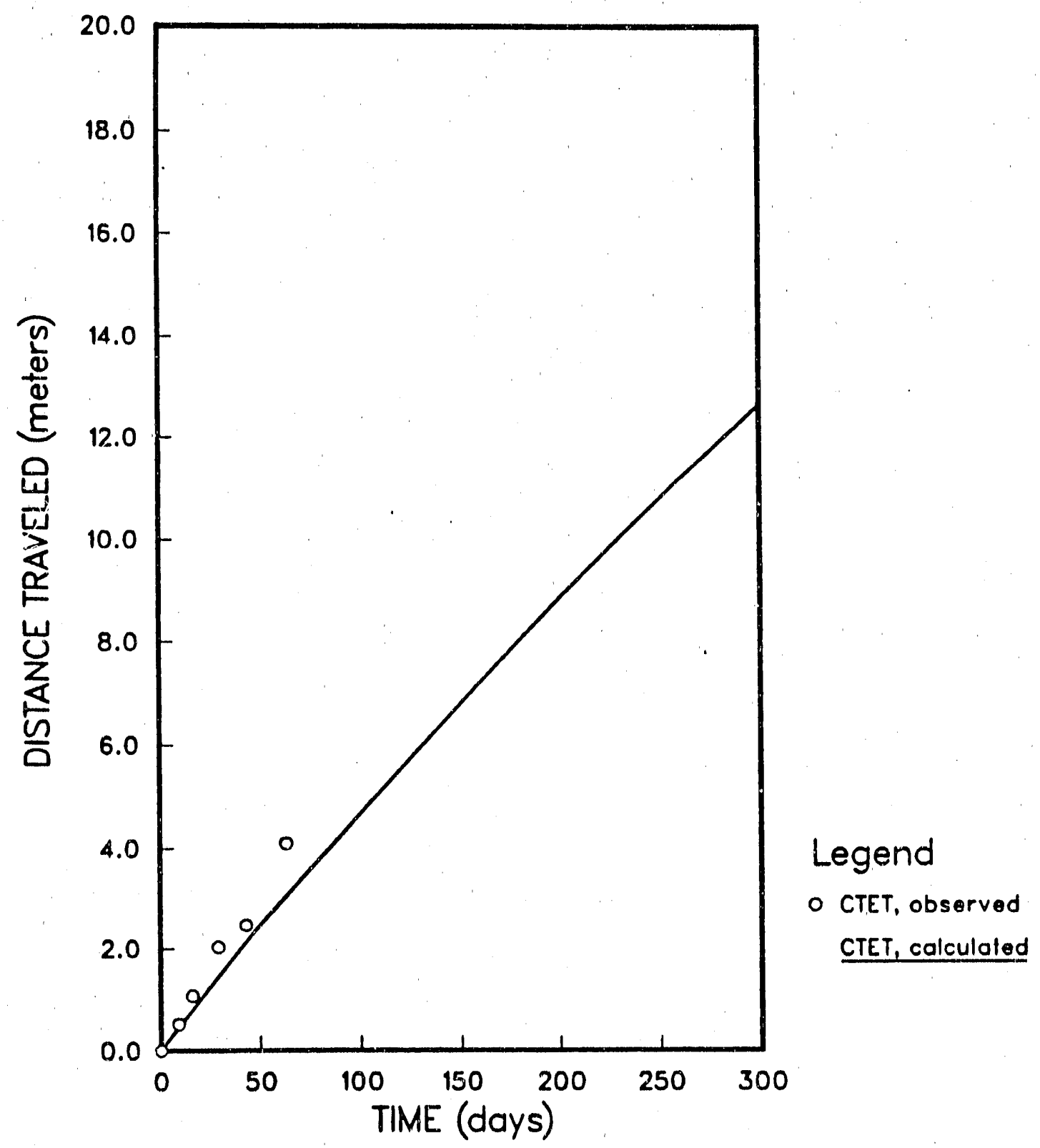

Figure 5.15. Center of mass location of the carbon tetrachloride plume during the transport simulation. (Experimental data from Roberts et al., (1986).) 


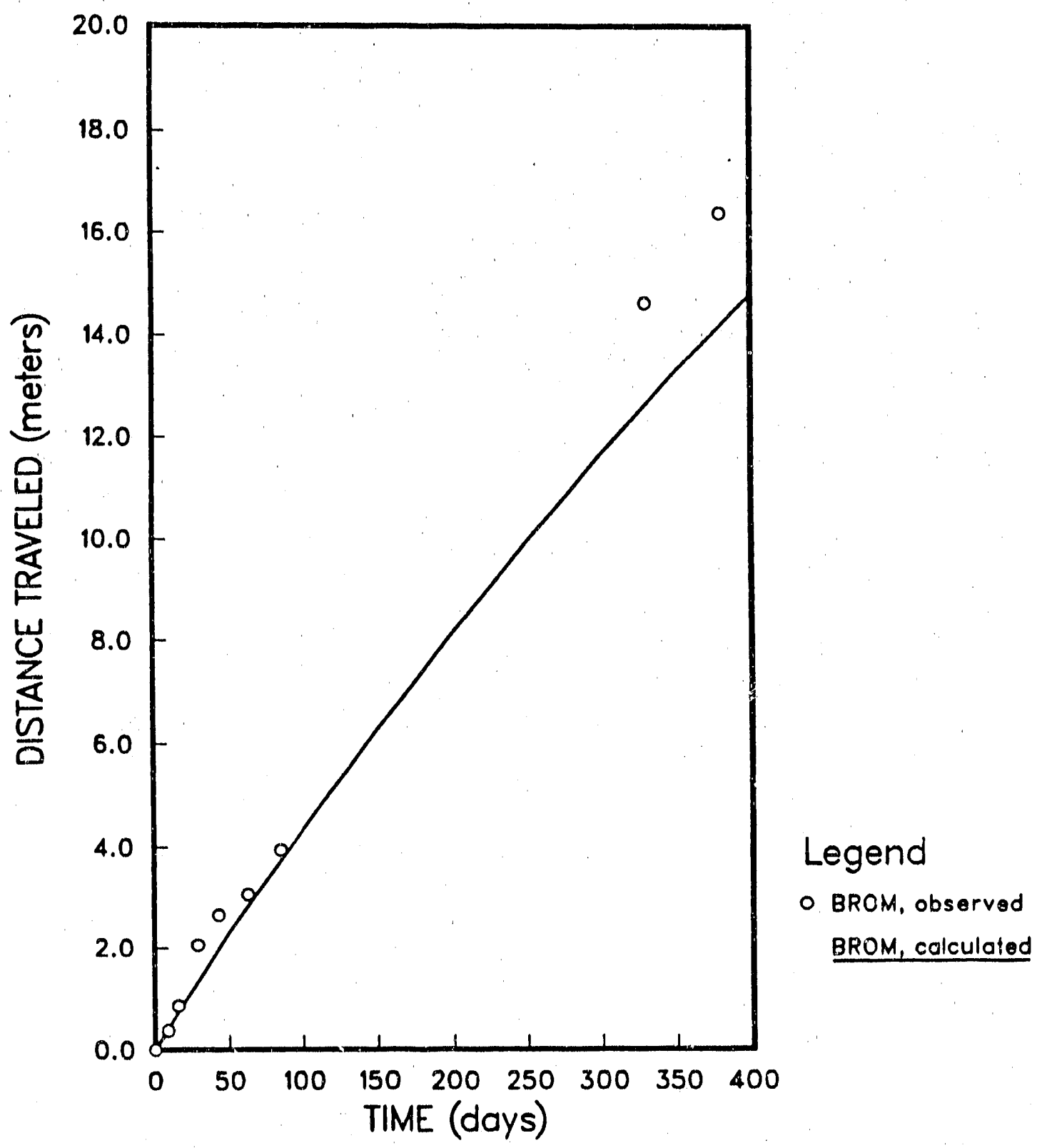

Figure 5.16. Center of mass location of the bromoform plume during the transport simulation. (Experimental data from Roberts et al., (1986).) 


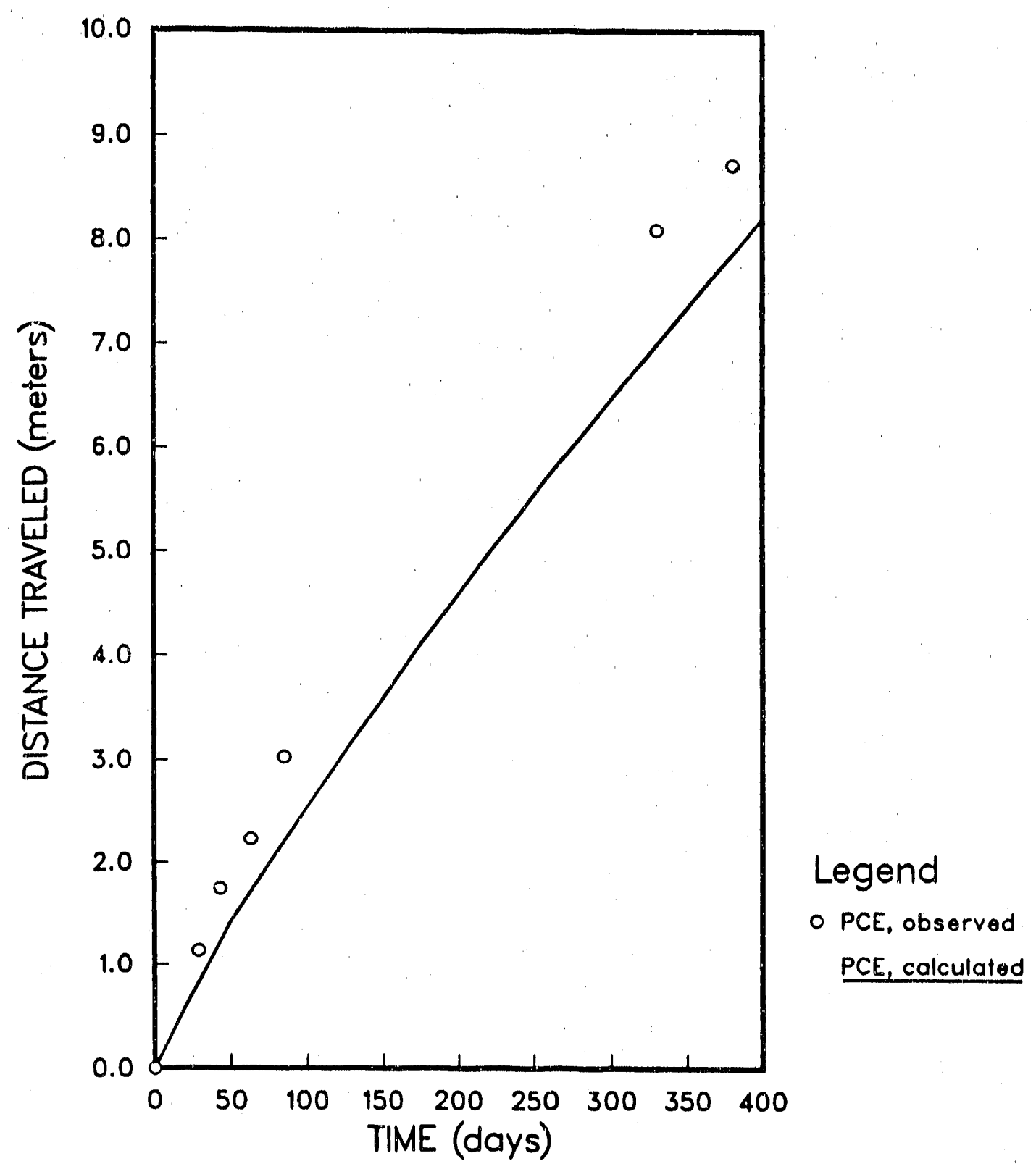

Figure 5.17. Center of mass location of the tetrachloroethylene plume during the transport simulation. (Experimental data from Roberts et al., (1986).) 


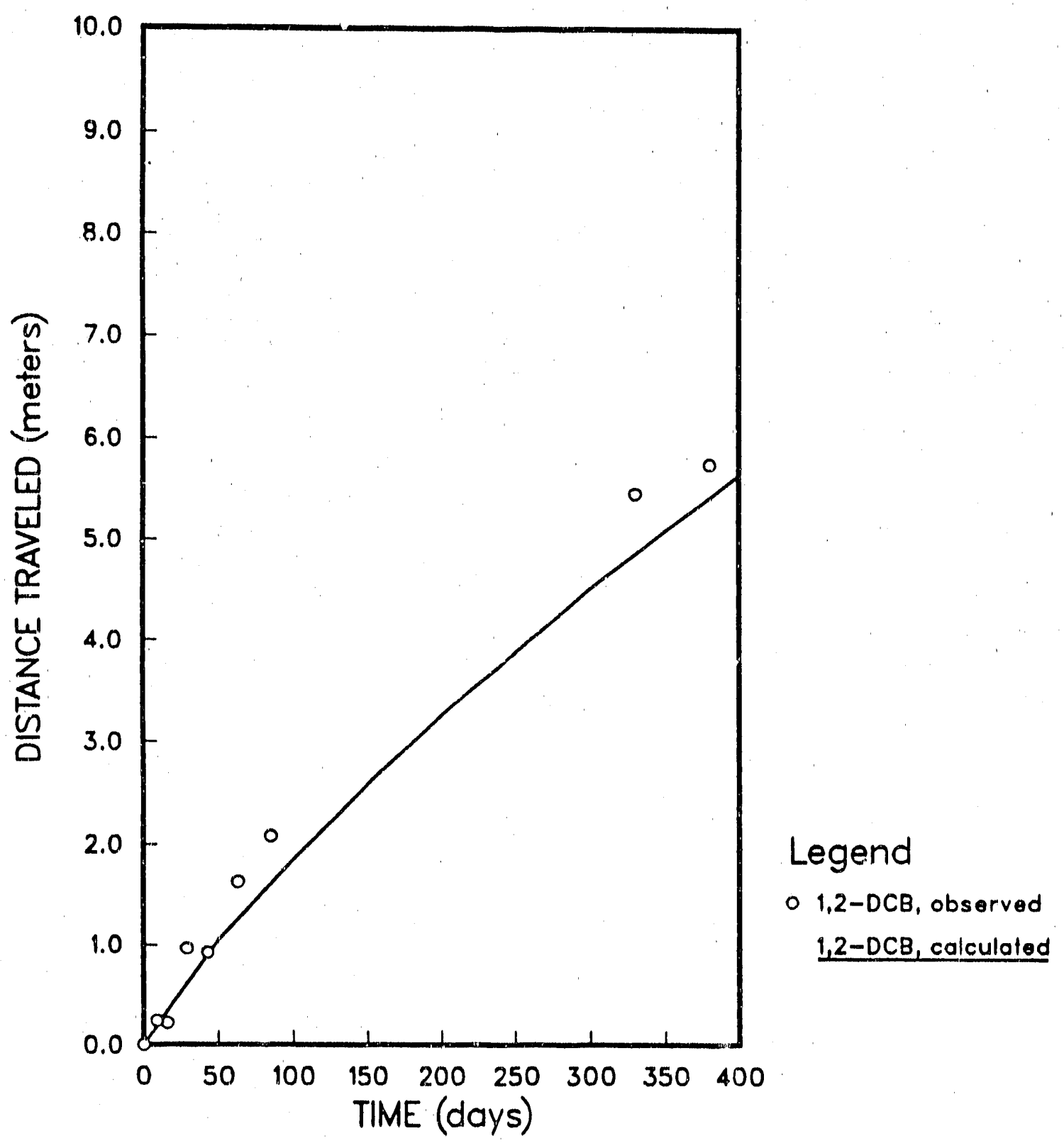

Figure 5.18. Center of mass location of the 1,2-dichlorobenzene plume during the transport simulation. (Experimental data from Roberts et al., (1986).) 


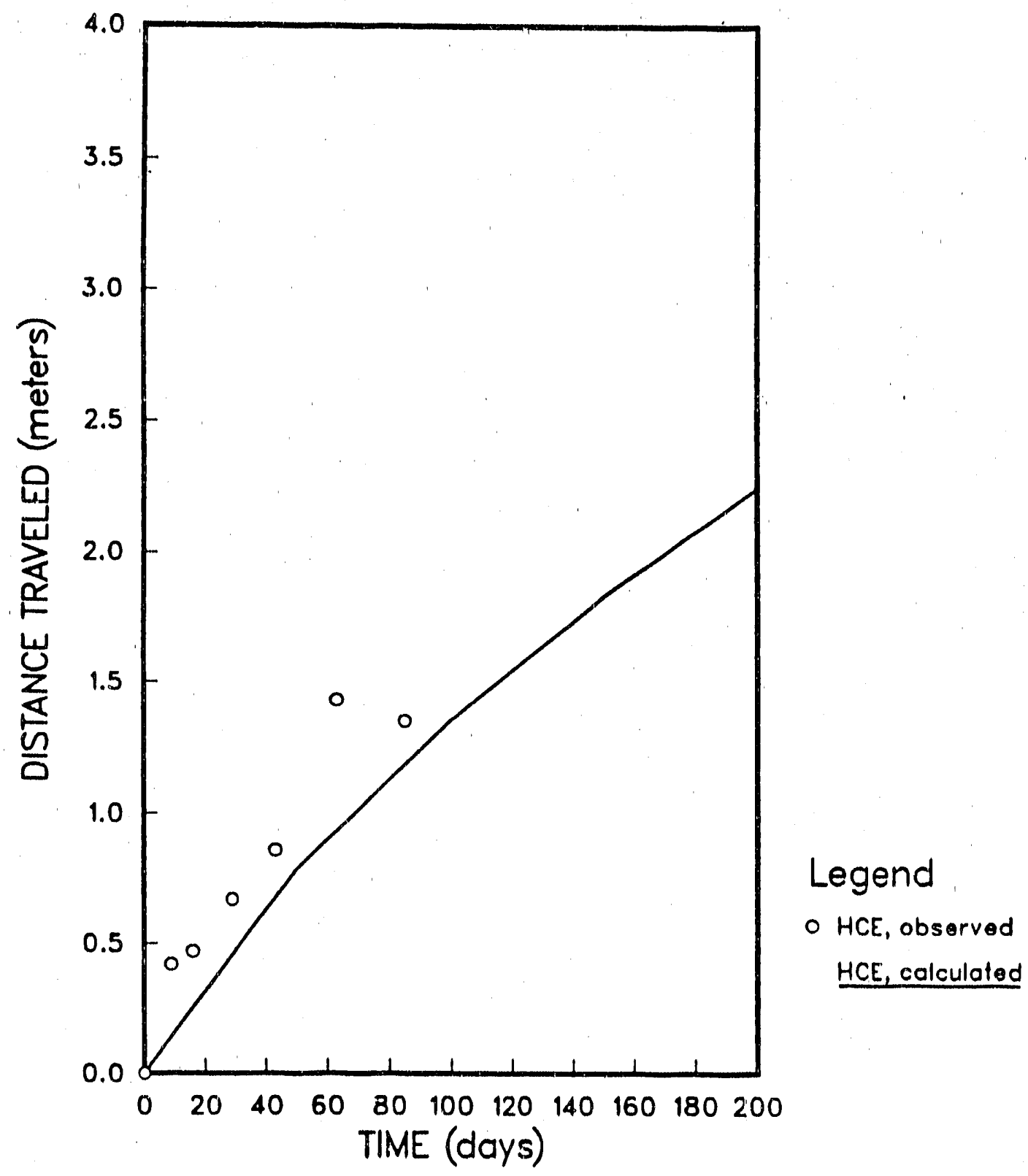

Figure 5.19. Center of mass location of the hexachloroethane plume during the transport simulation. (Experimental data from Roberts et al., (1986).) 


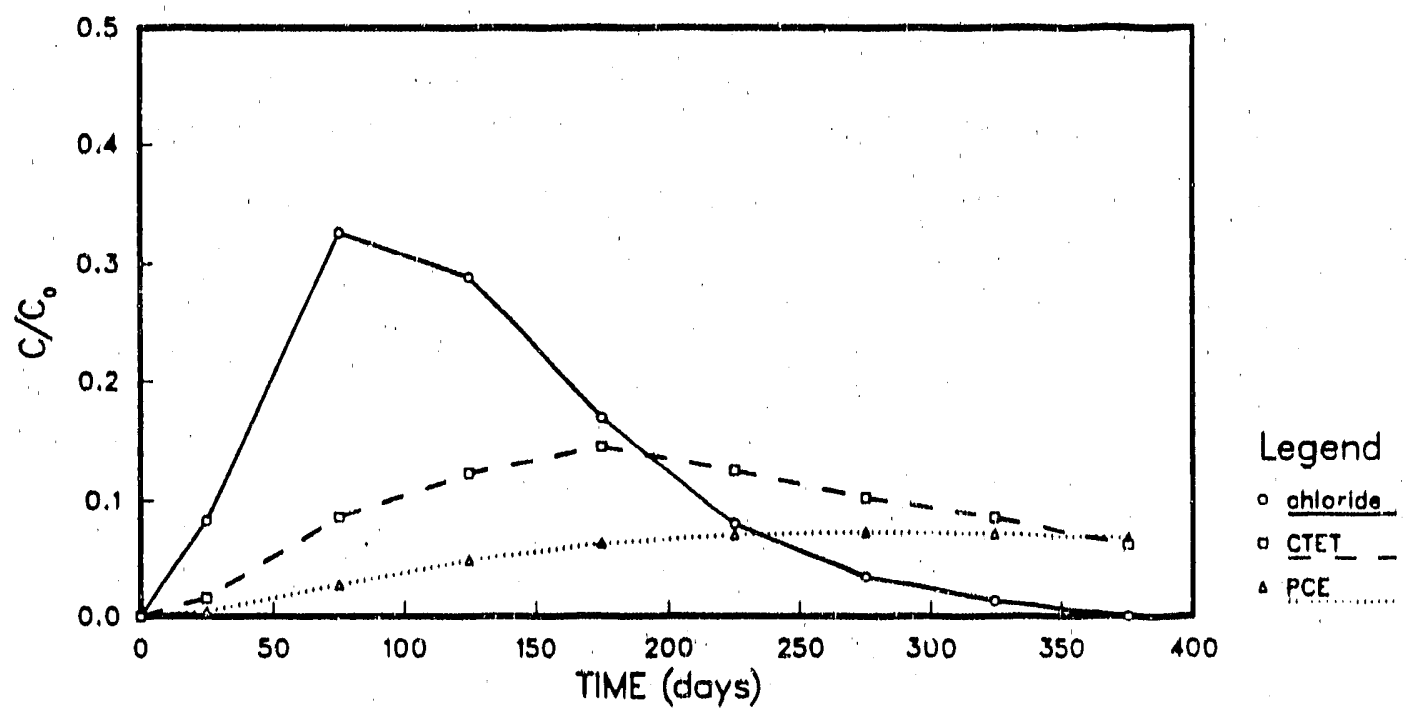

Figure 5.20. Breakthrough curves for chloride, carbon tetrachloride, and tetrachloroethylene at $10 \mathrm{~m}$ from the source.

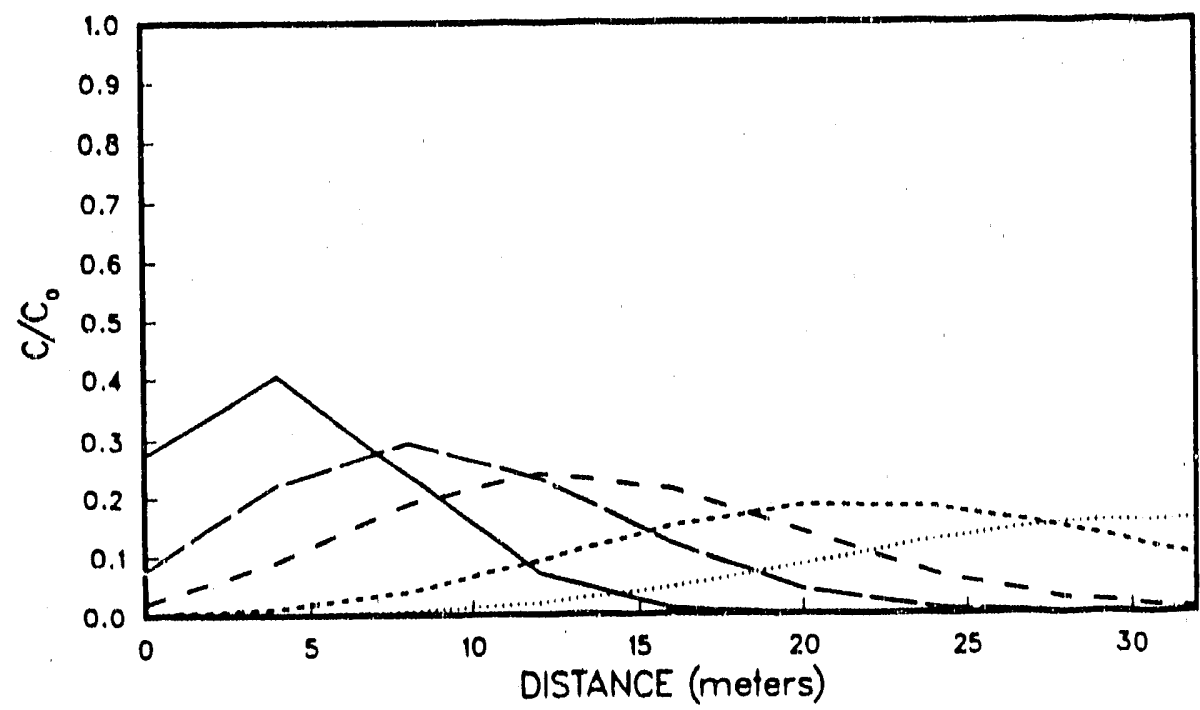

Legend

50 days

100 doys.

150 doys

250 doys.

350 doys

Figure 5.21. Evolution of chloride plume over time through the soil column, showing clear evidence of dispersion. 


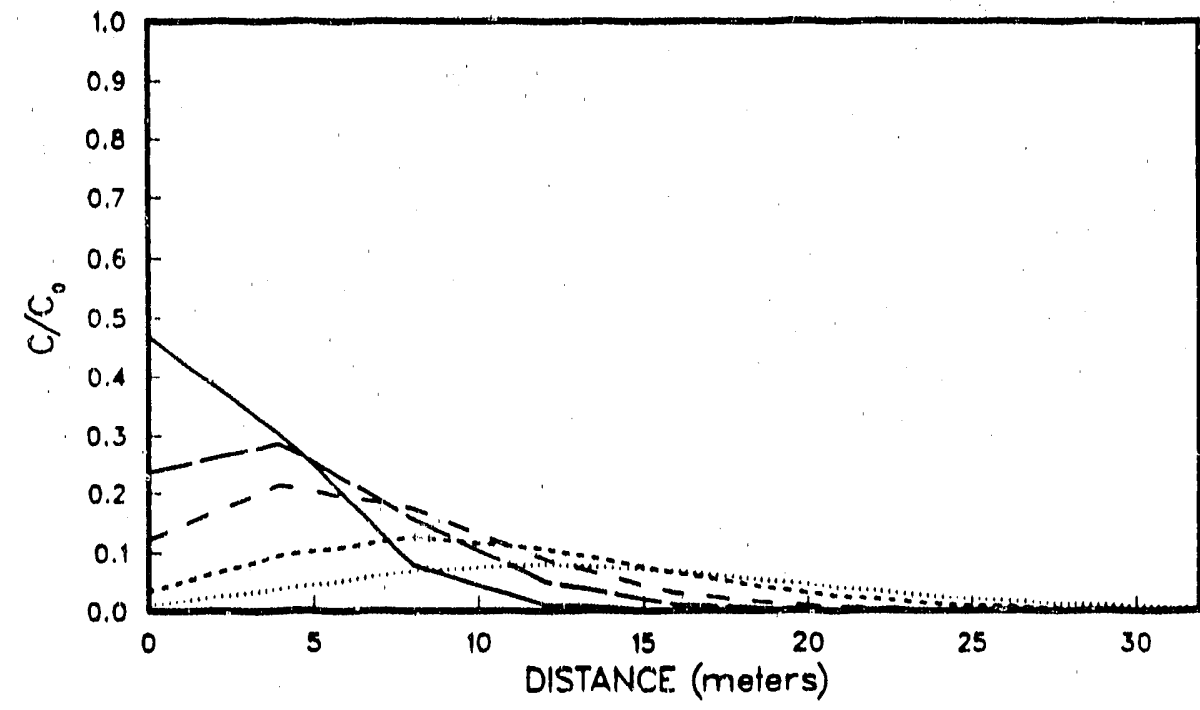

Legend

Figure 5.22. Evolution of bromoform plume profile in the soil column over time.

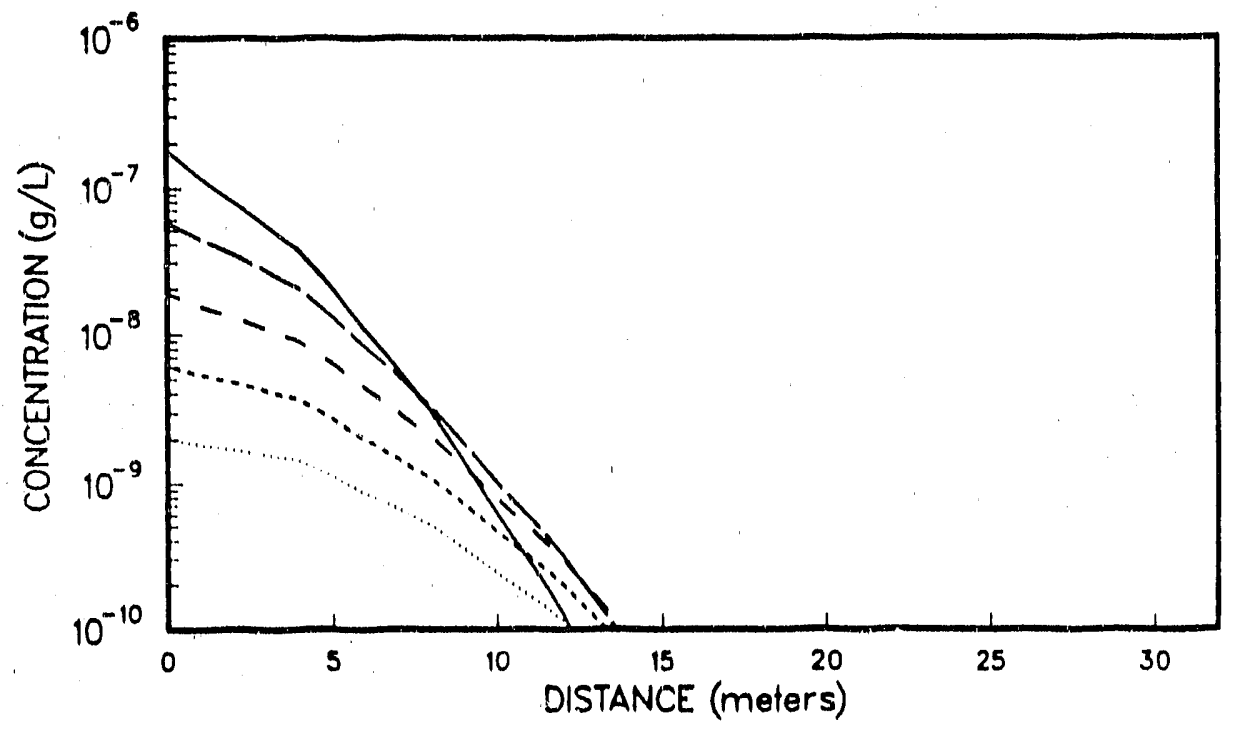

Legend 50 day 3 100 days. 150 days 200 days 250 doys

Figure 5.23. Evolution of hexachloroethane plume profile in the soil column over time. 


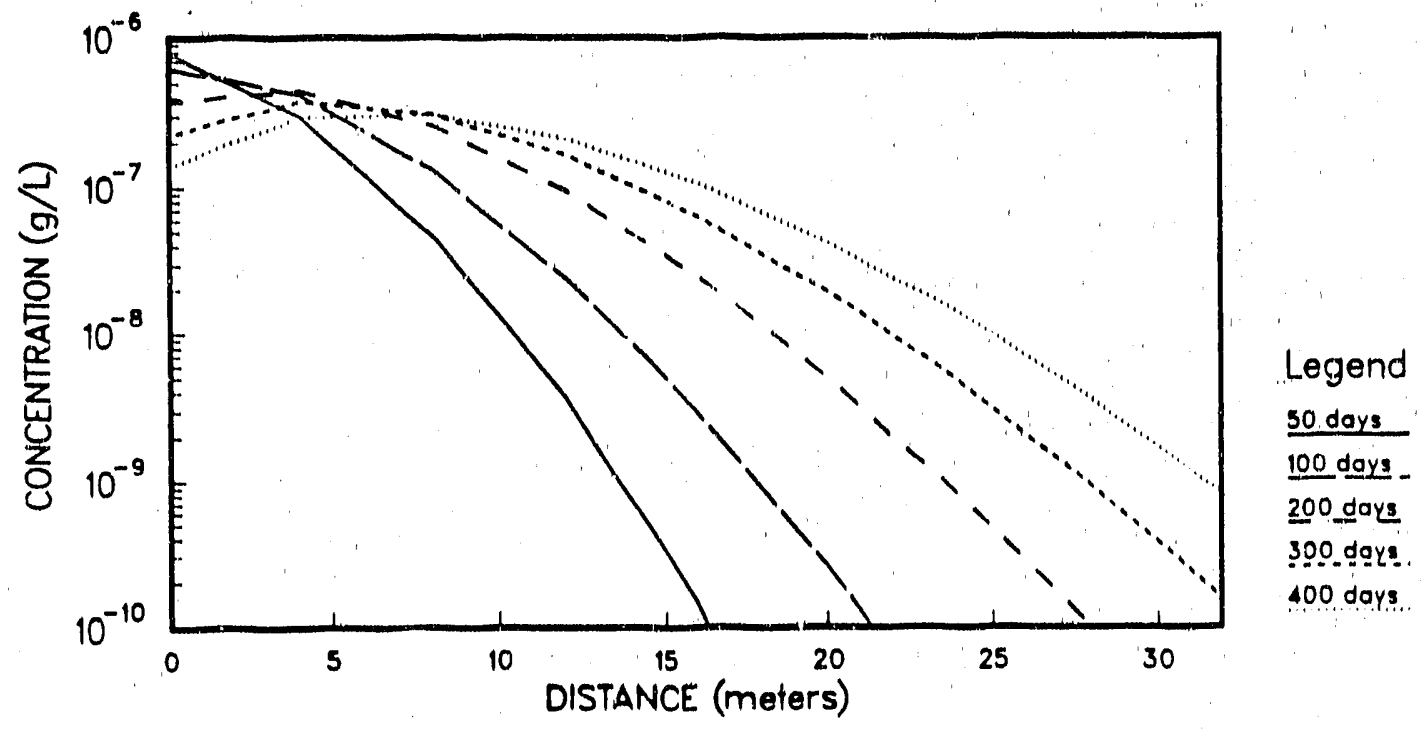

Figure 5.24. Evolution of tetrachlorocthylene plume, profile in the soil column over time.

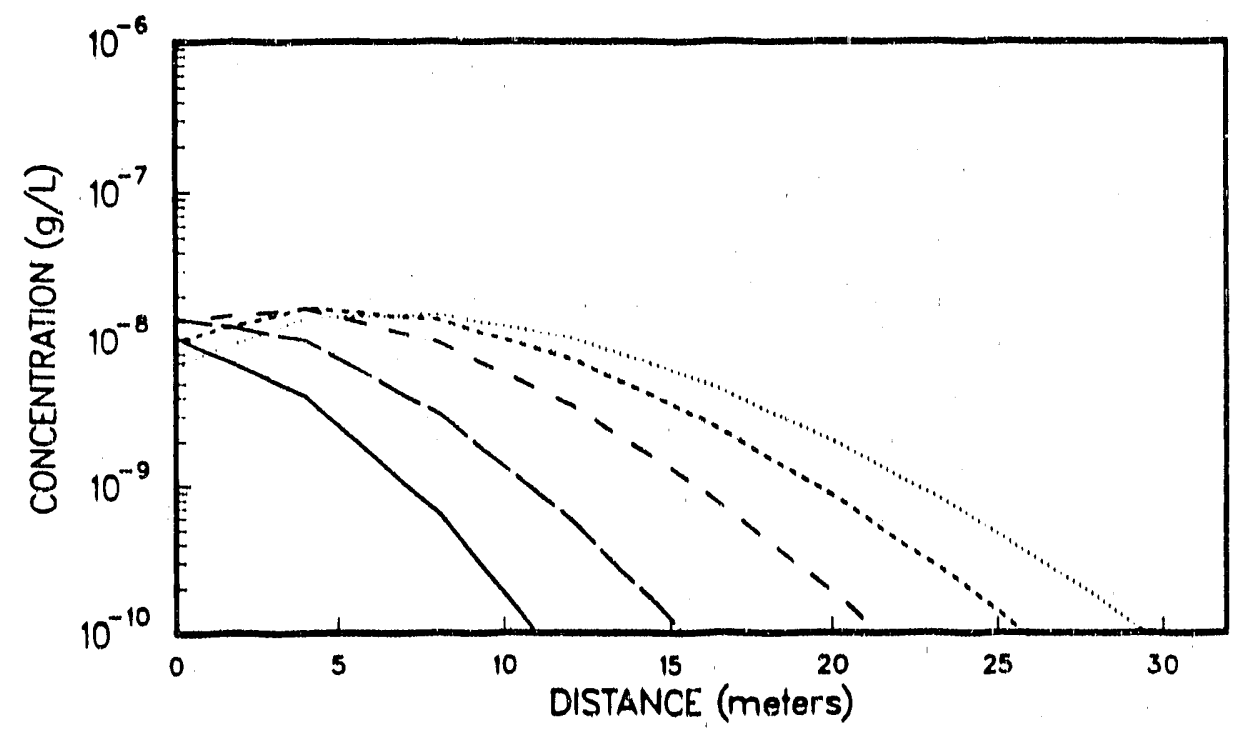

Legend 50 days 100 days. 200 days 300 dogs 400 doys.

Figure 5.25. Evolution of trichloroethylene plume profile in the soil column over time. 


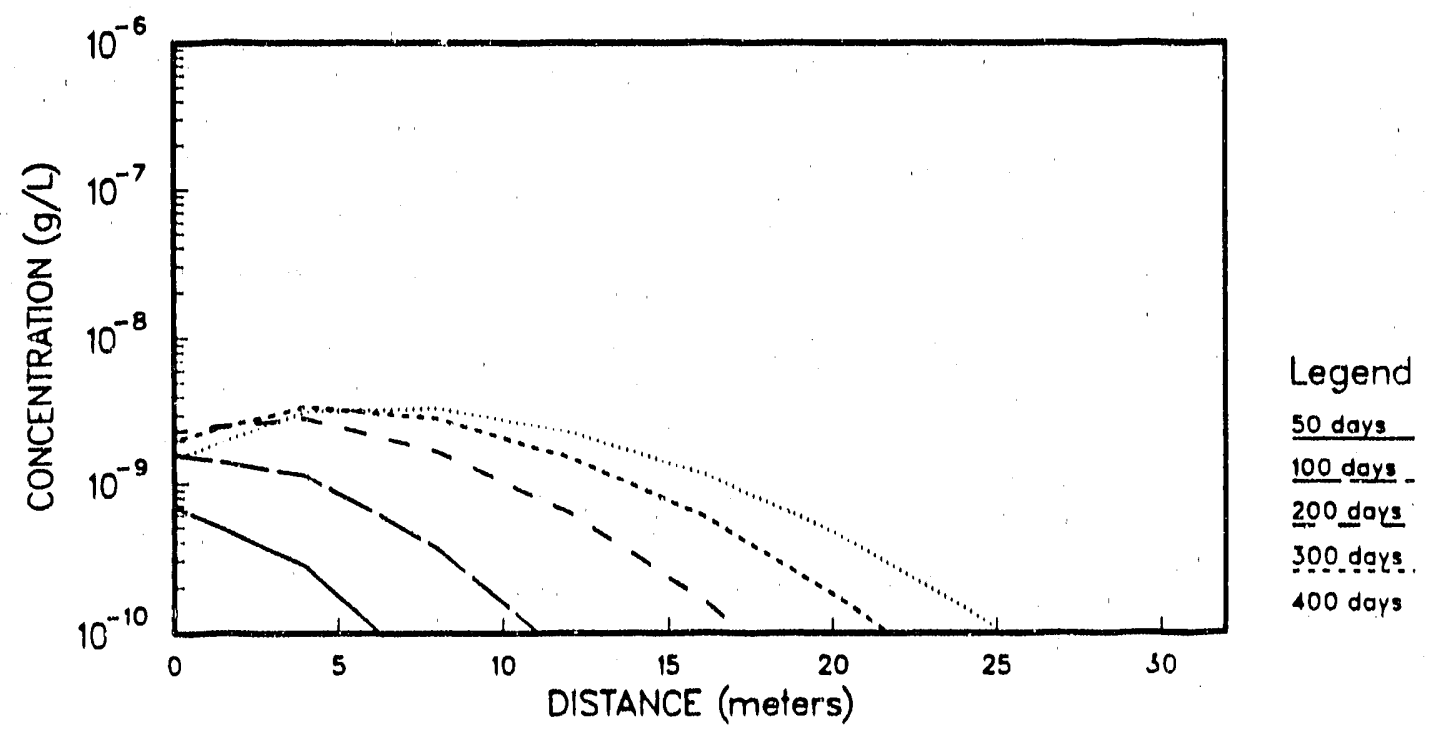

Figure 5.26. Evolution of vinyl chloride plume profile in the soil column over time. 


\section{CHAPTER 6: APPLICATION TO A TWO-DIMENSIONAL HYPOTHETICAL PROBLEM}

In this chapter we assess the applicability of the KINETRAN model to a hypothetical two-dimensional problem which is characterized by the presence of both physical and chemical heterogeneities. Such a scenario is more general than the problems considered so far and may be a more realistic representation of general field problems that may be encountered. We believe that some of the goneral features of the modeling results may indicate potential uses for the application of KINETRAN for the design of waste containment schemes for underground hazardous waste disposal.

\subsection{Problem Definition}

The physical configuration of the hypothetical problem is presented in Figure 6.1. Essentially, the problem consists of an infinite supply of dissolved carbon tetrachloride, representing a waste dump, leaking into a heterogencous block of soil due to percolating rain water. The soil block consists of two materials of differing physical and chemical properties. One material is a relatively oxidizing ( $\mathrm{Eh}=+0.1$ Volts) sandy aquifer that is generally permeable to fluid flow. The fluid flow connections are shown by the arrows drawn in the figure. The fluid fluxes are all calculated through a simple mass balance assuming a uniform infiltration rate into the top of the block of $0.254 \mathrm{~m} /$ year. The other material present, depicted as the shaded region in the figure, represents a clay lens. This material is assumec to be impermeable to fluid flow and thus solute transport within it will be due entirely to diffusive processes. through the stagnant pore water. We assume that this material is reducing in nature, with an Eh of -0.3 Volts. For 
both materials, we assign an effective diffusion coefficient of $1 \times 10^{-10} \mathrm{~m}^{2} / \mathrm{sec}$, a porosity of 0.30 , and a dispersivity of $0.1 \mathrm{~m}$.

The chemical degradation reactions, along with hypothetical first-order rate constants, are presented in Tables 6.1 and 6.2 for the oxidizing and reducing zones, respectively. The chloromethane degradation products of carbon tetrachloride $\left(\mathrm{CCl}_{4}\right)$ include chloroform $\left(\mathrm{CHCl}_{3}\right)$, methylene chloride $\left(\mathrm{CH}_{2} \mathrm{Cl}_{2}\right)$, methyl chloride $\left(\mathrm{CH}_{3} \mathrm{Cl}\right)$, and methane $\left(\mathrm{CH}_{4}\right)$. Each of these materials, in turn, may degrade into other secondary organic species, which include formaldehyde ( $\mathrm{HCHO})$, formic acid $(\mathrm{HCOO}, \mathrm{I})$, and total carbon dioxide $\left(\mathrm{CO}_{2}\right.$, which may be in the form $\mathrm{H}_{2} \mathrm{CO}_{3}, \mathrm{HCO}_{3}^{-}$, or $\mathrm{CO}_{3}^{2-}$ ).

A very simple-minded scheme is used to quantify the first-order reaction constants, depending on whether a reaction is taking place under oxidizing or reducing conditions (all reactions in the two tables are written in the thermodynamically-favored direction, calculated from equilibrium concentrations as was done in earlier sections of this thesis). We arbitrarily define reactions involving the transfer of two electrons or less as a weak redox reaction, while more than two electrons transferred is defined as a strong redox reaction. For the purpose of this simulation, we assume half-lives of 10 days for weak oxidation reactions under oxidizing conditions and weak reductions under reducing conditions, 100 days for strong oxidation reactions under oxidizing conditions (likewise for reductions), 1000 days for weak oxidation reactions under reducing conditions (likewise for reductions), and 10,000 days for strong oxidation reactions under reducing conditions (likewise for reductions). Non-redox reactions are assumed to have half-lives of 50 days. We feel that this approach is justified, given that a wide variety of abiotic and biologically-mediated processes may catalyze these reactions, and that our purpose here is to gain a phenomenalogical understanding of the problem, not a quantitative pred- 
iction.

The entire system is assigned a $\mathrm{pH}$ value of 7.0 , and a temperature of $25^{\circ} \mathrm{C}$. The concentration of carbon tetrachloride in the water percolating into the system is $153.8 \mathrm{mg} / \mathrm{L}(0.001$ mole/ $)$. The $\mathrm{Cl}^{-}$concentration is initially uniform throughout the entire system at $35.5 \mathrm{mg} / \mathrm{L}$. Total $\mathrm{CO}_{2}$ in the oxidizing zone is set initially at $44 \mathrm{mg} / \mathrm{L}$ and 0.0 in the reducing zone. The initial methane concentration in the oxidizing zone is 0.0 , while in the reducing zone it is set at $16 \mathrm{mg} / \mathrm{L}$ (also $0.001 \mathrm{~mole} / \mathrm{L}$ ). All other species have initial concentrations of 0.0 everywhere in the system.

The soil block, $1.25 \mathrm{~m}$ wide by $1.50 \mathrm{~m}$ deep, is discretized into 30 equal volume nodes, $0.25 \mathrm{~m}$ on each side. We attempt to study the temporal and spatial evolution of the concentrations of the various species involved over an approximately 14-year period, using constant 10day time steps. The monitoring points in the system, where the species concentrations are evaluated over time, are labelled in Figure 6.1 as points A-E.

Adsorption is neglected for this simulation, so all species present are assigned retardation factors of unity.

\subsection{Simulation Results}

\subsubsection{Overview}

We assumed prior to the simulation that, because of the steady-state fluid flow and the constant source of carbon tetrachloride, the system would eventually achieve steady-state concentrations of all species at all of the monitoring points, given sufficient time. A state of secular equilibrium should have been established for a given species between its rate of generation 
at a given location and its rate of removal, due to both physical and chemical processes. Our purpose is to discern how long this would take, given the initial conditions and problem parameters, which species would establish steady-state distributions faster than others, and what temporal concentration changes would occur prior to the establishment of the steady-state.

The simulation results, present below, do indeed show that for the majority of the species at most of the monitoring points, an apparent steady-state concentration is establi.hed, although not always at the same time. The chloro-methane species are particularly "well-behaved" in this respect. However, some of the other secondary (non-chlorinated) organic species display rather odd transient concentration behavior prior to the establishment of steady-state concentration. We have established that the likely cause of this phenomenon is the specification of initial conditions that are not consistent with the problem parameters (transport variables and kinetic rate constants). In other words, the initial concentration of a given species at a given point may be in thermodynamic equilibrium with the immediate local environment at time $t=0$, but at a later time we may find that the sum of transport and transformation effects may serve to produce a steady-state concentration that is higher or lower than the initial value. We found this to be a particular problem with the initial methane concentration in the reducing clay zone. This raises a series of rather subtle questions concerning the very nature of this type of simulation, which we will address in this chapter.

\subsubsection{Temporal Evolution of Species Concentrations}

The concentration of total aqueous $\mathrm{CO}_{2}$ over time at the various monitoring points are shown in Figure 6.2 There are several features worth noting. First of all; the $\mathrm{CO}_{2}$ concentrations at the two points in the oxidizing zone, $\mathrm{A}$ and $\mathrm{E}$, are greater than those in the reducing 
zone, with the lesser concentrations being found deeper within the clay lens, as should be expected. Secondly, steady-state concentrations have apparently been established at all monitoring points except point $D$ by about 1000 days. Because of the location of point $D$, deep inside the clay zone, concentrations there respond the slowest to any changes, due 10 the inherent nature of molecular diffusion. Presumably, the slow decline in $\mathrm{CO}_{2}$ concentration at this point is a result of its slow reduction to methane, which has not yet achieved secular equilibrium. An additional feature, which is very subtle here but is greatly pronounced in some of the other secondary species, is the slight rise and fall in concentration between roughly 100 and 1000 days at point $\mathrm{E}$. This feature results from the additive effects of advection and diffusion. When the advective front arrives at point $\mathrm{E}$, it is relatively rich in $\mathrm{CO}_{2}$ due to the breakdown of the various organic species in the oxidzing zone, thus there is an initial rise in the total concentration. However, $\mathrm{CO}_{2}$ is also produced locally at point $\mathrm{E}$ due to the breakdown of various substances diffusing in from the overlying clay lens, including methane itself. As we shall see, the concentration of methane declines in the clay lens during much of the simulation, while the other species eventually achieve steady-state values (thus, their concentrations in the clay lens stop increasing). The result of this is that the additional source for $\mathrm{CO}_{2}$ at point $\mathrm{E}$ eventually ceases to increase and in fact declines slightly during part of the simulation. The effect of this is to suppress any further increase in concentration of $\mathrm{CO}_{2}$ at point $\mathrm{E}$ and to force it to establish a steady-state value, where inflow + production $=$ outflow.

Figures 6.3 shows the temporal evolution of formic acid in the system. Comparison with the $\mathrm{CO}_{2}$ evolution profile shows great differences between the two. Perhaps the most striking feature here is that a great deal more time is required for steady-state concentrations to be established, with the amount of time needed increasing further into the clay lens. In fact, at point 
D, there is a hint that the steady-state may just be getting established at the end of the simulation (5000 days). This is a testimony to the subtle, yet complex interplay involved between the transformation and diffusive transport processes. The transient feature described for $\mathrm{CO}_{2}$ at point $\mathrm{E}$ is much more evident here, although it is still caused by the same mechanism. The reason for this is that the amount of formic acid in the arriving advective plume is now much greater than the amount present at point $\mathrm{E}$ prior to arrival, unlike the case for carbon dioxide. One notable feature at point $E$ with the formic acid profile is the sharp break in slope at approximately 40 days. This feature is easily explained. Prior to 40 days elapsed time, formic acid at point $E$ is produced only very slowly through the oxidation of methane diffusing out of the clay lens. At the 40 day point, the advective front arrives, enriched in formic acid formed in the degradation chain of the carbon tetrachloride degradation products.

Figures 6.4 and 6.5 show the temporal evolution of formaldehyde and methanol, respectively. The two species show generally similar behavior. Most notably, the concentrations of both species at points $B$ and $C$ achieve steady-state values at around 110-120 days, much more quickly than formic acid. This is probably because the reaction list shows that both of these species are produced directly from the degradation of the chloro-methanes, which achieve steady-state concentrations fairly rapidly themselves (discussed shortly). Formic acid, on the other hand, is not produced directly in this manner. Steady-state establishment at point A takes somewhat longer for both formaldehyde and methanol (on the order of 1100 days), as they show an initial rise in concentration, followed by a very gradual decline until steady-state occurs. This decline is due to the gradual decrease in methane concentration in the clay lens, a source for methanol, which is a source for formaldehyde (hence the decrease is more pro-

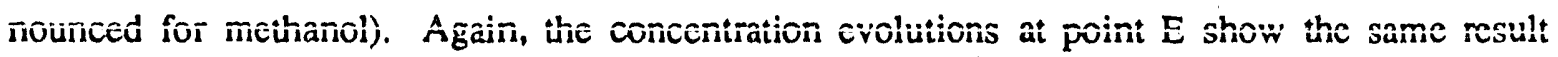


that was shown by formic acid, and again for the same reasons. The concentration evolutions at point $D$ are not depicted, as both are below $1 \times 10^{-8} \mathrm{~g} / \mathrm{L}$.

The only significant difference in the behavior of the two species is that the final steadystate concentrations for methanol in the oxidizing zone (points $\mathrm{A}$ and $\mathrm{E}$ ) are lower than that at point $B$ in the reducing zone, while the opposite is true of formaldehyde. This is because methanol is more stable than formaldehyde under reducing conditions, while formaldehyde is more stable under oxidizing conditions, thus a change in system Eh may result in a change reaction direction for a reaction between the two (see Tables 6.1 and 6.2).

The temporal evolution of methane is shown in figure 6.6. Clearly, the methane concentrations remain much higher in the reducing zone than in the oxidizing zone after steady-state values are achieved around 4000-5000 days. This is, of course, quite reasonable and is to be expected. The concentrations of methane in the oxiziding zone, points $A$ and $E$, show behavior very similar to that of methanol and formaldehyde. The reasons for the transient features produced are again the same as in the previous explanations. The interesting features here, however, are found in the reducing zone. The concentration of methane at all three points in the clay declines by one-half to one full order of magnitude before approaching steady-state values. This in turn influences the fates of some of the other species, as we have shown. It is impossible to attribute this on a single mechanism; rather this decline is the result of total production and transport of methane into the clay not being initially balanced by transport out of the clay (and its subsequent destruction in the surrounding oxidizing zone). For example, part of the problem may involve differences in concentration gradients between methane and methane-producing species. In other words, the concentration gradient for methane across the clay lens - sandy aquifer boundary remains relatively high, since methane that diffuses out of 
the clay lens is quickly swept away by advection. This is not true of $\mathrm{CO}_{2}$, the concentration of which is relatively high in the oxidizing zone, but which cannot maintain such a high gradient across the interface. As a result, methane may be removed from the clay lens faster than species which can generate it move in, resulting in an overal1 decline in its concentration. If the initial concentration of methane was assigned a smaller value at the start of the problem, its concentration in the clay lens may have remained constant or even increased. The difficulty involves knowing what this concentration should be before beginning the simulation.*

Figures 6.7 through 6.10 show the temporal evolution of the various chloro-methane species present. The behavior of these species is generally similar. Steady-state concentrations are established fairly rapidly for all species at each of the monitoring points. None of these species achieved concentrations greater than $1 \times 10^{-8} \mathrm{~g} / \mathrm{L}$ at point $\mathrm{D}$, hence these curves are not shown. The concentrations of all of the species decrease with increasing distance into the clay lens. This occurs because of rapid reductive dehalogenation within the reducing layer. This feature is also the reason why the concentration of methylene chloride is actually greater at point $B$ than at point $A$ for the first 100 days, even though it is further away from the carbon tetrachloride source. An additional feature is the rapid increase in concentration for each of the species evident at point $E$. This is due to the arrival of the advective front bearing fluid that contains carbon tetrachloride. This increase is far more pronounced than for the nonchlorinated secondary organic species. This is because the latter group of compounds are produced from methane diffusing into the oxidizing zone ahead of the carbon tetrachloride-bearing advective front, which serves apparently to smear-out the solute front for these species.

- The other obvious difficulty is that in real systems methane is produced through the action of anaerobic microbes on organic material. This could have been included in the simulation by introducing a separate ficticious reaction and specifying a reaction rate. However, this would have added additional complexities to the problem that would have

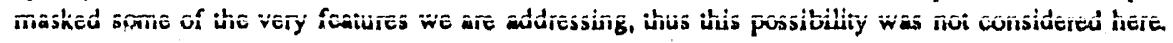


The only important difference between the species are the final steady-state concentrations in the oxidizing zone (points $\mathrm{A}$ and $\mathrm{E}$ ). Note that the concentration of methyl chloride at these points is less than that at point B, while it is greater than that at point B for methylene chloride and much greater for chloroform and carbon tetrachloride. This is because the more highly chlorinated chloro-methanes are more oxidized, and hence would be expected to be more stable in the oxidizing zone. Referring to the previous chapter, this is why Roberts et al., (1986) expected carbon tetrachloride and chloroform to be most degradable under reducing conditions.

The evolution of free chloride in the system is illustrated in Figure 6.11. This is the only species present which clearly has not, and may not ever, establish steady-state concentrations at all points. Most notably at point $\mathrm{B}$, and at point $\mathrm{C}$ to an extent, the concentration of $\mathrm{Cl}^{-}$continues to increase even after 5000 days. Referring to figure 6.1 , these monitoring points are located near the comer of the clay lens, where there is a maximum exposure to flowing fluid containing the highest amounts of dissolved carbon tetrachloride and chloroform in the system. The explanation here is that small amounts of these highly chlorinated compounds diffuse into this part of the clay lens, thus being readily reduced and stripped of chloride ions due to their relatively high oxidation states. Thus, $\mathrm{Cl}^{-}$continues to be generated in the region near point $\mathrm{B}$, slowly diffusing into the rest of the clay. This accumulation of $\mathrm{Cl}^{-}$does not occur in the oxizing zone adjacent to point $B$, because advection swiftly flushes it out of the system.

\subsection{Implications}

From the simulation of this hypothetical problem, we see that there are two important implications, one a computational one and one a practical one, for the applicability of the KINNETRAN mode!. 
We see immediately from our results that the initial conditions specified for a given region of the flow domain must be consistent with chemical transformation and transport parameters for the entire system. Failure to recognize this may result in "undesirable" behavior, such as the inability to maintain an initial methane concentration in a reducing material. 'The implication here, as was stated in the previous chapter, is that initial concentrations for all relevant species for a given field problem should be quantifiable, (i.e. simple guesses may not suffice), and that the relevant reactions should be known.

Secondly, from an entirely different perspective, we find in this study a clear example of how the model can actually be utilized to help solve a hazardous waste disposal problem. Assuming an appropriate level of knowledge of a given system, the model can predict steadystate concentration values as they approach secular equilibriurn, under certain conditions. These values can be used to assess whether or not toxic leachates will rise to unacceptable threshold concentration levels at a given location. This information may even be used to design or improve waste containment facilities. For example, if the hypothetical problem studied here were correct in its defined problem parameters, one may consider disposing of carbon tetrachloride in sites surrounded by impermeable clay, of sufficient thickness, that is chemically reducing. In this regard, studies on the role of diffusion-dominated transport of toxic materials through clay barriers, such as that of Johnson et al., 1989, must also consider the detailed chemistry of the system, not just the physical processes, if the results are to be meaningful. 


\section{Table 6.1}

Reactions for the two-dimensional problem in the oxidizing zone (Eh $=+0.1$ Volts).

\begin{tabular}{|c|c|c|}
\hline Reaction* & $\log K_{e q}$ & $\begin{array}{l}k_{\text {forward }} \\
\left(\sec ^{-1}\right)\end{array}$ \\
\hline $\mathrm{CCl}_{4}+\mathrm{H}^{+}+2 \mathrm{e}^{-} \rightarrow \mathrm{CHCl}_{3}+\mathrm{Cl}^{-}$ & 25.37 & $8.02 \times 10^{-9}$ \\
\hline $\mathrm{CHCl}_{3}+\mathrm{H}^{+}+2 \mathrm{e}^{-} \rightarrow \mathrm{CH}_{2} \mathrm{Cl}_{2}+\mathrm{Cl}^{-}$ & 22.41 & $8.02 \times 10^{-9}$ \\
\hline $\mathrm{CH}_{2} \mathrm{Cl}_{2}+\mathrm{H}^{+}+2 \mathrm{e}^{-} \rightarrow \mathrm{CH}_{3} \mathrm{Cl}+\mathrm{Cl}^{-}$ & 19.87 & $8.02 \times 10^{-9}$ \\
\hline $\mathrm{CH}_{3} \mathrm{Cl}+\mathrm{H}^{+}+2 e^{-} \rightarrow \mathrm{CH}_{4}+\mathrm{Cl}^{-}$ & 20.01 & $8.02 \times 10^{-9}$ \\
\hline $\mathrm{CCl}_{4}+\mathrm{H}_{2} \mathrm{O}+\mathrm{H}^{+}+6 \mathrm{e}^{-} \rightarrow \mathrm{CH}_{3} \mathrm{OH}+4 \mathrm{Cl}^{-}$ & 70.78 & $8.02 \times 10^{-10}$ \\
\hline $\mathrm{CHCl}_{3}+\mathrm{H}_{2} \mathrm{O}+\mathrm{H}^{+}+4 \mathrm{e}^{-} \rightarrow \mathrm{CH}_{3} \mathrm{OH}+3 \mathrm{Cl}^{-}$ & 45.42 & $8.02 \times 10^{-10}$ \\
\hline $\mathrm{CH}_{2} \mathrm{Cl}_{2}+\mathrm{H}_{2} \mathrm{O}+2 \mathrm{e}^{-} \rightarrow \mathrm{CH}_{3} \mathrm{OH}+2 \mathrm{Cl}^{-}$ & 23.01 & $8.02 \times 10^{-9}$ \\
\hline $\mathrm{CH}_{3} \mathrm{Cl}+\mathrm{H}_{2} \mathrm{O} \rightarrow \mathrm{CH}_{3} \mathrm{OH}+\mathrm{Cl}^{-}+\mathrm{H}^{+}$ & 3.15 & $1.60 \times 10^{-7}$ \\
\hline $\mathrm{CH}_{4}+\mathrm{H}_{2} \mathrm{O} \rightarrow \mathrm{CH}_{3} \mathrm{OH}+2 \mathrm{H}^{+}+2 \mathrm{e}^{-}$ & -16.86 & $8.02 \times 10^{-7}$ \\
\hline $\mathrm{CCl}_{4}+\mathrm{H}_{2} \mathrm{O}+4 \mathrm{e}^{-} \rightarrow \mathrm{HCHO}+4 \mathrm{Cl}^{-}$ & 62.78 & $8.02 \times 10^{-10}$ \\
\hline $\mathrm{CHCl}_{3}+\mathrm{H}_{2} \mathrm{O}+2 \mathrm{e}^{-} \rightarrow \mathrm{HCHO}+3 \mathrm{Cl}^{-}+\mathrm{H}^{+}$ & 37.41 & $8.02 \times 10^{-9}$ \\
\hline $\mathrm{CH}_{2} \mathrm{Cl}_{2}+\mathrm{H}_{2} \mathrm{U} \rightarrow \mathrm{HCHO}+2 \mathrm{Cl}^{-}+2 \mathrm{H}^{+}$ & 15.00 & $1.60 \times 10^{-7}$ \\
\hline $\mathrm{CH}_{3} \mathrm{Cl}+\mathrm{H}_{2} \mathrm{O} \rightarrow \mathrm{HCHO}+\mathrm{Cl}^{-}+3 \mathrm{H}^{+}+2 \mathrm{e}^{-}$ & -4.85 & $8.02 \times 10^{-7}$ \\
\hline $\mathrm{CH}_{3} \mathrm{OH} \rightarrow \mathrm{HCHO}+2 \mathrm{H}^{+}+2 \mathrm{e}^{-}$ & -8.01 & $8.02 \times 10^{-7}$ \\
\hline $\mathrm{HCHO}+\mathrm{H}_{2} \mathrm{O} \rightarrow \mathrm{HCOOH}+2 \mathrm{H}^{+}+2 \mathrm{e}^{-}$ & 0.96 & $8.02 \times 10^{-7}$ \\
\hline $\mathrm{HCOOH} \rightarrow \mathrm{CO}_{2}+2 \mathrm{H}^{+}+2 \mathrm{e}^{-}$ & 2.43 & $8.02 \times 10^{-7}$ \\
\hline $\mathrm{CH}_{3} \mathrm{OH}+\mathrm{H}_{2} \mathrm{O} \rightarrow \mathrm{CO}_{2}+6 \mathrm{H}^{+}+6 \mathrm{e}^{-}$ & -4.62 & $8.02 \times 10^{-8}$ \\
\hline $\mathrm{HCHO}+\mathrm{H}_{2} \mathrm{O} \rightarrow \mathrm{CO}_{2}+4 \mathrm{H}^{+}+4 \mathrm{e}^{-}$ & 3.39 & $8.02 \times 10^{-8}$ \\
\hline $\mathrm{CH}_{4}+2 \mathrm{H}_{2} \mathrm{O} \rightarrow \mathrm{CO}_{2}+8 \mathrm{H}^{+}+8 \mathrm{e}^{-}$ & -21.47 & $8.02 \times 10^{-8}$ \\
\hline
\end{tabular}

Equilibrium constants calculated from Wagman et al. (1968), Dean (1979), and Mackay and Shin (1981).

- The kinetic datu presented here are completely arificial and are used for demonstration purposea only. Such data are not to be used in evaluating the fate of any of the apecies mentioried for any real contamination site. 


\section{Table 6.2}

Reactions for the two-dimensional problem in the reducing zone (Eh $=-0.3$ Volts).

\begin{tabular}{|c|c|c|}
\hline Reaction* & $\log \mathrm{K}_{\mathrm{eq}}$ & $\begin{array}{l}k_{\text {forward }} \\
\left(\sec ^{-1}\right)\end{array}$ \\
\hline $\mathrm{CCl}_{4}$ & 25.37 & $8: \times 10^{-7}$ \\
\hline $\mathrm{CHCl}_{3}+\mathrm{H}^{+}+2 \mathrm{e}^{-} \rightarrow \mathrm{CH}_{2} \mathrm{Cl}_{2}+\mathrm{Cl}^{-}$ & 22.41 & $8.02 \times 10^{-7}$ \\
\hline $\mathrm{CH}_{2} \mathrm{Cl}_{2}+\mathrm{H}^{+}+2 \mathrm{e}^{-} \rightarrow \mathrm{CH}_{3} \mathrm{Cl}+\mathrm{Cl}^{-}$ & 19.87 & $8.02 \times 10^{-7}$ \\
\hline $\mathrm{CH}_{3} \mathrm{Cl}+\mathrm{H}^{+}+2 \mathrm{e}^{-} \rightarrow \mathrm{CH}_{4}+\mathrm{Cl}^{-}$ & 20.01 & $8.02 \times 10^{-7}$ \\
\hline $\mathrm{CCl}_{4}+\mathrm{H}_{2} \mathrm{O}+\mathrm{H}^{+}+6 \mathrm{e}^{-} \rightarrow \mathrm{CH}_{3} \mathrm{OH}+4 \mathrm{Cl}^{-}$ & 70.78 & $8.02 \times 10^{-8}$ \\
\hline $\mathrm{CHCl}_{3}+\mathrm{H}_{2} \mathrm{O}+\mathrm{H}^{+}+4 \mathrm{e}^{-} \rightarrow \mathrm{CH}_{3} \mathrm{OH}+3 \mathrm{Cl}^{-}$ & 45.42 & $8.02 \times 10^{-8}$ \\
\hline $\mathrm{CH}_{2} \mathrm{Cl}_{2}+\mathrm{H}_{2} \mathrm{O}+2 \mathrm{e}^{-} \rightarrow \mathrm{CH}_{3} \mathrm{OH}+2 \mathrm{C}$ & 23.01 & $8.02 \times 10^{-7}$ \\
\hline $\mathrm{CH}_{3} \mathrm{Cl}+\mathrm{H}_{2} \mathrm{O} \rightarrow \mathrm{CH}_{3} \mathrm{OH}+\mathrm{Cl}^{-}+\mathrm{H}^{+}$ & 3.15 & $1.60 \times 10^{-7}$ \\
\hline $2 \mathrm{H}^{+}+2 \mathrm{e}^{-} \rightarrow \mathrm{CH}_{4}+\mathrm{H}_{2} \mathrm{O}$ & 16.86 & $8.02 \times 10^{-7}$ \\
\hline $\mathrm{CCl}_{4}+\mathrm{H}_{2} \mathrm{O}+4 \mathrm{e}^{-} \rightarrow \mathrm{HCHO}+4 \mathrm{Cl}^{-}$ & 62.78 & $8.02 \times 10^{-8}$ \\
\hline $\mathrm{HO}+3 \mathrm{Cl}^{-}+\mathrm{H}^{+}$ & 37.41 & $8.02 \times 10^{-7}$ \\
\hline $\mathrm{H}_{2} \mathrm{O} \rightarrow \mathrm{HCHO}+2 \mathrm{Cl}^{-}+2 \mathrm{H}^{+}$ & 15.00 & $1.60 \times 10^{-7}$ \\
\hline $\mathrm{H}_{2} \mathrm{O} \rightarrow \mathrm{HCHO}+\mathrm{Cl}^{-}+3 \mathrm{H}^{+}+2$ & -4.85 & $8.02 \times 10^{-7}$ \\
\hline $\mathrm{HCI}$ & 8.01 & $8.02 \times 10^{-7}$ \\
\hline$+2 \mathrm{H}^{+}+2 \mathrm{e}^{-}$ & 0.96 & $8.02 \times 10^{-9}$ \\
\hline $\mathrm{HCOOH} \rightarrow \mathrm{CO}_{2}+2 \mathrm{H}^{+}+2 \mathrm{e}^{-}$ & 2.43 & $8.02 \times 10^{-9}$ \\
\hline $\mathrm{CH}_{3} \mathrm{OH}+\mathrm{H}_{2} \mathrm{O} \rightarrow \mathrm{CO}_{2}+6 \mathrm{H}^{+}+6 \mathrm{e}^{--}$ & -4.62 & $8.02 \times 10^{-16}$ \\
\hline$+4 \mathrm{H}^{+}+4 \mathrm{e}^{-}$ & 3.39 & $8.02 \times 10^{-16}$ \\
\hline $\mathrm{CO}_{2}+8 \mathrm{H}^{+}$ & 21.47 & $8.02 \times 10^{-8}$ \\
\hline
\end{tabular}

Equilibrium constants carculated from Wagman et al. (1968), Dean (1979), and MacKay and Shin (1981).

- Tho kinetic dala presented hero are completely artificial and aro used for demonstration purposea only. Such data are not to be used in evaluating the fale of any of the species mentioned for any real contamination sile. 


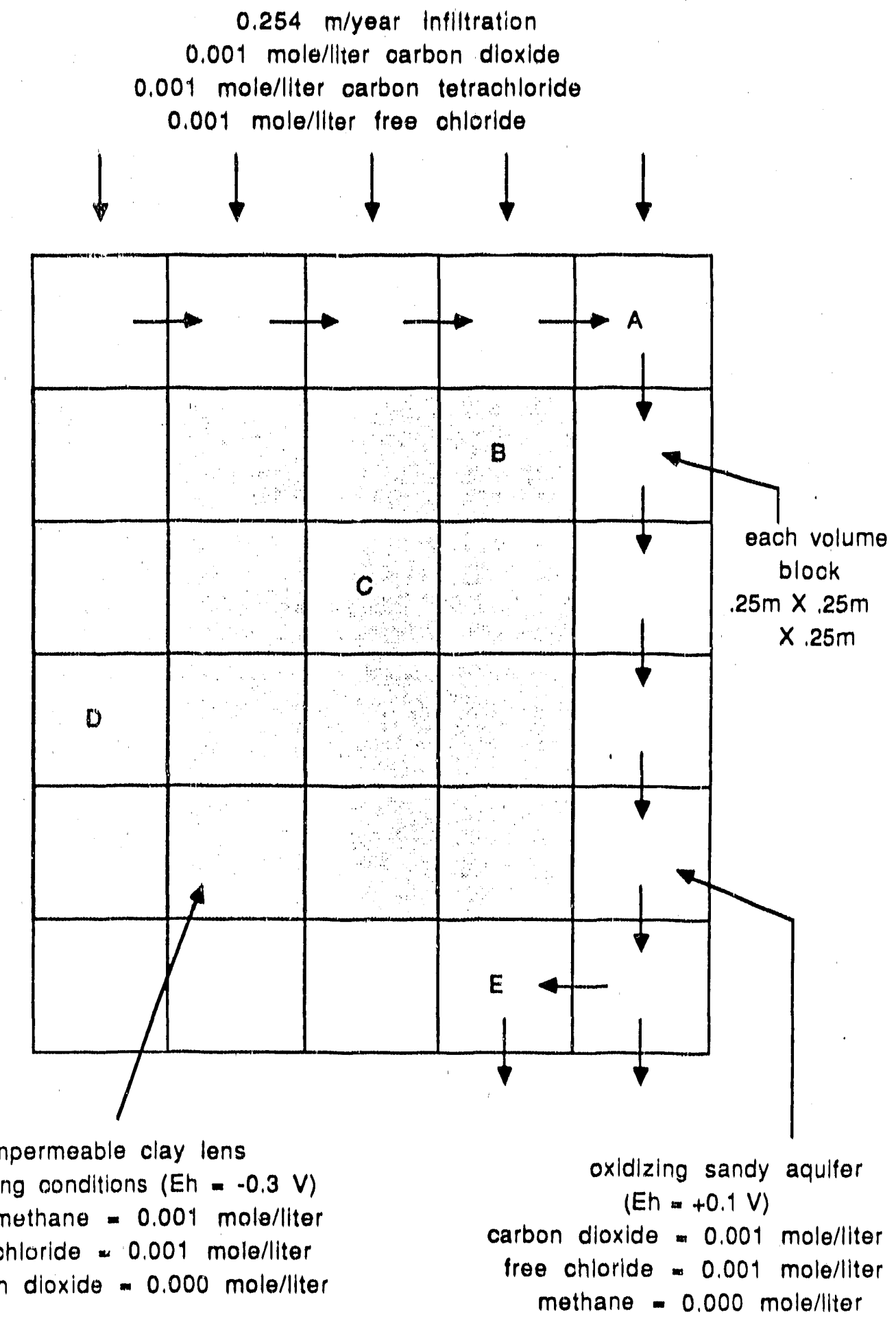

Figure 6.1. Physical conflguration of the hypothetical two-dimensional problem. 


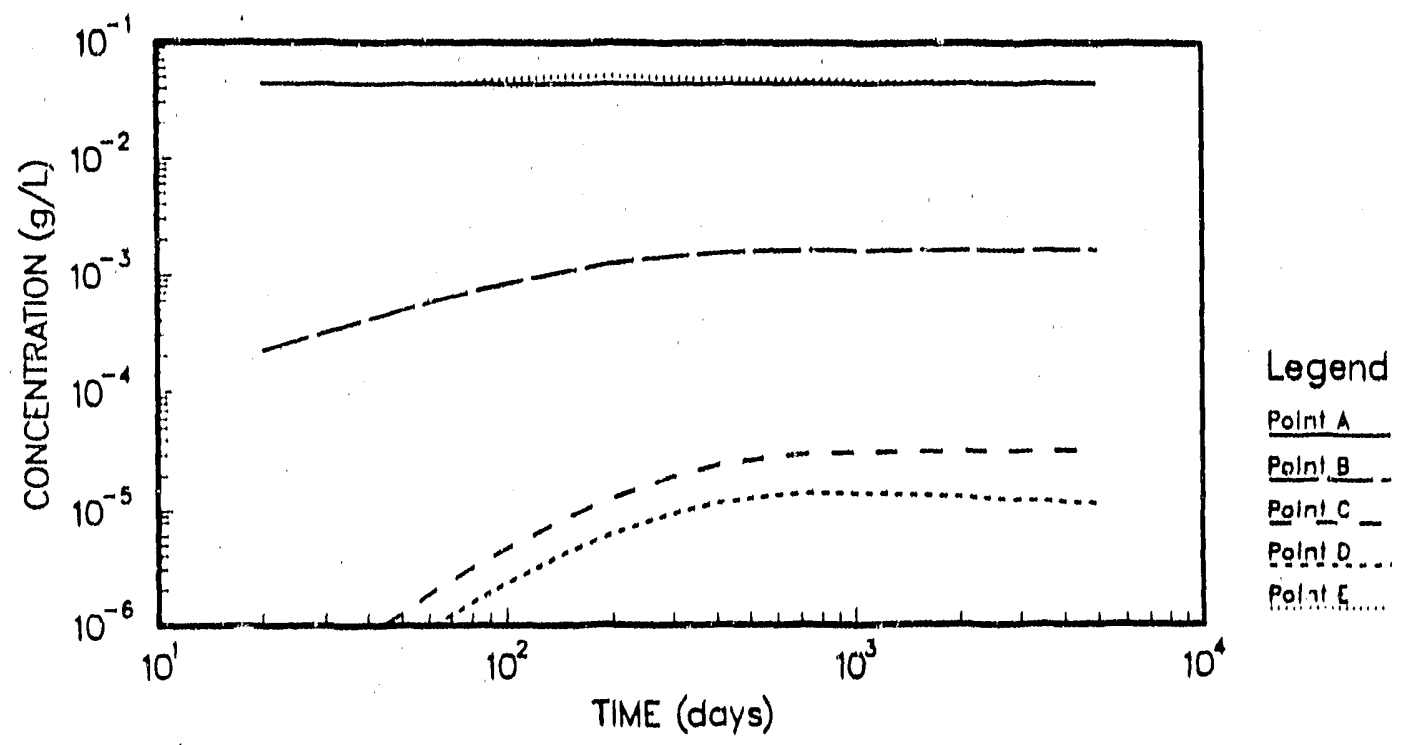

Figure 6.2. Temporal evolution of total $\mathrm{CO}_{2}$ concentration at the various monitoring points.

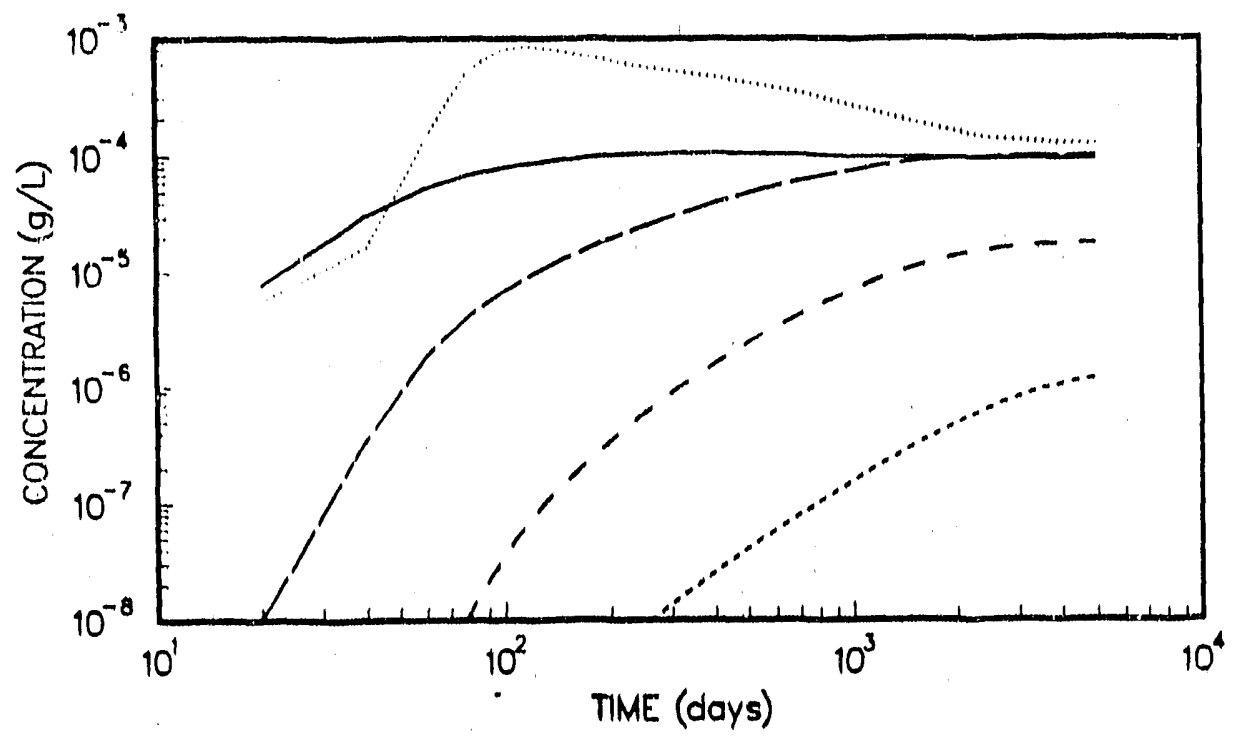

Legend

Point A

Point 旦.

Poinl C

Poin! D....

Poin! E....

Figure 6.3. Temporal evolution of formic acid concentration at the various monitoring points. 


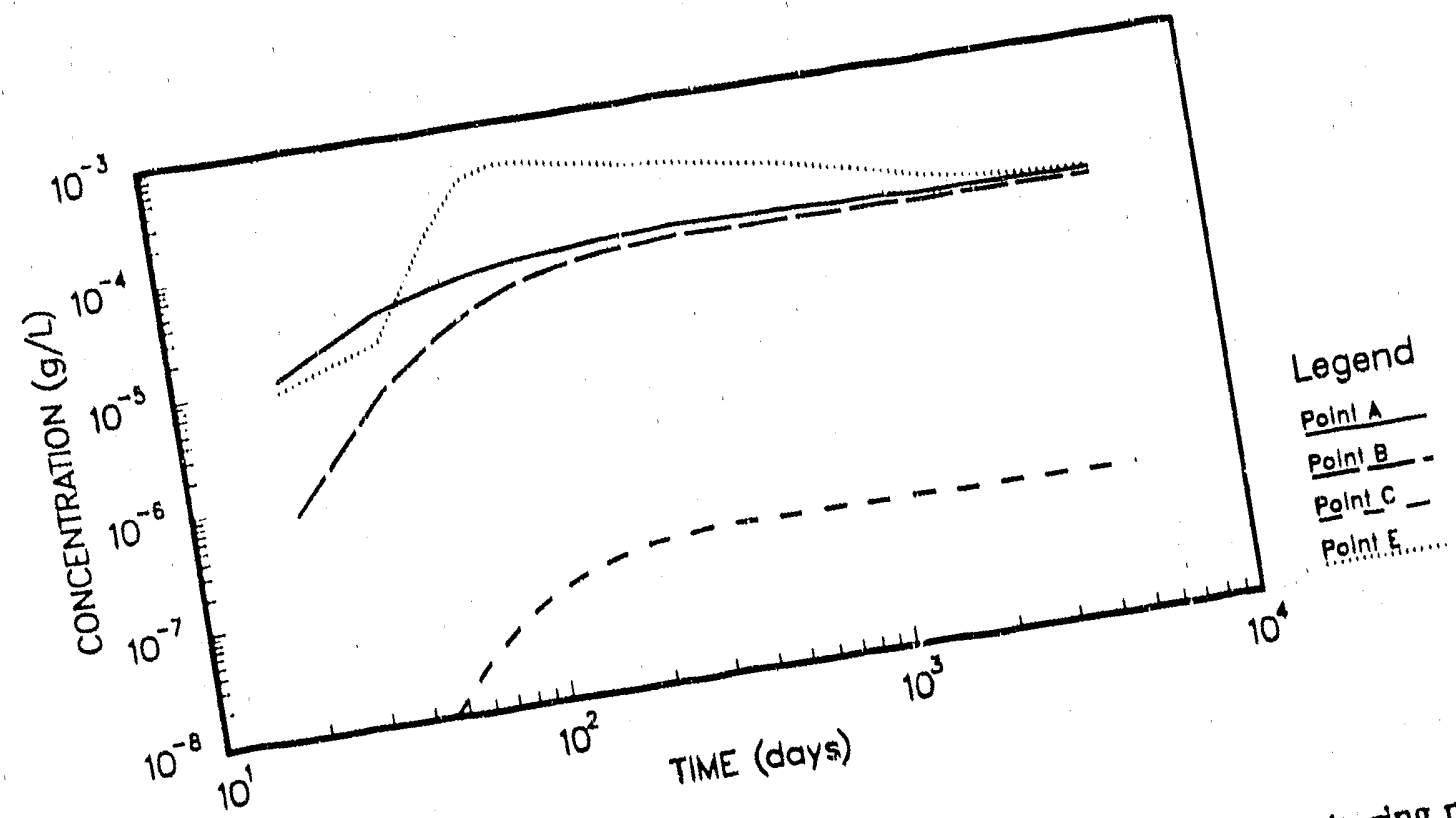

Figure 6.4. Temporal evolution of formaldehyde concentration at the various monitoring points

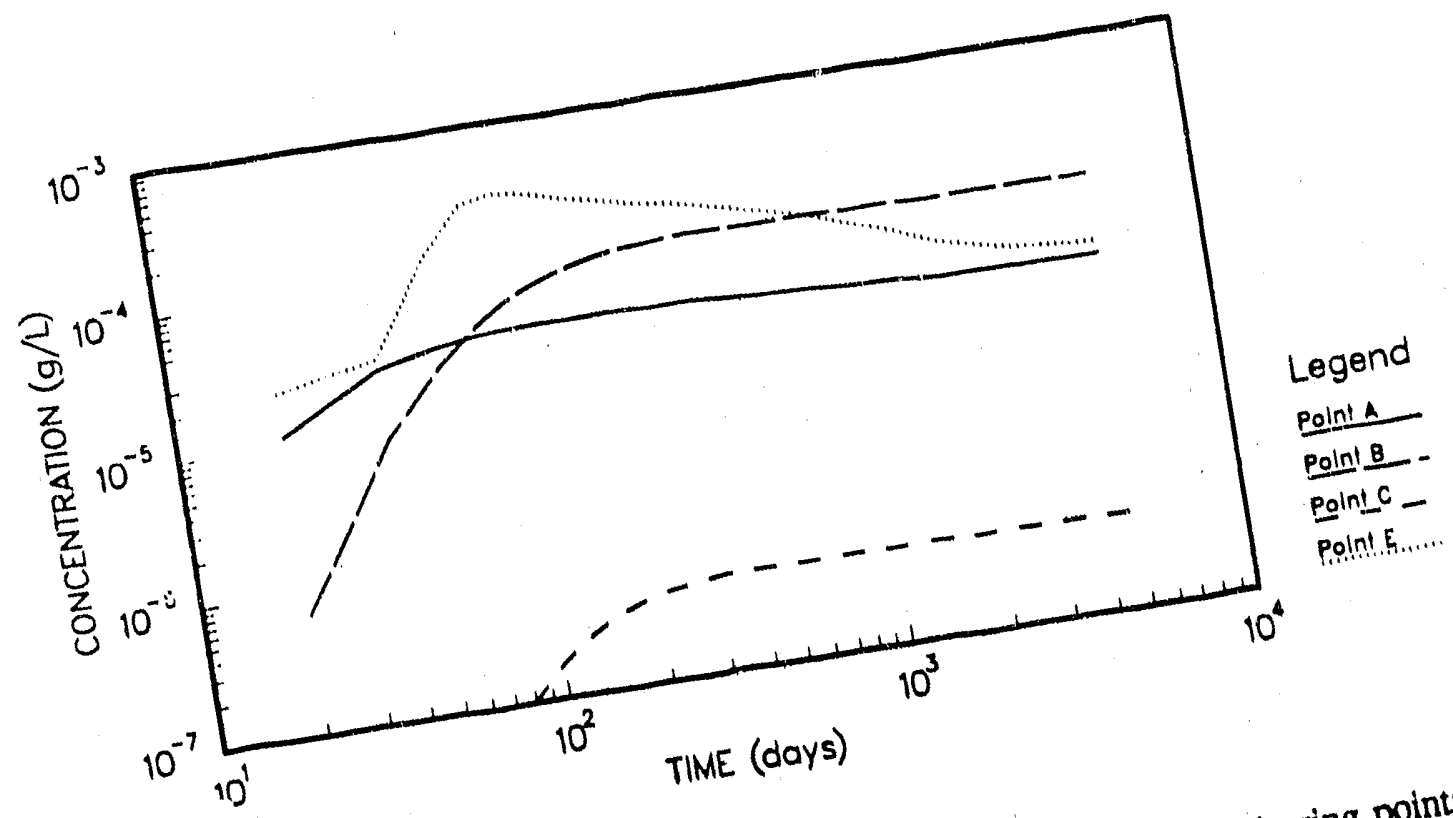

Figure 6.5. Temporal evolution of methanol concentration at the various monitoring points. 


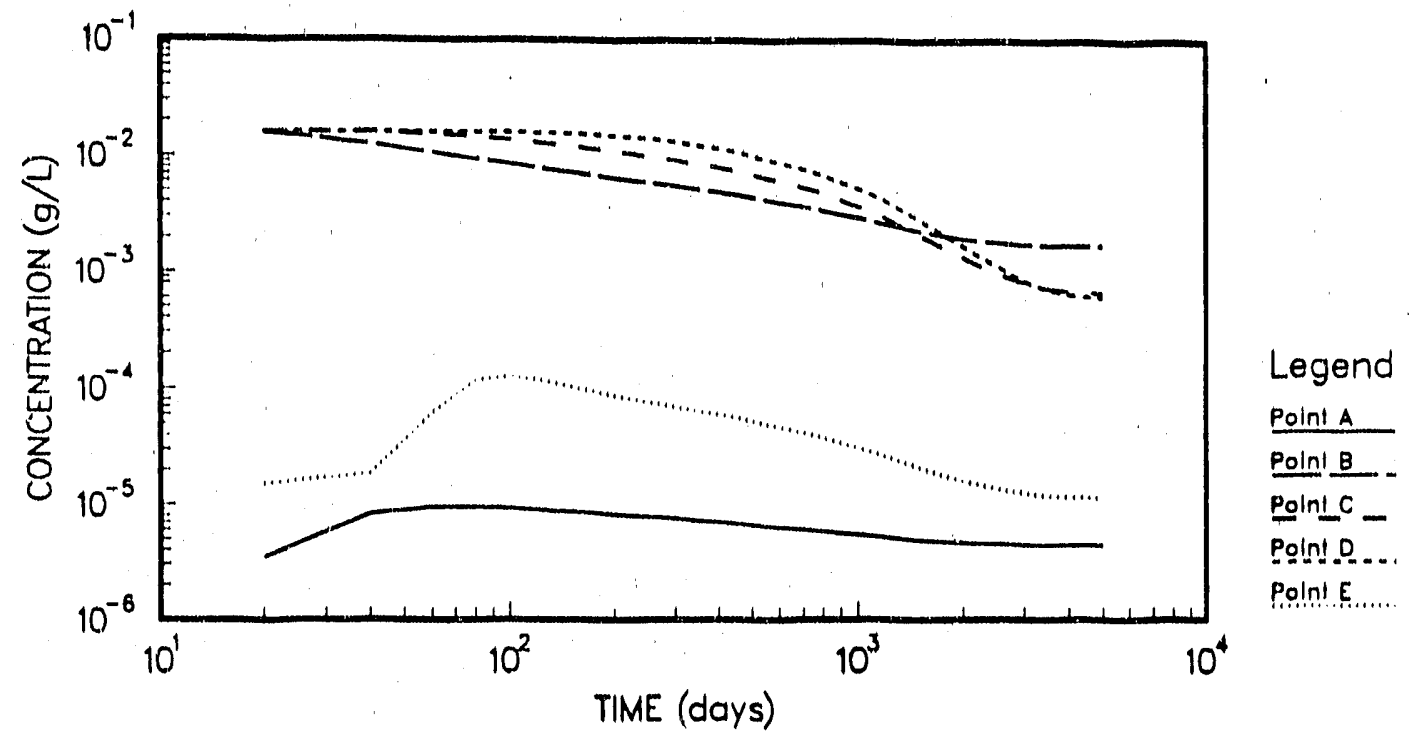

Figure 6.6. Temporal evolution of methane concentration at the various monitoring points.

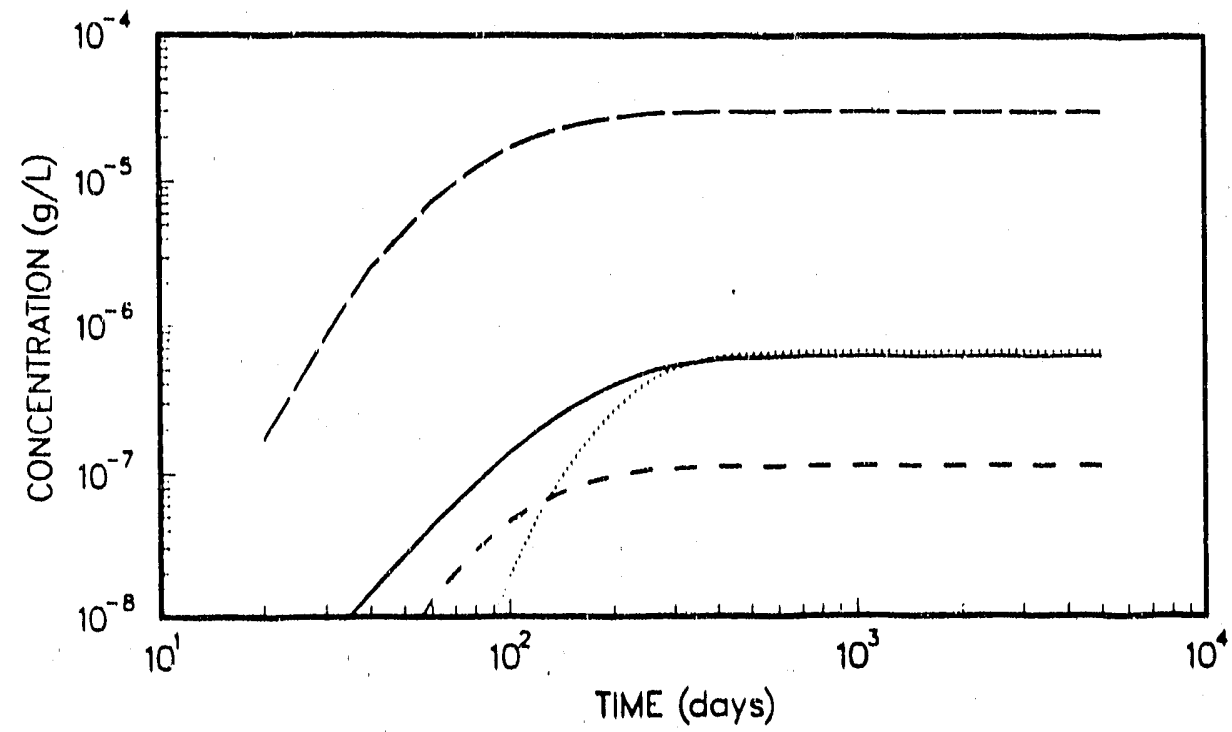

Legend

Polnt A

Puint B.

Polntc -

Polnt E

Figure 6.7. Temporal evolution of methyl chloride concentration at the various monitoring points. 


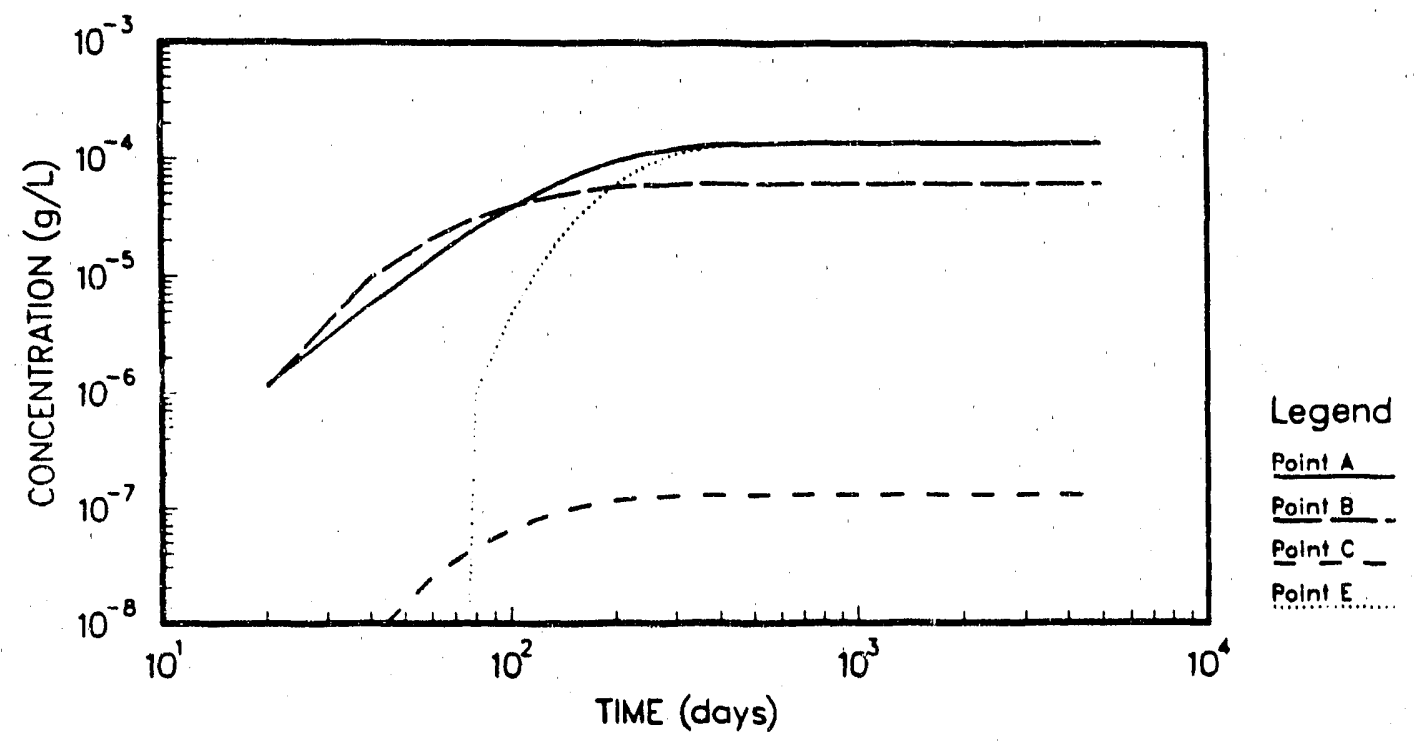

Figure 6.8. Temporal evolution of methylene chloride concentration at the various monitoring points.

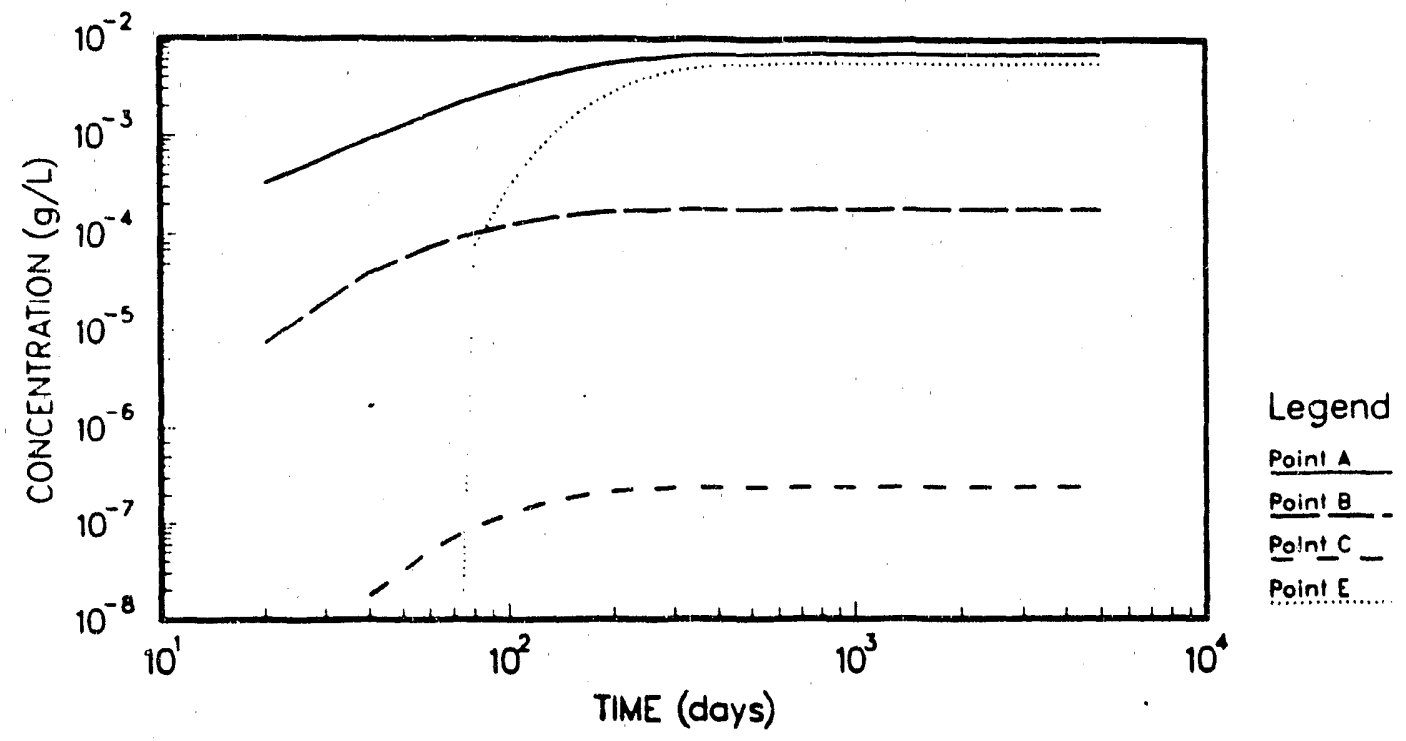

Figure 6.9. Temporal evolution of chloroform concentration at the various monitoring points. 


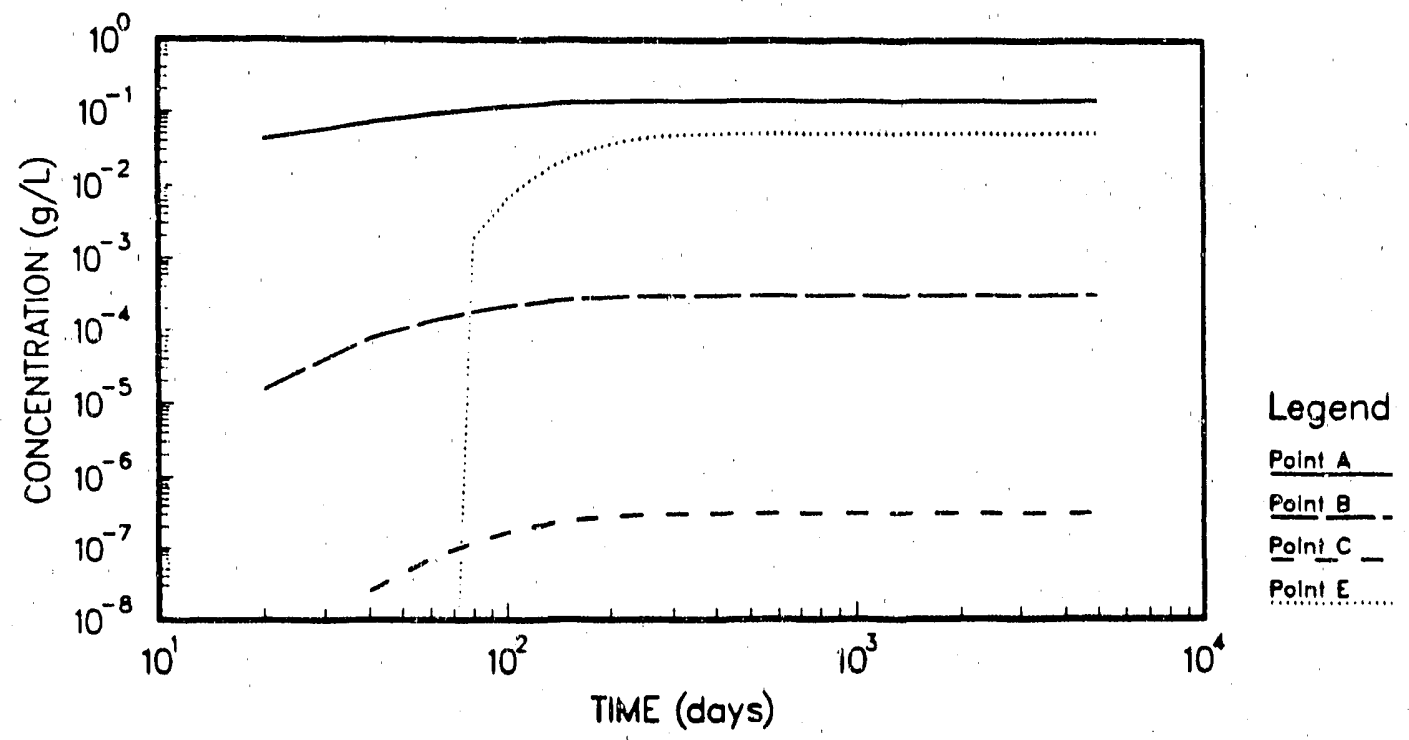

Figure 6.10. Temporal evolution of carbon tetrachloride concentration at the various monitoring points.

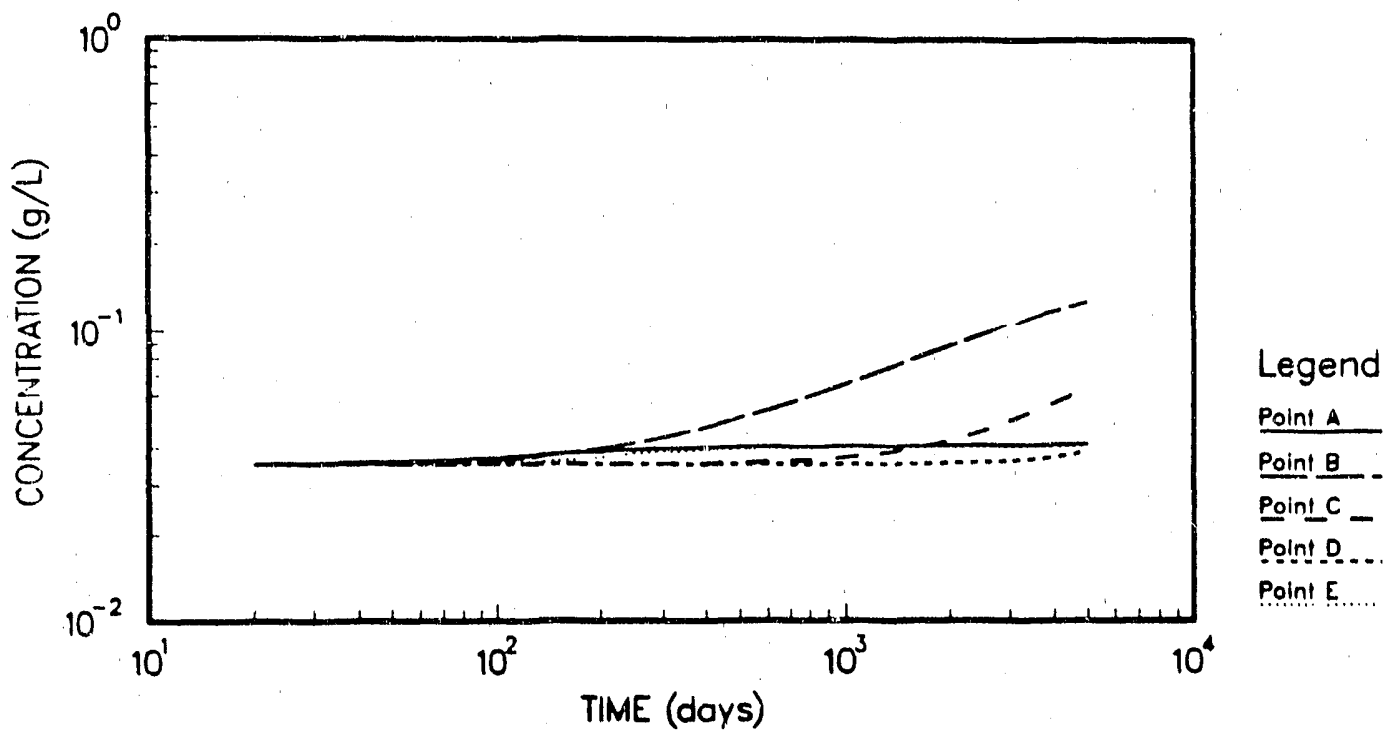

Figure 6.11. Temporal evolution of free chloride concentration at the various monitoring points. 


\section{CHAPTER 7: CONCLUSIONS}

\subsection{Summary and Conclusions}

A numerical model, KINETRAN, is presented in this study as an attempt to solve reactive transport problems involving chemical transformations of aqueous species which are controlled by reversible, first-order kinetics. The model simulates the appearance and decline of various transient species, which would not be explained properly using a purely equilibrium model. In fact, in many contamination scenarios, such transient species may be of paramount environmental concern.

In the first part of this work, we presented the logic for the mathematical development of the model and applied the simulator to a hypothetical problem. We believe that the modeling results show that the model is internally mathematically consistent and produces credible results, given the quality of the input data.

In the second part of the study, we applied the model to an actual field experiment. The results of this work show that the model is indeed capable of reproducing field data, even after many simplifying assumptions were made. The modeling results go beyond matching the data: given reasonable degradation scenarios, certain features of the system not directly measured in the experimental study may be hypothesized and analyzed.

Finally, we demonstrated that KINETRAN is applicable to a complex two-dimensional system which contains both physical and chemical heterogeneities, where both advective and diffusive solute transport become important. The results of this hypothetical study show that the model may indeed prove to be of some value in designing waste containment strategies for hazardous wastes in the subsurface environment. 
It is important to emphasize that KINETRAN is only a tentative, prototype model. It makes many simplifying assumptions; additional improvements will be required in order to simulate real systems. Nonetheless, our limited purpose here is to show that the model serves as a nucleus upon which to build further development that will eventually lead to a far more sophisticated simulator for field applications.

\subsection{Recommendations}

We believe that KINETRAN's ability to simulate real systems is limited in large part only by the a priori knowledge of the initial conditions and boundary conditions, and by the quality and amount of sampling data during the course of field work.

We feel that this last point may have important implications for the collection and analysis of raw field data, should computer models such a KINETRAN become widely applied in the future. The most important of these, by far, is a more thorough chemical analysis of groundwater samples taken from contamination sites. These analyses should seek to quantify not only the concentrations of the original contaminants, but also the concentrations of any likely daughter products produced by their decomposition. Even if good quantitative data are difficuli to obtain, qualitative data which merely confirms or refutes the presence of such materials would be enormously useful, as demonstrated in our work.

In addition, models such as KINETRAN may shed a considerable amount of light on the interpretation of solute retardation. Our study suggests some caution must be used when inferring retardation coefficients determined from the apparent relative movement of contaminant plumes. Such retardation coefficients may in fact be somewhat misieading, as onily part of the retardation behavior may be due to adsorption, as differing rates of chemical transformation 
throughout the flow domain may factor into account as well.

With regard to the capabilities of the model, we suggest a number of modifications that, if implemented, would greatly increase its versatility. First of all, a more sophisticated transport module could be utilized that would allow for the calculation of unsteady (transient) fluid flow in response to changing fluid potentials. Such a model would be very useful in assessing the effects of pumping contaminant-laden water into or out of an aquifer. Secondly, the model could be modified so as to account for the loss of volatile compounds through evaporation. This could be accomplished through the use of distribution coefficients based on Henry's Law, for example. Finally, an effort could be made to more precisely quantify the effects of microbial degradation by basing kinetics parameters on microbe population levels, which are in tum a function of pollutant concentrations.

In addition, more complex modifications are possible. Included among these is the coupling of KINETRAN with geochemical simulators in order for the pH to vary with the existing mineral assemblage, to more realistically quantify total $\mathrm{CO}_{2}$ and $\mathrm{Cl}^{-}$concentrations, and to assess the effects of the $\mathrm{Fe}^{2+}-\mathrm{Fe}^{3+}$ redox couple on the $\mathrm{Eh}$. An additional modification to the model might involve an expansion of the transport module to allow for the transport of heat in weakly non-isothermal systems. Such a feature would, of course, also require the kinetic constants and equilibrium constants to be listed as a function of temperature. 


\section{APPENDIX A: CHEMICAL REACTIONS CONSIDERED IN THE ONE DIMENSIONAL PROBLEM}

We present here the complete set of chemical reactions that were used in the demonstration problem in Chapter 3 of this thesis, along with the corresponding equilibrium constants. The values for the various $\mathrm{K}_{e q}$ were determined from the Gibbs free energies of formation of the species in the aqueous state. In cases where these were unavailable, the gaseous state $\Delta \mathrm{G}_{\mathrm{f}}^{0}$ values were used, and adjusted for the aqueous state using the formula,

$$
\Delta G_{f}^{0}(a q)=\Delta G_{f}^{0}(g)+R T \ln H
$$

where $\mathrm{H}$ is the value of Henry's constant for the particular species.

These data were collected from several sources, and there is almost certainly some degree of error within our thermodynamic data base. This is often a problem in trying to accurately determine the equilibrium chemistry of complex systems in general. However, we do not believe that this is serious enough to have a major impact on our simulation results. As our study has shown, the systems we consider are generally far from equilibrium anyway, and most of the reactions considered remain dominant in one direction. As a result, uncertainties in the values for the reverse direction kinetic constants, where errors in the $\mathrm{K}_{\text {eq }}$ values would be manifested, are probably not critical to the outcome of the simulation.

Table A.1 shows all of the reactions considered. These include reactions that are controlled by kinetics as well as reactions that are used for equilibration. Note that some of the equilibration reactions, such as $\mathrm{CH}_{3} \mathrm{Cl} \rightarrow \mathrm{CO}_{2}$, are not considered to actually take place in the system, at least directly. 
Table A.1.

\begin{tabular}{|c|c|}
\hline Reaction & $\log \mathrm{K}_{\mathrm{sg}}$ \\
\hline $\mathrm{CH}_{3} \mathrm{Cl}+\mathrm{H}^{+}+2 \mathrm{e}^{-} \rightarrow \mathrm{CH}_{4}+\mathrm{Cl}^{-}$ & 20.01 \\
\hline $\mathrm{CH}_{3} \mathrm{Cl}+\mathrm{H}_{2} \mathrm{O} \rightarrow \mathrm{CH}_{3} \mathrm{OH}+\mathrm{H}^{+}+\mathrm{Cl}^{-}$ & 3.154 \\
\hline $\mathrm{CH}_{3} \mathrm{Cl}+\mathrm{H}_{2} \mathrm{O} \rightarrow \mathrm{HCHO}+3 \mathrm{H}^{+}+\mathrm{Cl}^{-}+2 \mathrm{e}^{-}$ & -4.852 \\
\hline $\mathrm{CH}_{3} \mathrm{Cl}+2 \mathrm{H}_{2} \mathrm{O} \rightarrow \mathrm{CO}_{2}+\mathrm{Cl}^{-}+7 \mathrm{H}^{+}+6 \mathrm{e}^{-}$ & -1.465 \\
\hline $\mathrm{CH}_{3} \mathrm{Br}+\mathrm{H}^{+}+2 \mathrm{e}^{-} \rightarrow \mathrm{CH}_{4}+\mathrm{Br}^{-}$ & 22.41 \\
\hline $\mathrm{CH}_{3} \mathrm{Br}+\mathrm{H}_{2} \mathrm{O} \rightarrow \mathrm{CH}_{3} \mathrm{OH}+\mathrm{H}^{+}+\mathrm{Br}^{-}$ & 5.557 \\
\hline $\mathrm{CH}_{3} \mathrm{Br}+\mathrm{H}_{2} \mathrm{O} \rightarrow \mathrm{HCHO}+3 \mathrm{H}^{+}+\mathrm{Br}^{-}+2 \mathrm{e}^{-}$ & -2.449 \\
\hline $\mathrm{CH}_{3} \mathrm{Br}+2 \mathrm{H}_{2} \mathrm{O} \rightarrow \mathrm{CO}_{2}+\mathrm{Br}^{-}+7 \mathrm{H}^{+}+6 \mathrm{e}^{-}$ & -0.938 \\
\hline $\mathrm{CH}_{4}+2 \mathrm{H}_{2} \mathrm{O} \rightarrow \mathrm{CO}_{2}+8 \mathrm{H}^{+}+8 \mathrm{e}^{-}$ & -21.47 \\
\hline $\mathrm{CH}_{3} \mathrm{OH}+2 \mathrm{H}^{+}+2 \mathrm{e}^{-} \rightarrow \mathrm{CH}_{4}+\mathrm{H}_{2} \mathrm{O}$ & 16.855 \\
\hline $\mathrm{CH}_{3} \mathrm{OH} \rightarrow \mathrm{HCHO}+2 \mathrm{H}^{+}+2 \mathrm{e}^{-}$ & -8.006 \\
\hline $\mathrm{CH}_{3} \mathrm{OH}+\mathrm{H}_{2} \mathrm{O} \rightarrow \mathrm{CO}_{2}+6 \mathrm{H}^{+}+6 \mathrm{e}^{-}$ & -4.619 \\
\hline $\mathrm{HCHO}+\mathrm{H}_{2} \mathrm{O} \rightarrow \mathrm{HCOOH}+2 \mathrm{H}^{+}+2 \mathrm{e}^{-}$ & 0.96 \\
\hline $\mathrm{HCHO}+\mathrm{H}_{2} \mathrm{O} \rightarrow \mathrm{CO}_{2}+4 \mathrm{H}^{+}+4 \mathrm{e}^{-}$ & 3.387 \\
\hline $\mathrm{HCOOH} \rightarrow \mathrm{CO}_{2}+2 \mathrm{H}^{+}+2 \mathrm{e}^{-}$ & 2.427 \\
\hline $\mathrm{H}^{+}+\mathrm{HCO}_{3}^{-} \rightarrow \mathrm{H}_{2} \mathrm{CO}_{3}$ & 6.37 \\
\hline $2 \mathrm{H}^{+}+\mathrm{CO}_{3}^{2-} \rightarrow \mathrm{H}_{2} \mathrm{CO}_{3}$ & 16.7 \\
\hline $\mathrm{HCOO}^{-}+\mathrm{H}^{+} \rightarrow \mathrm{HCOOH}$ & 3.739 \\
\hline
\end{tabular}

Sources: Garrels and Christ (1965), Wagman et al. (1968), MacKay and Shin (1981) 


\section{APPENDIX B: NUMERICAI DISPERSION}

We previously discussed the possibility that numerical dispersion may have played a role in influencing the computed plume profiles in the soil column for the problem in Chapter 5. Here, we investigate this in more detail.

The concentration profile of the non-reactive chloride tracer, as computed in our simulation, is shown in Figure 5.21. These calculations were based on the use of nodal blocks with a length of 4.0 meters (10 nodes overall), a time step of 10 days, and a full upstream weighting factor, 1.0. Qualitatively, the profiles appear to be somewhat more dispersed than the experimental data suggest (a precise quantitative comparison is difficult because the experiment was actually three-dimensional, whereas the simulation was one-dimensional).

Figure B.1 depicts the simulated chloride concentration profile in the same column when the number of nodes is tripled to 30 (each 1.33 meters in length), an upstream weighting factor of 0.80 is used, and a time step of 2 days is taken. We again solve the problem through the use of the Integral Finite Difference Method, although here we ignore the contribution to the total chloride mass from the degrading chlorinated hydrocarbons, which is not significant. This time, the initial contaminant plume at $t=0$ is assumed to be constrained to the $3 r d$ and 4 th nodes from the upstream boundary.

The centers of mass of the plume over time do not differ greatly from those determined with the coarser mesh, but plume dispersion has clearl.' been reduced, even though the transpor conditions (dispersivity, porosity, and advective flux) have been held constant. In fact, at this level of resolution, dispersion may have been underestimated with respect to the experimental data, hence the dispersivity determined by Freyberg (1986) of $0.49 \mathrm{~m}$ may be preferrable to the value of Sudicky that we used, $0.08 \mathrm{~m}$ (see section 5.13 ). This immediately 
suggests that the concentration profiles calculated in our simulation have indeed been subjected to numerical dispersion.

The reason for this difficulty becomes clear if the Peclet number is considered. This quantity for a one-dimensional system is given by,

$$
P e=\frac{1}{2} \frac{V_{f} \Delta y}{D}
$$

where $V_{f}$ is the pore fluid velocity, $\Delta y$ is the volume element width, and $D$ is the sum of the diffusion and dispersion coefficients. For this system, the Peclet number is approximately 25, indicating dominance of advection over dispersion. Under such circumstances, generally sharp solute fronts occur, and these are difficult to maintain precisely using numerical methods.

Attempts at maintaining the sharpest possible solute front in strongly advective systems may suppress numerical dispersion but will usually create new problems. For example, reduction of the upstream weighting factor to a value below 1.0 will reduce numerical dispersion but often leads to non-physical oscillations of the solution near the solute front. To suppress these oscillations, finer discretization is required. If a finer mesh is used, the explicit time step size must be reduced in order to avoid unstable oscillations in the solution (a different type of oscillation than that caused by insufficient upstream weighting). The result of all of this is that for a moderate improvement in solute front resolution, a great deal of additional computational effort may have to be expended. This is of particular concern for reactive transport models, which must solve an array of chemical equations, for each node and each time step, in addition to the transport equations. Thus, for reactive chemical transport modeling, the need for greater resolution must be carefully weighed against computational economics. In many situations, the expense involved in establishing greater solute front resolution may not be warranted. This is, 
however, somewhat less of a problem when large mainframe computers are utllized. Under such circumstances, finer meshes may indeed be utilized in order to reduce the Peclet number (the $\Delta y$ term in the above expression), so that the front may be modeled more realistically. 


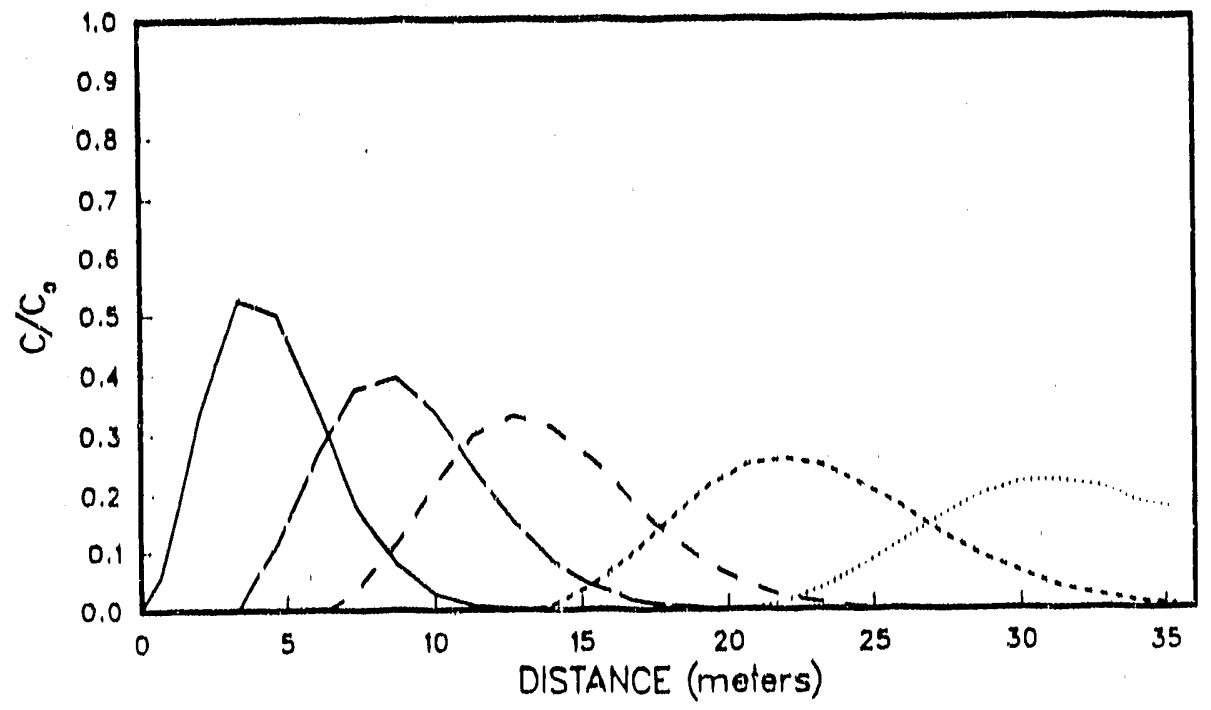

Legend 50 days 100 doys. 150 days 250 days 350 days

Figure B.1. Temporal evolution of chloride plume with the use of a finer mesh. 


\section{APPENDIX C: NUMERICAL APPROXIMATION FOR DECAY GREATER THAN FIRST-ORDER}

For many chemical reactions that describe the degradation of organic pollutants in groundwater under environmental conditions, the differential rate expression is assumed to be first-order such that,

$$
\frac{\mathrm{d}[\mathrm{x}]}{\mathrm{dt}}=-\mathrm{k}[\mathrm{x}]
$$

In a simple system, where there are no other significant sources or sinks for species $x$, this rate expression may be integrated to yield an exponential decay equation which describes the temporal evolution of $[x]$ as a result of degradation:

$$
[x]=\left[x_{0}\right] e^{-k \Delta t}
$$

However, for a more general case, where stolchiometry and other effects may result in a departure from a first-order rate dependence on $[\mathrm{x}]$, we have a more general expression,

$$
\frac{\mathrm{d}[\mathrm{x}]}{\mathrm{dt}}=-\mathrm{k}[\mathrm{x}]^{\mathrm{n}}
$$

where $\mathrm{n}>1$. From this rate expression,

$$
\frac{\mathrm{d}[\mathrm{x}]}{[\mathrm{x}]^{\mathrm{n}}}=-\mathrm{kdt}
$$

Integrating,

$$
\frac{-1}{(n-1)[x]^{(n-1)}}=-k \Delta t+c
$$


When $t=0,[x]=\left[x_{0}\right]$. Thus,

$$
c=\frac{-1}{(n-1)\left[x_{0}\right]^{(n-1)}}
$$

Rearranging terms, we find,

$$
\begin{aligned}
& \frac{1}{(n-1)[x]^{(n-1)}}=k \Delta t+\frac{1}{(n-1)\left[x_{0}\right]^{(n-1)}} \\
& (n-1)[x]^{(n-1)}\left[k \Delta t+\frac{1}{(n-1)\left[x_{0}\right]^{(n-1)}}\right]=1 \\
& (n-1)[x]^{(n-1)}=\frac{k \Delta t+\left[\frac{1}{(n-1)\left[x_{0}\right]^{(n-1)}}\right]}{[x]^{(n-1)}=\frac{1}{(n-1) k \Delta t+\left[\frac{1}{\left[x_{0}\right]^{(n-1)}}\right]}} \\
& {[x]=\left[\frac{1}{(n-1) k \Delta t+\left[\frac{1}{\left[x_{0}\right]^{(n-1)}}\right]}\right]}
\end{aligned}
$$

Equation (C.2) will describe the evolution of $[\mathrm{x}]$ with time through decay relationships other than first-order (nth-order). In Chapter 2 we argued that the quantity $\left[x_{0}\right]$ in such equations is not well-defined in multiple species systems where species $x$ is may be simultaneously produced and destroyed in a number of reactions. Instead, we discretized the differential rate equation and used a time-averaging scheme such that

$$
\frac{\Delta[\mathrm{x}]}{\Delta t}=-k[\bar{x}]
$$


where $[x]=\left[x_{0}\right]+\lambda \Delta[x]$, an effective average value for $[x]$ over the given time interval $\Delta t$. The factor $\lambda$ is evaluated by

$$
\lambda=\frac{1}{1-\mathrm{e}^{-k_{1} \Delta t}}-\frac{1}{\mathrm{k}_{1} \Delta \mathrm{t}}
$$

Through the use of (C.3), a system of simultarleous linear equations can be generated that allows for the solution of $\Delta x_{i}$ for all species $i$ present.

Al first glance, it appears that the linear nature of such a system of equations depends on (C.3) being first-order. However, linearity can be maintained for higher-order relationships by using the approximation, for small time steps, that

$$
\mathrm{k}^{\prime} \approx \mathrm{k}\left[\mathrm{x}_{0}\right]^{(\mathrm{n}-1)}
$$

The parameter $\lambda$ is calculated using (C.4), substituting $k^{\prime}$ for $k$. At the start of the next time step, $\mathrm{k}^{\prime}$ is re-evaluated using the updated value for $\left[\mathrm{x}_{0}\right]$.

Using $\Delta t=5$ days, $k=1 \times 10^{-7} \sec ^{-1}$, and $\left[x_{0}\right]=1.0$, the results of the numerical method and the analytical equation (C.2) were compared. The solutions, as shown in Figure C.1, show excellent agreement. 
$-136-$

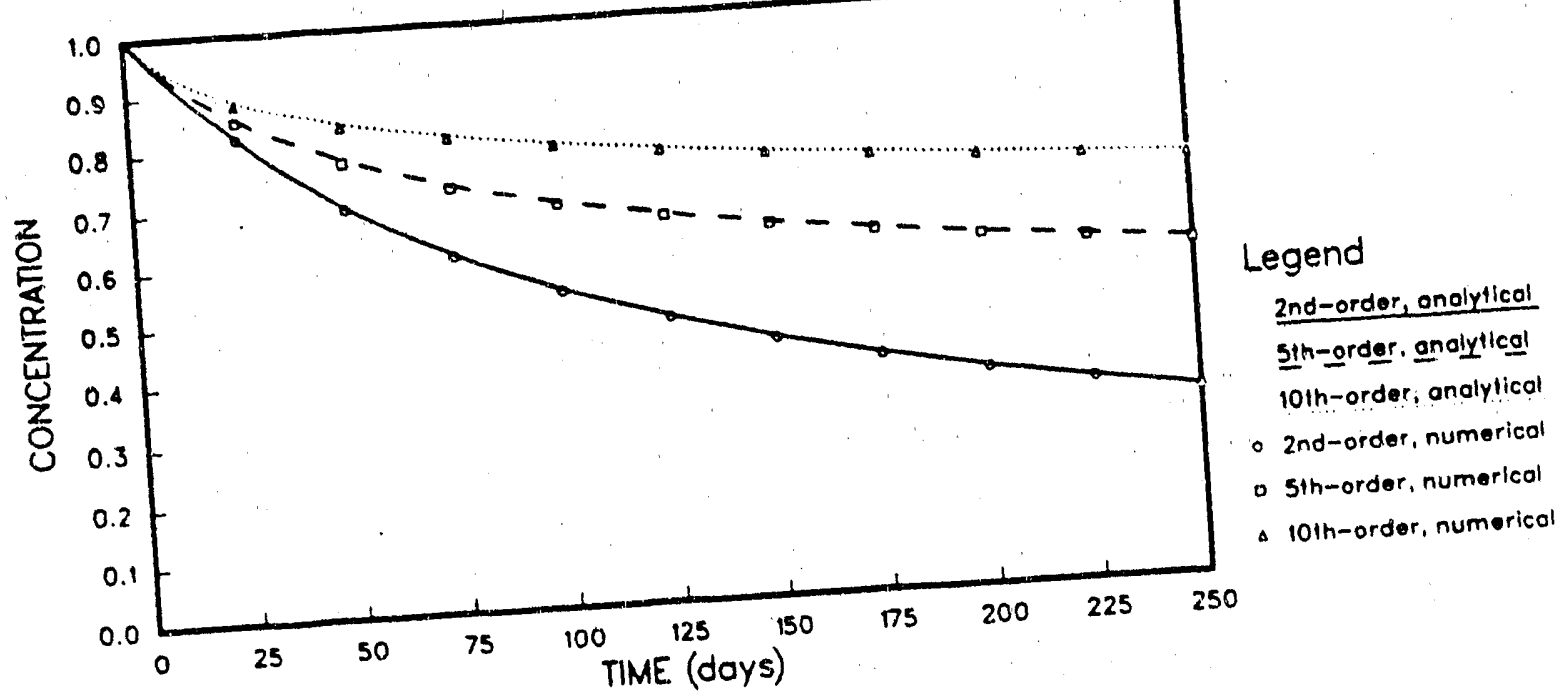




\section{APPENDIX D: LOGIC STRUCTURE OF THE KINETRAN ALGORITHM}

A schematic flow chart of the logic structure of KINETRAN is shown in Figure D.1. The program consists of essentially two primary modules, a transport module and the kinetics module, which is isself divided into smaller units. The program is designed so that a simple switch can be used to completely uncouple the entire kinetics module, reducing the program to strictly a non-reactive chemical transport model. This option is useful in comparing the concentration profiles of a given species in the reactive case and the non-reactive case.

\section{The Input Module.}

The input module is entered only once at the start of the program. Here, all of the critical information describing the physical and chemical characteristics of the system are input. The program is designed to handle both physical and/or chemical heterogeneities, so the user must specify how many different materials are present in the system, and then define separate diffusion coefficients, dispersivities, and distribution coefficients (per species), as well as material density, porosity, $\mathrm{pH}, \mathrm{Eh}$, and the kinetic coefficients for the dominant reactions (sec section 2.1) for each material. Data regarding the discretization of the system is input, and an indexing system assigns the correct material number to the correct volume elements. At present, the steady-state advective fluxes between the volume elements must be user-specified. If these are not well known beforehand, a groundwater fluid flow model can be used to determine the final steady-state fluid flow if fluid potentials are known initially. Finally, initial concentrations of the species present in the system are input for each node.

In addition to the physical and chemical characterization of the system, overall simulation 
controls, such as time step size, printout times, and termination criteria are also input from within this module.

\section{The Transport Module.}

The chemical transport module simply solves Equation (12), in Chapter 2, for $\Delta c_{i}$. This is done every time step, volume element by volume element. $c_{i}$ is then updated for every node. This process must be repeated for every species $i$ in the system. When this entire process is finished, the kinetics module is called, if required, to solve for $\Delta c_{i}$ for all $i$ as a result of chemical reactions separately for every node. Then the problem time is incremented by $\Delta t$, and the entire scheme is repeated.

The present transport routine is somewhat limited in that it cannot handle transient advective fluid flow which results from changing fluid potentials. By replacing this module with a more sophisticated model capable of handling such features, the utility and flexibility of KINETRAN will be greally increased.

\section{The Kinetics Module.}

The module which handles the reaction kinetics between the various species present simply follows the logic outlined in this paper. $\Delta c_{i}$ is calculated for every species, within every volume element in the system. This is done by looking at each of the volume elements separately, solving for the species concentrations within each as if they were separate batch systems.

The final equilibrium state of all of the species within given yolume element is calculated first. These values are stored so that the program can then calculate the kinetic coefficients of the reverse reactions. These constants are then indexed according to the reaction they are asso- 
ciated with and the direction. Using Equation (10), the $\lambda$-parameters are then determined and indexed accordingly.

Next, the matrix of equations is set up using the newly determined parameters. The matrix is solved using standard Gaussian elimination with pivoting. The species concentrations for the particular volume element are then updated (hence the source term in the transport equation), and the process is repeated for the next volume element until the entire domain has been covered.

Following this, the simulation time is updated and a check is made to see if output is to be produced for the just completed time step. If it is, any instantaneous reactions, such as the speciation of $\mathrm{CO}_{2}$ into carbonate and bicarbonate ions, are calculated using the iterative technique used earlier. Output is then produced, and a new cycle is initiated. 


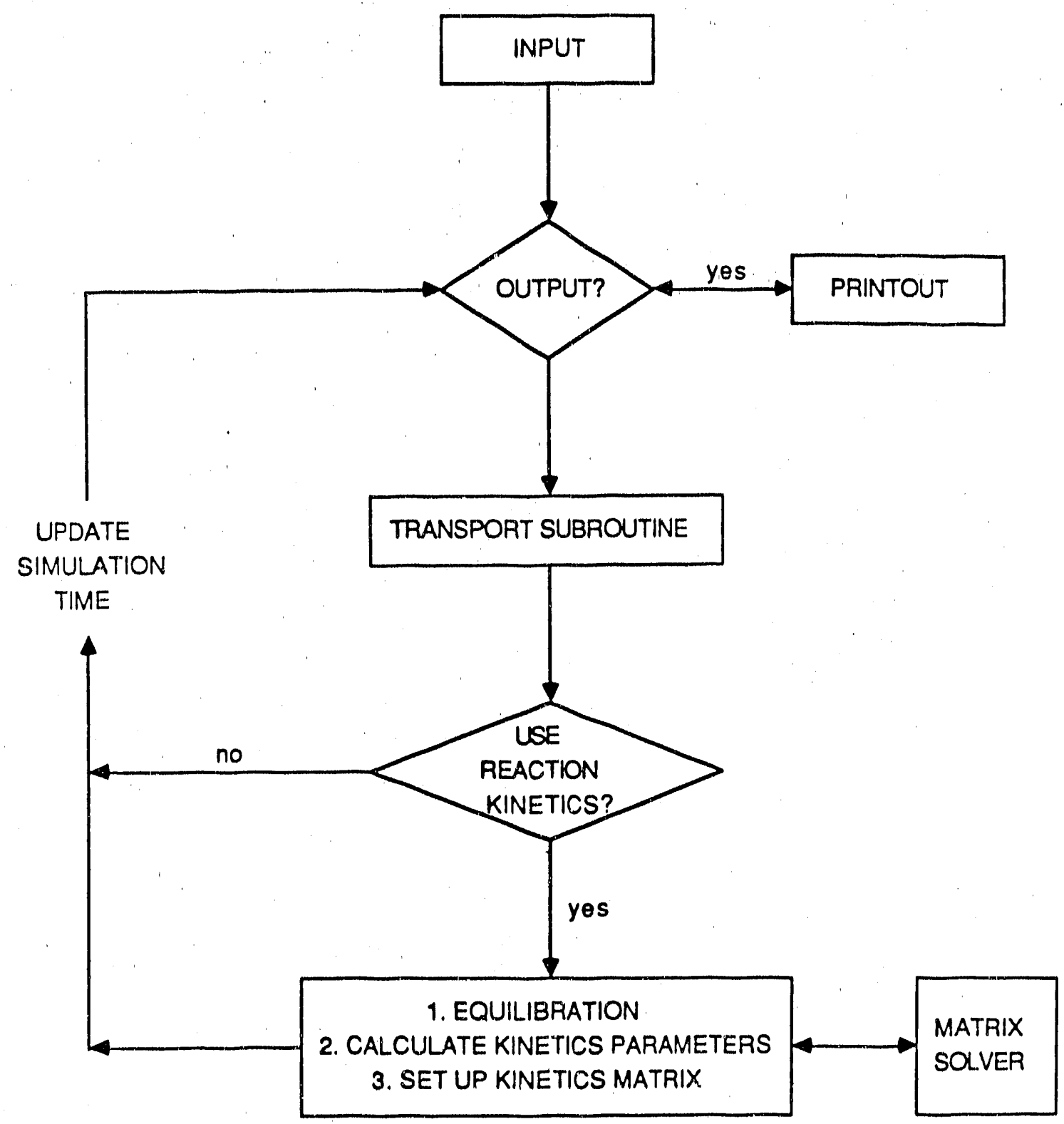

Figure D.1. The logic structure of KINETRAN. 


\section{APPENDIX E: INSTRUCTIONS FOR PREPARING KINETRAN INPUT DECK}

Data Block 1 - problem controls.

Card 1 Type BLOCK 1 in columns 1 to 7.

Card 2 Format(4e10.3,2i5)

TSTEP(1-10) - time step size (seconds). For transport problem, must not exceed critical time step. For transformation simulation, should not greatly exceed any of the half-lives for the various reactions, as some loss of accuracy may result.

TIMAX(11-20) - maximum problem time (seconds).

PRSTEP(21-30) - printout interval (seconds). Must be divisible by TSTEP.

SLOW (31-40) - constant equal to time step size times kinetic constant for a given reaction, below which the $\lambda$ time-averaging factor will be automatically set at 0.5 . The default value is $8.64 \times 10^{-5}$.

$\operatorname{KCHEM}(41-45)$ - flag for calling kinetics subroutine. If $\mathrm{KCHEM}=1$, the kinetics subroutine will be called. For any other value, it will not be called, so the program will be reduced to a non-reactive transport model.

ITER(46-50) - number of iterations for equilibration routine. Usually, 2 or 3 iterations will süffice. 
KIBP(51-55) - flag for bypassing the equilibration routine, which will not be needed in some situations. If $\mathrm{KIBP}=1$, this routine will not be used.

Card 3 Blank.

Dasa Block 2 - species list.

Card 1 Type BLOCK 2 in columns 1 to 7.

Card 2 Format(i5)

NOSPEC(1-5) - total number of aqueous species present in simulation (up to 30 allowed).

Card 3 Format(i5,5x,a10,e10.3)

NSPEC (1-5) - species number. Number sequentially, $1 \rightarrow$ NOSPEC. $\mathrm{CO}_{2}$ must be listed as species \#1. If chloride and/or bromide are present, they must be listed last, with chloride listed before bromide.

SNAME(11-20) - species name (up to 10 characters).

AMOLWT(21-30) - species molecular weight (grams/mole).

Card 4 Blank.

Data Block 3 - solute properties.

Card 1 Type BLOCK 3 in columns 1 to 7. 
Card 2 Format(15)

NOMAT(1-5) - number of different materials in flow domain.

Card 3 Format(15,5x,e10.3)

MATNO(1-5) - material number. Card 3 may be read over up to 5 different times ( 5 different materials).

$\operatorname{POROS}(11-20)$ - material porosity.

Card 4 Format(15,5x,3e10.3)

NSPEC(1-5) - species number (list sequentially, include all species).

RET(11-20) - retardation coefficient in MATNO.

DIFF(21-30) - diffusion coefficient (meters ${ }^{2} /$ second) in MATNO.

DISPER(31-40) - dispersivity (meters) in MATNO.

Card 5 Blank.

Data Block 4 - node descriptions.

Card 1 Type BLOCK 4 in columns 1 to 7.

Card 2 Format(4i5,e10.3)

NODE(1-5) - node identification number (up to 500 nodes possible). 
NSEQ(6-10) - number of identical nodes to be generated in sequence.

NADD(11-15) - increment between successive values of NODE in the sequence of NSEQ nodes generated when NSEQ is used.

MATNO(16-20) - identification number of material of which the node is a part of.

VOL(21-30) - bulk volume of node. Set VOL $\geq 1 E+30$ for boundary nodes.

Card 3 Blank.

Data Block 5 - node connections and advective fluxes.

Card 1 Type BLOCK 5 in columns 1 to 7.

Card 2 Format(5i5,5x,5e10.3)

NODE1(1-5) - identification numbers of the connected nodes.

NODE2(6-10)

NSEQ(11-15) - number of additional identical connections (a total of 500 connections are allowed).

NAD1(16-20) - increment between successive values of NODE1 in the sequence of NSEQ connections generated when NSEQ is used.

NAD2(21-25) - increment between successive values of NODE2 in the sequence of NSEQ connections generated when NSEQ is used. 
DIST1(31-40) - distance (meters) from nodal point of NODE1 to NODE1-NODE2 interface.

DIST2(41-50) - distance (meters) from nodal point of NODE2 to NODE1-NODE2 interface.

AREA(51-60) - area (meters $\left.{ }^{2}\right)$ of the NODE1-NODE2 interface.

QFLUX(61-70) - darcy velocity of fluid flux from NODE1 into NODE2 (meters/second).

UPSWT(71-80) - upstream weighting function for calculating advective solute flux (must lie between 0.0 and 1.0 , recommend greater than 0.5 ).

Card 3 Blank.

Data Block 6 - kinetically-controlled reactions.

Card 1 Type BLOCK 6 in columns 1 to 7.

Card 2 Format(15)

NRCTNS(1-5) - total number of kinetically-controlled reactions in the system (up to 50 allowed).

Card 3 Format( $315,5 x, 3 \mathrm{e} 10.3)$

NREACT(1-5) - reaction number (number sequentially).

NSPEC1(6-10) - primary species number, reactant.

NSPEC2(11-15) - primary species number, preduct. 
S'TOIC1(21-30) - stolchlometric coefficient for primary reactant.

STOIC2(31-40) - stoichiometric coefficient for primary product.

EQKONS(41-50) - log equilibrium constant of reaction.

Card 4 Blank.

Data Block 7 - reaction conditions.

Card 1 Type BLOCK 7 in columns 1 to 7.

Card 2 Format(15)

MATNO(1-5) - material identification number (can be read up to 5 times).

Card 3 Format(i5,5x,e10.3)

NREACT(1-5) - reaction number (number sequentially).

RKIN(11-20) - forward first-order reaction rate $\left(\mathrm{sec}^{-1}\right)$ coeffictent for reaction NREACT in material MATNO.

Card 4 Blank.

Data Block 8 - stoichiometry of additional species produced in kinttically-controlled reactions.

Card 1 Type BLOCK 8 in columns 1 to 7.

Card 2 Format( $(5,5 \times, 4 \mathrm{e} 10.3)$ 
NREACT(1-5) - reaction number (number sequentially).

II(11-20) - stoichiometry of hydrogen lons produced in reaction NREACTS.

$E(21-30)$ - stoichiometry of free electrons produced in reaction NREACTS.

CL(31.40) - stoichiometry of chloride lons produced in reaction NREACTS.

BR(41-50) - stoichiometry of bromide ions produced in reaction NREACTS.

Card 3 Blank.

Data Block 9 - stoichiometry of additional species produced in equilibration reactions, assuming $\mathrm{CO}_{2}$ is the master species.

Card 1 Type BLOCK 9 in columns 1 to 7.

Card 2 Format(15)

NOEQAL(1-5) - number of species that occur as primary reactants or products in kinetics equations (i.e. all species other than $\mathrm{Cl}^{-}$or $\mathrm{Br}^{-}$). Species in this list will be equilibrated, if $\mathrm{KIBP} \neq 1$, using mass action constraints. Since $\mathrm{CO}_{2}$ does not have a corresponding mass action equation, it will not be listed in this block. Thus, number this block sequentially, starting with species $\# 2$ and ending before $\mathrm{Cl}^{-}$or $\mathrm{Br}^{-}$. NOEQAL must not be less than NOSPEC - 2 .

Card 3 Format $(15,5 x, 6 e 10.3)$

NSPEC(1-5) - species number. 
$\mathrm{HQ}(11-20)$ - stolchiometry of hydrogen ions produced in equilibration reaction with $\mathrm{CO}_{2}$.

$\mathrm{EQ}(21-30)$ - stolshiometry of free electrons produced in equilibration reaction with $\mathrm{CO}_{2}$.

CLQ(31-40) - stoichiometry of chloride ions produced in equilibration reaction with $\mathrm{CO}_{2}$.

BRQ(41-50) - stoichiometry of bromide lons produced in equilibration reaction with $\mathrm{CO}_{2}$.

$\mathrm{CO} 2(51-60)$ - stoichiometry of $\mathrm{CO}_{2}$ produced in equilibration reaction.

EQC(61-70) - log equilibrium constant for equilibration reaction.

Card 4 Blank.

Data Block 10 - data for halogen concentration corrections.

Card 1 Type BLOCK 10 in columns 1 to 7.

Card 2 Format(15,5x,2e10.3)

NSPEC(1-5) - species number. For this block, list only species $1 \rightarrow$ NOEQAL.

CLN(11-20) - stoichiometry of chlorine in species NSPEC.

BRM(21-30) -stoichiometry of bromine in species NSPEC.

Card 3 Blank.

Data Block 11 - initial conditions. 
Card 1 Type BLOCK 11 in columns 1 to 7.

Card 2 Format(315,5x,2e10.3)

NODE(1-5) - node identification number.

NSEQ(6-10) - number of additional nodes with identical initial conditions.

NADD(11-15) - increment between successive numbers in the sequence NSEQ nodes to be generated when NSEQ is used.

PH(21-30) - constant pH value for fluid in NODE.

EH(31-40) - constant Eh value (Volts) for fluid in NODE.

Card 3 Format(15,5x,e10.3)

NSPEC(1-5) - species identification number.

C.1(11-20) - total concentration of NSPEC (grams/liter) in NODE. All nodes must be spiked with a finite amount of background $\mathrm{CO}_{2}$. If reducing conditions are present, methane may be substituted instead. If $\mathrm{Cl}^{-}$or $\mathrm{Br}^{-}$are present in the simulation, all nodes must be spiked with background concentrations of these as well. For example, if $\left[\mathrm{Cl}^{-}\right]=0.0$ in a given node, $\mathrm{C} 1($ node, chloride $)=1 \mathrm{E}-30$.

Cards 2 - 3 may be read over up to 500 times.

Card 4 Blank. 


\section{APPENDIX F: ADDITIONAL IMPORTANT \\ KINETRAN VARIABLES}

ADFLX - advective solute flux (moles/second) between two given nodes.

ALMBDA(R,D) - time-averaging factor $\lambda$ for kinetics reaction $R$, direction $D$ (forward $=1$, reverse $=2$ )

B(I) - B-matrix element for species I in kinetics matrix.

C(N,I) - total concentration (moles/meter ${ }^{3}$ ) of species $I$ in node $N$.

CEFF - approximate interfacial concentration for a given species between two given nodes, using the appropriate upstream weighting value.

CGRAD - approximate concentration gradient (moles/meter ${ }^{3} /$ meter) for a given species between two given nodes.

DC(I) - change in concentration (moles/liter) of species $I$ in a given node as a result of chemical transformation.

DCONC(N,I) - change in concentration (moles/meter $\left.{ }^{3}\right)$ of species $I$ in node $N$ as a result of solute transport.

DFX - diffusive solute flux (moles/second) between two given nodes.

DHX - dispersive solute flux (moles/second) between two given nodes. 
EE - hypothetical free aqueous electron concentration (moles/liter) in a given node.

EQSPC(I) - log equilibrium concentration of species I in a given node.

EQSPC2(I) - equilibrium concentration (moles/liter) of species I in a given node.

FARAD - Faraday constant $(9.648456 \mathrm{E}+4 \mathrm{C} / \mathrm{mol})$.

HY - hydogen ion concentration (moles/liter) in a given node.

FALG - $\log _{e} 10(2.30258509)$

$\mathbf{G}(\mathbf{I}, \mathbf{M})$ - element of $i \times m$ kinetics matrix.

RGC - Universal Gas Constant $\left(8.31441 \mathrm{~J} \mathrm{~K}^{-1} \mathrm{~mol}^{-1}\right)$.

S(I) - concentration (moles/liter) of species I in a given node.

TEMP - temperature (Kelvin) of simulation domain (298.15 K).

TIME - problem time since start of problem (seconds). 


\section{REFERENCES}

Ague, J.J., 1987. 'Geochemical Modeling of Fluid Flow and Chemical Reaction During Supergene Enrichment of Porphyry Ore Deposits', Ph. D. Dissertation, University of California, Berkeley, CA, 61pp.

Apps, J.A., 1989. Personal communication.

Barrio-Lage, G., F.Z. Parsons, R.S. Nassar, and P.A. Lorenzo, 1986. 'Sequential Dehalogenation of Chlorinated Ethenes', Environmental Science and Technology, 20(1), 96-99.

Curtis, G.P., P.V. Roberts, and M. Reinhard, 1986. 'A Natural Gradient Experiment on Solute Transport in a Sand Aquifer: 4. Sorption of Organic Solutes and its Influence on Mobility', Water Resources Research, 22(13), 2059-2067.

Dean, J.A. (ed.), 1979. Lange's Handbook of Chemistry, 12th Edition, McGraw Hill, New York, pp.965-994.

Edwards, A.L., 1972. 'TRUMP: A computer program for transient and steady state temperature distributions in multidimensional systems, Lawrence Livermore National Laboratory', Rep. 14754, Rev. 3, Livermore, CA.

Freyberg, D.L., 1986. 'A Natural Gradient Experiment on Solute Transport in a Sand Aquifer: 2. Spatial Moments and the Advection and Dispersion of Nonreactive Tracers', Water Resources Research, 22(13), 2031-2046.

Freyberg, D.L., 1989. Personal communication.

Garrels, R.M and C.L. Christ, 1965. Solutions, Minerals, and Equilibria, Freeman, Cooper and Company, San Francisco, 450pp.

Hart, 1987. Organic Chemistry: A Short Course, Houghton Mifflin Company, Boston, 485pp.

Jeffers, P.M. and N.L. Wolfe, 1989. 'Hydrolysis of Carbon Tetrachloride', Science, 246, p1638.

Johnson, R.L., J.A. Cherry, and J.F. Pankow, 1989. 'Diffusive Contaminant Transport in Natural Clay: A Field Example and Implications for Clay-Lined Waste Disposal Sites', Environmental Science and Technology, 23(3), 340-349.

Liu, C.W., 1988. 'Multiple Species Chemical Transport Involving Oxidation/Reduction Reactions in Geological Media', Ph. D. Dissertation, University of California, Berkeley, CA, 257pp.

Liu, C.W. and T.N. Narasimhan, 1989a. 'Redox-Controlled Multiple-Species Reactive Chemical Transport: 1. Model Development', Water Resources Research, 25(5), 869-882. 
Liu, C.W. and T.N. Narasimhan, 1989b. 'Redox-Controlled Multiple-Species Reactive Chemical Transport: 2. Verification and Application', Water Resources Research, 25(5), 883-910.

Mabey, W. and T. Mill, 1978. 'Critical Review of Hydrolysis of Organic Compounds in Water Under Environmental Conditions', Journal of Physical and Chemical Reference Data, 7(2), 383-415.

MacKay, D. and W.Y. Shin, 1981. 'A Critical Review of Henry's Law for Chemicals of Environmental Interest', Journal of Physical and Chemical Reference Data, $10,1175-1199$.

MacKay, D.M., D.L. Freyberg, and P.V. Roberts, J.A. Cherry, 1986. 'A Natural Gradient Experiment on Solute Transport in a Sand Aquifer: 1. Approach and Overview of Plume Movement', Water Resources Research, 22(13), 2017-2029.

Narasimhan, T.N. and P.A. Witherspoon, 1977. 'Numerical model for saturatedunsaturated flow in deformable porous media, Part I: Theory', Water Resources Research, 13(3), 657-664.

Narasimhan, T.N., A.F. White, and T. Tokunaga, 1986. 'Groundwater Contamination From an Inactive Uranium Tailings Pile', Water Resources Research, 22(13), 1820-1834.

Nicholson, R.V., J.A. Cherry, and E.J. Reardon, 1983. 'Migration of Contaminants in Groundwater at a Landfill: A Case Study: 6. Hydrogeochemistry', Journal of Hydrology, 63, 131-176.

Parkhurst, D.L., D.C. Thorstenson, and L.N. Plummer, 1980. 'PHREEQE: A Computer Program for Geochemical Calculations', U.S. Geological Survey, Water Resources Investigation, PBN81-167801.

Rasmuson, A., T.N. Narasimhan, and I. Weretnieks, 1982. 'Chemical Transport in a Fissured Rock: Verification of a Numerical Model', Water Resources Research. 18(5), 1479-1492.

Roberts, P.V., M.N. Goltz, and D.M. MacKay, 1986. 'A Natural Gradient Experiment on Solute Transport in a Sand Aquifer: 3. Retardation Estimates and Mass Balances for Organic Solutes', Water Resources Research, 22(13), 2047-2058.

Sudicky, E.A., J.A. Cherry, and E.O. Frind, 1983. 'Migration of Contaminants in groundwater at a Landfill: A Case Study: 4. A Natural Gradient Dispersion Test', Journal of Hydrology, 63, 81-108.

Sudicky, E.A., 1986. 'A Natural Gradient Experiment on Solute Transport in a Sand Aquifer: 5. Spatial Variability of Hydraulic Conductivity and its Role in the

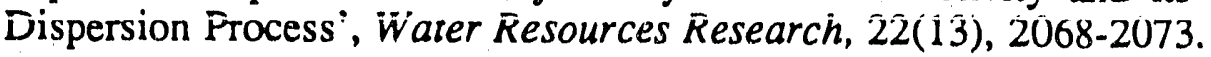

Thortenson, D.C., 1984. 'The Concept of Electron Activity and Its Relation to Redox Potentials in Aqueous Geochemical Systems', U. S. Geological Survey, Open- 
File Report 84-072, 48pp.

Vogel, T.M., C.S. Criddle, and P.L. McCarty, 1987. 'Transformations of Halogenated Aliphatic Compounds', Environmental Science and Technology, 21(8), 722-736.

Wagman, D.D., W.H. Evans, V.B. Parker, I. Halow, S.M. Bailey, and R.H. Schumm, 1968. 'Selected Values of Chemical Thermodynamic Properties, Tables for the First Thirty-Four Elements in the Standard Order of Arrangement', National Bureau of Standards Technical Note 270-3.

Wolery, T.J., 1979. 'Calculation of chemical equilibrium between aqueous solution and minerals: the EQ3/6 software package', Lawrence Livermore National Laboratory, UCRL-52658, 41pp.

Wolery, T.J., 1983. 'EQ3NR, A Computer Program for Geochemical Aqueous Speciation-Solubility Calculations: User's Guide and Documentation', Lawrence Livermore National Laboratory, UCRL-53414, 191pp. 

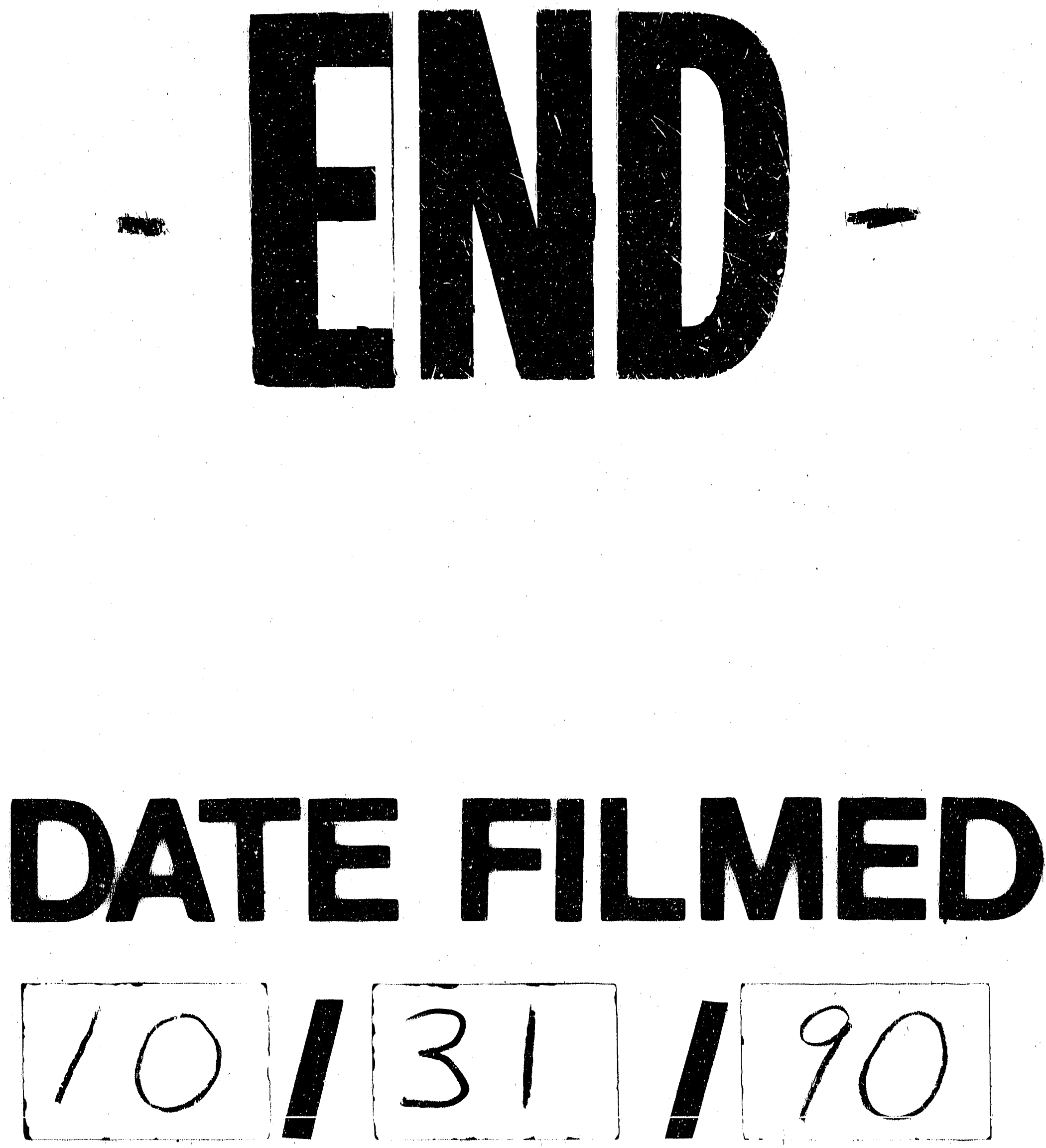
